UC-NRLF

|| |||| || ||| ||||||||||

B $3 \quad 388 \quad 224$ 







\title{
BIBLIOGRAPHICAL AND TEXTUAL PROBLEMS OF THE ENGLISH MIRACLE CYCLES
}

\author{
BY \\ W. W. GREG, LitT.D. \\ Sometime librarian of Trinity College, Cambridge
}

LECTURES DELIVERED AS SANDARS READER IN BIBLIOGRAPHY IN THE UNIVERSITY OF CAMBRIDGE 1913

REPRINTED FROM 'THE LIBRARY' 1914

LONDON

ALEXANDER MORING LIMITED

1914 



\section{CONTENTS}

I.-Introduction: Bibliography and Litera-

TURE • • • • . • •

II.-The Coming of Antichrist: Relation of the Manuscripts of the Chester

CYCle . . . . . . . . 32

III.-Christ and the Doctors: Inter-Relation

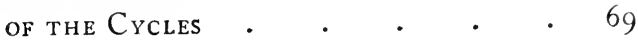

IV.-Ludus Coventriae: The Fabrication of a Cycle. . . . . . . . 108

"** The folding leaf illustrating the texts of 'Christ and the Doctors' is inserted between pages 92 and 93 . 



\title{
BIBLIOGRAPHICAL AND TEXTUAL PROBLEMS OF THE ENGLISH MIRACLE CYCLES. ${ }^{1}$
}

\section{I.-INTRODUCTION : BIBLIOGRAPHY AND LITERATURE.}

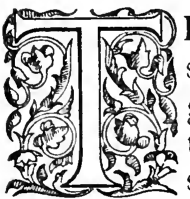

$\mathrm{HE}$ importance of bibliography for the study of literature is sometimes forgotten alike by the bibliographer and the critic. The former immerses himself in subjects which, however interesting in themselves, lead to few developments beyond their own horizon: the latter is habitually shy of investigations in a region in which he feels he is not at home. It is well therefore, occasionally, to insist on the connexion between the two provinces, and to show how intimate it is by attending to some of the problems that lie along the border.

I The four lectures, of which this is the first, formed a course delivered as Sandars Reader in Bibliography at Cambridge, on 21, 24,28 , and 31 October, 1913 . They are here printed as originally written, but references and notes have been added in the hope that these may prove of use to students.
\end{abstract}




\section{PROBLEMS OF THE ENGLISH}

This must be my excuse if I appear to have chosen as the subject of these lectures one which has little to do with bibliography in the narrower sense. It may be that I allow the term a somewhat generous extension, it is certain that I shall have occasionally to deal with matters that cannot by any stretch be called bibliographical, but I hope before I have done to show how impossible it is to treat at all adequately the literary problems of the early drama without at every turn having recourse to what a friend of mine has recently styled 'the higher bibliography.'

Thus my second lecture will be devoted to the strictly bibliographical problem of the relationship among a group of manuscripts, those of the Chester plays, and I shall endeavour to explain what light their divergence throws on the history of the cycle. Next I shall consider, in a single remarkable instance, that textual interdependence which characterizes several of our great cycles; a more literary investigation this, yet one in which bibliographical considerations are constantly coming into play. Lastly, dealing with the 'Ludus Couentriae,' I shall point out that it is only by following two parallel paths of bibliographical and literary criticism that we can hope to solve the problem of that mysterious compilation. In to-day's introductory lecture I propose to consider some more general aspects of my subject, and will endeavour to make clear how the peculiar conditions under which the miracle drama arase came to leave their mark on the extant manuscripts, how therefore a bibliographical investigation of the latter may throw 
light on the literary evolution of the cycles, and how a study of documents and records may elucidate both.

Neither time nor occasion will allow of anything like a detailed account of the origins of the medieval drama, but I must remind you as briefly as I can of the strange manner in which that drama sprang from a germ that lies, it has been said, even beyond the bounds of articulate speech, and was nourished in the bosom of that Church which had shown itself the bitterest enemy of every form of theatrical activity. In tracing rapidly the outline of this development I shall do little more than summarize certain chapters in Mr. Chambers' admirable work on the 'Mediaeval Stage,' and I shall not scruple at times to borrow his very words.'

Literary students have long since recognized the theatrical possibilities in the offices of the Church. How essentially dramatic was the central mystery of the Mass itself must at all times have been apparent, and many other rituals were from an early date instinct with mimetic significance. The liturgical drama, however, whatever incidental influence such rites may have had upon its development, took its rise at a different and unexpected point.

About the year 800 , some two centuries after the choral portions of the Mass had been fixed in the Gregorian Antiphoner, a general tendency to

' Chiefly chapters xviii and xix in the second volume; but the following three chapters have also been freely used. I have Mr. Chambers' courteous permission for the extensive use I have made of his work, but I need hardly say that he is in no degree responsible for any shortcomings of my summary. 
elaboration of ritual led to the insertion of new melodies in the recognized services. These melodies were originally sung to vowel sounds only, but soon words came to be written for them, and before the end of the ninth century several distinct schools of composition arose, represented by such authors as Adam of St. Victor and Notker of St. Gall. These texts, often closely based on scripture, and known as 'tropes,' were introduced at many different points of the office. In particular they attached themselves to the 'introit,' the chant sung by the choir at the beginning of Mass as the celebrant approaches the altar. Lending themselves to division between the two halves of the choir, they readily fell into the form of dialogue, and it is such a one, from the office for Easter Day, that claims our immediate attention. 'Quem quaeritis in sepulcro, o Christicolae?' sang one semi-chorus, in the words of the angel at the empty tomb. 'Iesum Nazarenum crucifixum, o coelicolae,' replied the other for the mourning women. ' Non est hic, surrexit sicut praedixerat. Ite, nuntiate quia surrexit de sepulcro,' resumes the angelical voice, and then the whole choir takes up the introit, 'Resurrexi et adhuc tecum sum, alleluia.' Here already we have something like an embryonic play, and if, as seems possible, it was chance more than anything else that made this, rather than various other dialogued tropes, the starting-point of the modern drama, at least the chance was a happy one.

Dialogue of a sort had been achieved, it remained to introduce mimesis. No doubt this crept in 
gradually, but it cannot have been long before individual voices took the responsive parts, or before individual singers detached themselves from the choir and enacted some sort of primitive drama. By the third quarter of the tenth century this drama had, even in England, become something more than primitive. One performer seats himself by a prepared sepulchre, three others, making as though in search of something, approach him. The dialogue is then chanted. The three pass on the tidings to the full choir. Then the one at the sepulchre invites the three to come and see for themselves. They lift the cloths out of the empty grave and display them before the face of the people. Further elaboration both of theatrical business and of text was inevitable and readily followed, but the greater the complexity of the drama enacted, the less suitable it became as an incident in the office of the Mass. In the English use just described it has already found a more fitting position immediately before the 'Te Deum' in the third nocturn at matins on Easter morning, and this appears to have become its regular though not invariable place. It has also attached itself to the widespread ceremony of the Easter sepulchre. On Good Friday a cross or crucifix was solemnly laid in a prepared tomb, sometimes part of the high altar, sometimes a separate shrine, where it remained till early on Easter morning, when, either secretly or with ceremony, it was taken from the sepulchre again and set up in a convenient place. There were the cloths in which this, and sometimes a reserved Host as well, had been wrapped, that the 
performers displayed before the congregation in token of Christ's Resurrection.

Both the date and place of origin of the "Quem quaeritis' are open to some question, though the latter seems most probably to have been Frankish, and the former cannot have been far from the end of the ninth century. In the same way the dates and localities of its stages of growth are at best matter of conjecture, but the logical sequence is not difficult to determine. Textual elaboration took place through the incorporation of anthems borrowed from other portions of the liturgy, notably the 'Victimae paschali,' composed by Wipo of St. Gall in the earlier part of the eleventh century. Corresponding dramatic elaboration soon extended the scheme of the liturgical drama which was now firmly established. Thus, when two further performers detached themselves from the choir and followed the Maries to the sepulchre, they stood for Peter and John, and another scene was added to the miniature play. Later a yet more important addition was made, according to the uses of some churches, in the person of the risen Christ himself, who enacted the 'Hortolanus' scene with Mary Magdalen.

Separate from, but probably in imitation of the 'Quem quaeritis,' there developed another Easter drama, known as the 'Peregrini,' dealing with the appearance of Christ to the two disciples at Emmaus. This play, which is not found before the twelfth century, attached itself to the 'Processio ad fontes,' belonging to the office of Vespers in Easter week, and appears to have been usually 
performed on the Monday. It developed, as a second scene, the Incredulity of Thomas.

The next step was the coalescing of the 'Quem quaeritis' and the 'Peregrini' into a single drama. A long text of the twelfth or thirteenth century presents a play still strictly attached to the liturgy, which includes the following incidents. Pilate sets a watch before the tomb. An angel sends lightning and the soldiers fall as if dead. Then come the Maries with 'planctus.' They buy ointment from an 'unguentarius.' There follows the 'Quem quaeritis,' after which the soldiers announce the Resurrection to Pilate. A 'planctus' by the Magdalen leads up to Christ's appearance to her. The Maries return to the disciples. Christ appears to the two pilgrims, and afterwards to Thomas. This was probably acted at Easter matins.

The most vital of the accretions which the 'Quem quaeritis' had so far gathered was the lament technically known as the 'planctus.' This originally expressed the sorrow of the Virgin and her companions round the cross. It included reminiscences of the sufferings of Christ, and, once introduced into the Easter drama, inevitably suggested the representation of such incidents. True, the liturgical drama of Easter remained essentially a Resurrection drama, and cannot be shown to have advanced beyond a very rudimentary representation of the Passion. Nevertheless, such development as took place appears to have started from the germ of the 'planctus.' I One 'ludus breuiter

I This view has not passed unchallenged. See G. C. Taylor on 'The English Planctus Mariae,' in 'Modern Philology,' 1 906-7, 


\section{IO PROBLEMS OF THE ENGLISH}

de Passione' serves for a prologue, as it were, to an elaborate 'Quem quaeritis,' and includes events from the preparation of the Passover to the Burial. It is for the most part in dumb show, but in it the 'planctus' of the Virgin occupies a conspicuous place.

Meanwhile the Easter trope had been imitated for the Christmas office: 'Quem quaeritis in praesepe, pastores, dicite?' Originally an introit trope for the 'magna Missa,' it was subsequently, like its prototype, transferred to matins, a position in which a dramatic 'Officium Pastorum' is found in at least one use. And just as the Easter play attached itself to the sepulchre, so that of Christmas attached itself to the 'praesepe' or 'crèche.' A boy ' in similitudine angeli' perched ' in excelso' sang the good tidings, others ' in uoltis ecclesiae' took up the 'Gloria in excelsis.' Five of the clergy, representing the shepherds, advanced to

iv. 623 note, $636-7$. A minute investigation has also appeared by Karl Young, 'Publications of the Modern Language Association of America,' 1910, xxv. 309. Both writers, however, express themselves very guardedly. Taylor concludes: 'Whatever the truth may be in other languages as regards the origin and development of the passion-plays, when considered in connection with the English plays as we have them, this theory cannot be accepted without at least certain qualifications.' Young sums up thus: 'Although it may be true that the planctus provided the first tangible impulse towards a dramatising of the Passion, the true passion-plays actually written seem, in general, to rest firmly upon the passio, and to use the planctus only incidentally.' Neither of these criticisms seems to me to touch the point. Like a good deal of modern, particularly American, work they ignore the distinction between the origin of a literary form and the sources of actual texts. Young's article is, however, of very great importance as regards the dialogued 'passio.' 
the 'praesepe' singing. They were met with the 'Quem quaeritis' by two priests 'quasi obstetrices.' But the Christmas 'Quem quaeritis' is not very common as an independent play, and the date of its origin is uncertain. More important and perhaps earlier is the 'Stella,' a play that had for its material starting-point a star lit with candles, which at the feast of the Epiphany was hung from the roof of the church. In the simplest form of this play three performers, representing the Magi, enter the choir singing and displaying their gifts. They see the star and follow it to the high altar, where they make their 'offertorium.' A boy, dressed as an angel, announces to them the Birth of Christ, after which they retire. In more elaborate versions they, too, are met by the midwives, and a dialogue ensues. Further elaboration includes the appearance of an angel to them in sleep, and the warning to return another way, which in its turn naturally leads to the introduction of a Herod scene and the Massacre of the Innocents. There is some evidence of an independent ' $R$ achel' play, so that the appearance of the Massacre in the 'Stella' may be due, not to natural expansion, but to coalescence.

Before long the 'Pastores' and the 'Stella' themselves coalesced. A drama of considerable dimensions resulted, especially when the flight into Egypt and the deposition of Herod were likewise included. In some cases we find the play performed before a 'rex,' presumably none other than the 'rex fatuorum,' and this 'rex' apparently acting the part of Herod. Chambers makes the interesting suggestion that herein we have the origin of the 


\section{I2 PROBLEMS OF THE ENGLISH}

rant which became a proverbial characteristic of that personage. ${ }^{\mathrm{T}}$

One other liturgical play can be traced to an independent starting-point in the office, this time not a chant, but a 'lectio.' A highly rhetorical passage from the pseudo-Augustinian sermon on the prophecies of Christ, which figured in different uses on a variety of occasions during the Advent and Christmas seasons, apparently came to be chanted instead of read, and was later recast in metrical dialogue. Each prophet is summoned in turn and repeats his prophecy of the coming of the Messiah. Costumes and symbols appear, and the choir comments on the utterance of each. Later Balaam was introduced, and his dialogue with the ass expanded into a miniature drama. This was almost certainly not, as has often been asserted, the origin of the 'festum asinorum,' or Feast of Fools, but is much more likely to have been a deliberate and ingenious attempt to turn the established presence of an ass in the church to the purposes of edification. Anyhow, in this 'processio prophetarum' we have an anticipation of the Old Testament plays of the later cycles.

There were, indeed, other liturgical plays-plays, that is, designed for performance in church during intervals of the service. But while in the case of those we have been considering it is possible to

${ }^{1}$ It should be mentioned that a semi-dramatic ceremony of the descent of a white dove from the roof of the church attached itself to the dialogued gospel for the feast of the Annunciation, and that later, as is not surprising, this rite came to be associated with the festivities of Advent, and was thus absorbed into the Christmas dramatic cycle. 
trace pretty clearly their spontaneous growth out of the liturgy itself, in that of the others such growth cannot be asserted, though neither, in the present state of our knowledge, can it be confidently denied. I refer to those plays, founded on the legends of saints or on isolated episodes of the biblical narrative, which have the appearance or being deliberate imitations of the already developed liturgical dramas proper. Such are the three plays of the vagrant scholar Hilarius, the pupil of Abelard, dealing in mixed French and Latin with St. Nicholas, Daniel, and Lazarus, which by their rubrics are explicitly if loosely connected with the offices of the Church. They belong to the first half of the twelfth century. Through a fortunate accident of fire we learn of a 'miracle' of St. Catherine prepared by the scholars of a school at Dunstable about i Ioo. Other plays seem to be recorded on all the themes treated by Hilarius, as likewise on Isaac and Rebecca, Elisha, Salome, and the conversion of St. Paul. Finally, we have two important pieces less closely connected with the liturgy, though still clearly intended to be acted in church and to take their places in the ritual cycle of the year. One of these is the 'Sponsus,' a play, partly in French, based on the parable of the Wise and Foolish Virgins, which by its subject is closely connected with the Advent or Christmas season. The other is the long and elaborate Tegernsee 'Antichrist,' a remarkable anti-papal and anti-clerical composition, introducing allegorical figures, which was probably written about I 160 , and is extant in a manuscript only some half 


\section{I4 PROBLEMS OF THE ENGLISH}

century later. This, too, almost certainly belongs to Advent.

With the completion of the Christmas and Easter cycles the strictly liturgical stage in the evolution of the drama came to an end. So long as the two maintained their connexion with the offices of the different seasons, amalgamation was clearly impossible. But the tie was weakening. Every fresh elaboration rendered the representation of the plays as part of the Church service more and more difficult, and at times unseemly; every loosening of the connexion offered fresh opportunity for dramatic growth. The Nativity and Resurrection plays subsisted awhile parallel and independent, but the 'Prophetae' came to be prefixed as a prologue to either, and each was thus linked into its fitting place in the history of the world, or, what is more important, in the great drama of the Redemption. It remained to place the two cycles together behind their common prophetic prologue, and the vast scheme was complete. This step is known to have been taken before the year ${ }_{3} 300$.

But both before and after that date considerable elaboration of material took place. As already said, the Passion proper never grew beyond an embryonic stage so long as drama was closely connected with ritual. But the line of development was obvious, and it was soon followed, when greater freedom and latitude were gained by the severance of the liturgical bond. The actual Resurrection came to be enacted, Christ stepping out of the tomb with the 'labarum' or banner in his hand, and a new scene was introduced in the Harrowing of Hell. 
But it was among the episodes previous to the Burial that the greatest scope for elaboration lay. We soon find the events from the Entry into Jerusalem onwards fully treated, and the dramatic and romantic possibilities of the story of the Magdalen recognized:

\section{Mundi delectatio dulcis est et grata Cuius conuersatio suauis et ornata;}

and it was not long before the whole missionary iife of Christ was included. At the other end the narrative was carried on beyond the Ascension to the Second Advent. This eschatology had already been adumbrated in the 'Sponsus,' and the 'Antichristus' was already there to serve as a preface to Doomsday.

Of the scheme of the 'Stella' little further elaboration was possible, but a few late examples are known which include scenes from the earlier life of the Virgin. The most vital portion was the prophetic prologue, which necessarily rose in importance as soon as it was prefixed to a complete Redemption drama. Its development is particularly interesting. We find, to begin with, the simple list of prophets; we find miniature dramas, such as those of Balaam and Daniel, arising within the 'processio'; we find a collection of such plays introduced by Augustine, the accredited author of the sermon from which the 'Prophetae' sprang; we find complete Old Testament cycles retaining in the form of a Prophet play such material as refused 


\section{I6 PROBLEMS OF THE ENGLISH}

more dramatic treatment. The chain of evolution appears complete. ${ }^{\mathrm{I}}$

The Old Testament sections of the miracle cycles are, of course, not confined to the representations of prophets, but they are governed by what may be called the prophetic principle. This is a point upon which I desire to lay stress. They do not appear for their own sake, but for their relation to what follows: they are not themselves dramas, but dramatic prologues. The Fall is there as being implied by the Redemption, the Creation as the counterpart of Doomsday. The necessary data for the plot are given, otherwise it is for their prophetic significance that episodes are introduced. Some of the plays are actual Prophet plays, many more concern the so-called types of Christ. This curious principle of type and antitype, most familiar to us perhaps from the 'Biblia Pauperum,' appears in some of the earliest English church-decoration. The Klosterneuburg altar enamels, which exhibit it, date from I $8 \mathrm{I}$. It is found in illuminations of the thirteenth century, and it is probable that that century saw the evolution of the 'Biblia Pauperum' itself, the earliest manuscripts of which date from soon after I 300 . Of course, the prophetic principle was not invariably applied.

1 This evolution again has been directly challenged in a recent article by Hardin Craig in 'Modern Philology,' I9I2-3, x. 473, not, I think, very successfully. No doubt the development took place under the influence of the 'lectiones' for Septuagesima to Lent, which deal with Old Testament subjects, particularly types of Christ; but in the absence of any clear indication of dramatic development of these within the actual liturgy, they cannot be themselves regarded as a source. 
Occasionally Old Testament history as such was put on the stage. A 'Prophetae' at Riga included scenes from the wars of Gideon, David, and Herod. An independent play of the Old Testament was performed at that dramatically anomalous place, London. There is the French 'Mystère du Viel Testament.' But on the whole, and more particularly in England, it is true that the Old Testament section remained essentially a prophetic prologue. Certainly the extant English miracle cycles are not theatrical epics of universal history, but strictly dramas of the Redemption of man, and as such proclaim a legitimate descent from their far-away source in the words of the angel:

Quem quaeritis in sepulcro, o Christicolae?

So far, we are to think of the great Nativity and Passion cycles, if not of the whole composite drama, as being performed in church. The next step was from the church to the market-place, and the growth that necessitated or suggested it likewise led to the introduction of lay performers. The effect of these two changes was momentous. Roughly it meant that the plays from being ecclesiastical became human, from being Latin became vernacular, from being cosmopolitan became national. The change of place naturally did not occur at any definite date; it was a gradual shifting. The Dunstable school play was probably as early as I I OO, and plays were acted in the refectory at Augsburg about II23. But the shift into the open air does not appear to have taken place till nearly a century later, and the transitional 


\section{8 PROBLEMS OF THE ENGLISH}

period that ended with the complete secularization of the plays did not come to an end before the middle of the thirteenth century at earliest.

We now come to what is, I think, the most obscure part of the development of the religious drama, namely its transference to the hands of the guilds, its association with the procession of Corpus Christi, and its consequent elaboration into the highly specialized form which we find more or less perfectly or imperfectly represented by the extant English cycles. This form and this manner of representation were not universal. In France the tendency was for the plays to be acted by societies formed for the purpose. Something of the same sort seems to have occurred in London. But, so far as the extant English cycles are concerned, there can be no doubt what was the typical method of production, and ample evidence exists in the records of many towns for regarding it as at any rate a very usual method in this country.

How and at what date the religious plays fell into the hands of the craft guilds is uncertain. But whether the guilds already had charge of them when the Corpus Christi feast became popular, or whether they assumed charge as being themselves as it were branches of the Corpus Christi guild, there is no question of the importance of the festival itself, and consequently of the date I 3 II, in the history of the religious drama. It was namely through the procession, which appears from the first to have been the chief feature in the rites of the new festival, that the drama acquired 
its processional character. For the organization of the lay elements of that procession a guild of Corpus Christi was formed in the more important towns, and seems commonly to have included the bulk of the civic population. It would therefore embrace the craft or trade guilds. Between procession and drama the association is clear in the records. It has sometimes been held that the processional drama actually sprang from the procession, taking its origin in members of different guilds appearing in the costumes of biblical characters, which is known in some places to have been customary, passing through a stage of processional acting, and ending in pageants or movable scenes giving performances at fixed stations. This view, however, assumes an evolution of the drama afresh from distinct origins, and independent or largely independent of that which had previously taken place out of the liturgy. Moreover, we know that the stations of the procession belonged originally not to the pageants but the Host. It seems to me more reasonable to suppose that previously existing plays somehow became attached to the procession, or that new ones were written on existing models to suit a new method of representation. We know that the players sometimes walked in costume in the procession before giving a performance at a different time and place, and the presence of costumes in the procession at places where no performance followed may be explained as deliberate imitation on the part of those townships which were either not rich or not energetic enough to support a regular dramatic cycle. 
Of course, not all the plays acted even in England were of the same type. Some great processional cycles have survived, and others are well known from the records. Some fragmentary cycles are extant. Some isolated plays that have come down to us are known to belong to recorded cycles, as in the case of the Norwich 'Fall,' or conjectured to belong to lost cycles, as in those of two plays on the 'Sacrifice of Isaac.' ' Other cycles, however, were not divided into separate pageants at all, but were intended, like those of Cornwall, for continuous performance on a fixed stage. Such were probably two cycles performed at Aberdeen, and such was certainly the intention of the reviser who left the Passion section of the 'Ludus Couentriae' in its present form. Saints' plays, again, are well known from records, while a 'Conversion of St. Paul' and a vast Magdalen drama are extant in late manuscripts. It is noticeable that no instance of a St. Nicholas play has so far been recorded in England, nor, I believe, has any saint play for which a traditional connexion with the liturgy can be claimed. Several plays of St. George are mentioned, apart from the popular mummings. One curious drama of a miracle of the Host, founded on an incident alleged to have happened in Spain in $146 \mathrm{I}$, is preserved; while a recently discovered manuscript of a single actor's part out of a very typical Miracle of Our Lady proves that this strange branch of the religious drama, so

I The so-called Dublin play (MS. at T. C. D.), which may belong to Northampton, and that in the Brome Hall manuscript. 
prolific in France, was not unknown in this country either.

But normally the religious play in England consisted of a series of individual scenes from sacred history or belief from Creation to Doomsday, centring in the Redemption, acted by the various city guilds on movable pageants drawn in procession through the streets and halting at recognized stations. The management of these performances, which are represented sometimes as an asset of the community, and sometimes as a burden on its resources, were usually under the direct or indirect control of the corporation. At Leicester and Beverley the city seems to have owned some at least of the properties, and this may originally have been the case even at York. At Lincoln the plays were managed by a guild of St. Anne, at Norwich by a guild of St. Luke. The relation between such guilds and the corporation, and between this and the guild of Corpus Christi, is very obscure; but it is, I think, significant that at Ipswich, where the Corpus Christi guild had the whole conduct of the plays, this was itself a reorganization or the old guild-merchant, and was practically identical with the corporation. Anyhow, the connexion between the plays and the feast of Corpus Christi was traditional, and is constantly insisted on. At Chester the plays were acted at Whitsuntide, but they are constantly spoken of as Corpus Christi plays. A supplementary performance seems to have been given on the feast day; no doubt that was the original date. Even at York, where it 
remained the recognized season for the plays, they were once at least acted on Whit Tuesday. The clash of plays and procession was always inconvenient, and would account for any shifting. In I 426 it was proposed at York that the plays should be postponed to the Friday after the feast, but ultimately it was the procession that gave way. The close connexion between the plays and the Corpus Christi festival also appears when we consider the dates to which the former can be traced back. The feast was instituted in I 3 I I. A reasonable tradition assigns the origin of the Chester plays to I 328. The guild of Corpus Christi at Cambridge performed plays about I $35^{\circ} .^{\text {I }}$ The Beverley plays are recorded in 1377 , and were an 'antiqua consuetudo' in I 390 ; those of York are recorded in 1378 , and were acted in 1394 at stations 'antiquitus assignatis.' The Coventry plays, in their day the most famous of all, cannot be traced back further than 1392. Most of the cycles came to an end in the last quarter of the sixteenth century. It is possible that an abortive attempt was made to act the Chester plays in I600, and at Kendal a Corpus Christi play is said to have lingered well on into the seventeenth century.

You will ask very properly what all this has to do with bibliography. I propose to spend the rest of my hour in answering that question.

Those who have studied the extant plays in detail will know how deeply the peculiar circum-

I A 'ludus Filiorum Israelis' is mentioned. The position of the similarly named play in the Beverley list shows that a 'Massacre of the Innocents' is intended. 
stances of representation reacted on the texts of the plays represented-a reaction which extends in the case of the 'Ludus Couentriae,' for instance, to the very make-up of the surviving manuscript, and necessitates our starting on a criticism of that cycle with an examination of the watermarks in the paper on which it is written. Over and over again the comparison of different manuscripts and the examination of records is found to illustrate the history of the miracle drama. To deal fully with the subject would require a course of lectures in itself. All I can do is to take almost at random a few points that may help to make my meaning clear.

The most distinctive feature of the cycles we are considering is that the representation of the individual plays or pageants composing them was allotted to different guilds. Now the guilds were not constant, unchanging bodies. Some grew in importance and wealth, others declined and died out, there was amalgamation and there was division. As a consequence the cycles were in frequent need of alteration. Plays had to be shortened or extended, fused or severed. The marks of this may constantly be seen in our extant texts, though unfortunately it is seldom that we can trace exactly what has happened. It is recorded that the Smiths of Chester once submitted alternative plays for the choice of the aldermen. Their extant play consists of two quite distinct parts, one of which is clearly not an original portion of the cycle. Again, manuscripts of the Chester cycle differ in making the Trial and Crucifixion oue play or two. In its 


\section{PROBLEMS OF THE ENGLISH}

earlier state it was acted by the Bowyers, Fletchers, and Ironmongers, who probably formed a flourishing company; and when with these were associated the Stringers and Coopers, the play, which had already outgrown its limits, split into two. The connexion between Bowyers and Stringers is obvious enough, but it is not very easy to see how a guild of Coopers should come to bud off from the same parent stem. Yet a similar thing seems to have happened at Beverley. There, in I $4 \mathrm{I}$, the Bowyers and Fletchers acted both the 'Sacrifice of Isaac' and the 'Flight into Egypt,' while about a hundred years later the latter play was in the hands of the Coopers. But Coopers and Bowyers continued to elect one alderman between them. ${ }^{1}$ Here then is an instance in which the growth of a cycle can be traced in the extant manuscripts and illustrated by extant records. Again, at Beverley, in 1493, the Drapers split off from the Mercers, with the result that the Trial before Herod had to be divided from that before Pilate. The process can also be traced at York. There, in 1415 , the cycle consisted of fifty-one pageants, somewhat later of fifty-seven. The extant manuscript contains fortyfive, but at least three were omitted. Of these one was subsequently supplied, and two others of later date were also added. The two Magi plays seem to have arisen by splitting. On the other hand, several Chester plays suggest fusion. Substitution also took place. We have two versions of the

I Historical MSS. Commission, 'Beverley MSS.,' pp. 99, 69; See M. L. Spencer, 'Corpus Christi Pageants in England,' pp. 36, 80 . 
'Fall' from the Norwich cycle, and the Wakefield or Towneley manuscript contains alternative Shepherd plays.

I pass to another point. A striking feature of the York cycle is the great difference in the length of the plays, the earlier ones being very short and some of the later very long. The same feature may also be observed elsewhere, though in the Chester cycle it has apparently been obscured by amalgamation. In a processional cycle this would cause great inconvenience and can hardly have been deliberately designed. It may possibly be an accidental result of subsequent revision, but it may equally be a natural though undesigned consequence of the manner of representation. For there is evidence that in the Corpus Christi procession the pageants originally preceded the Host, and we know that the place of greatest honour was that nearest the latter. Consequently, the least important crafts would come first, and the shortness of the earlier plays may be due to the small resources of the guilds undertaking them.

In studying the texts of the miracle plays that have come down to us, we have to be very careful to distinguish the nature of the manuscripts in which they are extant. At York, according to the records, the 'originals' of the plays were in the hands of the various guilds; when the corporation found it necessary to have copies for their own use they caused a 'register' to be compiled, transcribing the separate plays in order into a volume. A similar origin may reasonably be postulated for the Wakefield manuscript. At 


\section{PROBLEMS OF THE ENGLISH}

Chester, on the other hand, the 'original' was a complete manuscript in the possession of the corporation, the guilds having transcripts of their individual plays. On one occasion the Smiths paid for permission to peruse the 'original.' At Beverley they were copies, 'registra,' of the Pater Noster play that were given to the crafts, the 'original' being retained by the corporation. It would perhaps be unwise to insist much upon the use of the words 'original' and 'register' in the records, but the distinction is corroborated by an examination of the extant manuscripts. That of the York cycle is a manifest compilation, blanks having been left for the insertion of plays which were not at the moment forthcoming. In the Wakefield manuscript blanks were not left, but missing plays were sometimes inserted later on out of their proper order. One separate manuscript of a York play is extant. It is made to fold in a wrapper for the pocket, and bears marks of having been much handled. On the cover is the name of the Scriveners' guild. Inside is a late transcript of that guild's pageant, the 'Doubting of Thomas,' without title, number, or heading of any kind. It is not a copy from the 'register,' which, though younger, it sometimes corrects, but is clearly itself an 'original' descended from a line of earlier 'originals' now lost. Turning to the Chester plays, we find no less than five collective manuscripts. All are late, the earliest being dated I59I. A comparison of the text proves both that a number more must have perished, and that the general features of the cycle are of some 
antiquity. There is no evidence that the manuscripts represent a compilation of separate texts. In this case likewise we are fortunate enough to possess an independent manuscript of a single play, and this happens to be nearly a hundred years older than the oldest collective manuscript. Like the York Scriveners' book, it has been folded for the pocket, but it has lost its original cover, so that we cannot tell whether it ever bore the name of the guild to which it belonged, presumably the Dyers. But at the head of the text appears both the subject of the play, the Coming of Antichrist, and its number in the complete cycle. It follows that it must have been at some time transcribed from a collective manuscript. With this corroboration we shall, I think, be justified in trusting the records in the matter of 'originals' and 'registers.'

The distinction once grasped, explains certain curious differences between the York and Chester cycles. The former is clearly seen to be in the main a collection of separate plays which have grown and developed individually without restraint and largely independent of one another. ${ }^{2}$ Where

1 At Coventry the recorded manuscripts are certainly the original copies of the sixteenth century reviser, Robert Crow, and we know that in the middle of the fifteenth century the 'original' of the Smiths' play was kept by the master of the company and handed over to the pageant contractor when Corpus Christi day approached ('T. Sharp, 'Coventry Mysteries,' p. 15). There is no evidence that a collected register was ever compiled at Coventry.

$=$ There is no reason against postulating a complete manuscript of the cycle in its original form, or even against supposing that 


\section{PROBLEMS OF THE ENGLISH}

each guild was the owner of its particular play this is precisely what we should expect, for it did what it liked with its own in the absence of central control, and there is no evidence of any 'register' being compiled before about I $475^{\circ}$ The character of the Chester plays is quite different. They form a whole far more homogenous than any of the other known cycles. Not but what there has been plenty of alteration. Plays have been amalgamated and divided, inserted, and perhaps omitted, as well as interpolated and revised. But the alterations are throughout of a kind that may quite well have been made in an official copy and incorporated in the transcripts which must have been periodically needed.

The crcles were elastic in another way. Not only did the contents vary from time to time, but at no time possibly was it quite certain what a given cycle included. We know that the extant manuscripts of the Chester plays do not contain all the pageants that were sometimes performed as part of the cycle, and it is doubtful whether any manuscript ever did. For instance, we miss the 'Assumption of the Virgin,' a play of which we have record, and the theory that it was omitted from our manuscripts out of Protestant prejudice can, I think, be disproved. It was presented, which

such a manuscript may have survived into later times; but if it survived, it did so as an antiquarian monument, not as an authorized standard for the text.

The editor of the York Plays assigned the extant MS. to I $430-40$, but this is certainly too early. I do not think that any competent critic to-day would place it much before the middle of the second half of the century. 
does not mean acted, by 'the worshipfull wyues of this towne, and was also performed independently. It was, therefore, one of those plays which did not belong to the regular guilds, but were given by loosely attached companies which sometimes associated with them on these occasions. The Assumption was a favourite subject for such bodies to choose. Both at Lincoln and at Beverley it was performed by the priests. At York, on the other hand, it was given by the Innkeepers, who were reorganized for this purpose in 1483 , but never became a regular guild, and the text of their play in the 'register' is a fragment added in a later hand.' Perhaps it is significant that in the 'Ludus Couentriae' the Assumption play is clearly of a different origin from the rest of the cycle. Again, in 1415 the Hospital of St. Leonard at York took charge of the 'Purification,' and the play is absent from the extant manuscript. Also it is recorded that there was discontent at Beverley because the 'generosi' escaped the burden of a play, and in I 4 I I they were charged with the production of one. But in this case the newcomers seem to have been allotted one of the most fundamental plays of the cycle, for about a hundred years later we find them giving the 'Peregrini.' Thus we have to assume that not only were the regular guild plays constantly changing and being altered and revised, but that round or through this comparatively stable

They had, however, produced a play on the same subject earlier, the text of which is preserved in the original 'register.' They are there called the 'Osteleres,' and a later hand has added 'alias Inholders' and also the word 'caret,' indicating apparently that this text had been cancelled in favour of the later version. 
planetary system wandered or revolved a variety of errant dramatic comets which were never permanently captured by the central attraction of the Corpus Christi festival.

All this adaptation and revision naturally involved a great deal of rewriting and copying. Perhaps we ought not to complain that we have less information concerning authors and scribes than we could desire: the wonder is that the records have yielded as much as they have. Hilarius, who wrote in French and Latin in the twelfth century, may have been an Englishman. The earliest name connected with English miracle plays is that of Ranulf Higden, author of the 'Polychronicon,' who is credited with having written the Chester plays in I 328 . One Thomas Bynham was paid for writing the 'banns' at Beverley in 1423. At Coventry there were new plays in I 520 , and the Weavers paid five shillings 'for makyng of the play boke' in I 535, the year in which the extant text of their pageant was 'newly translate' by Robert Crow. The Shearmen and Tailors' play was also ' newly correct' by him a few days later. At Bungay, Stephen Prewett, a priest of Norwich, was paid for copying the play in 1526 , and in $155^{8}$ William Ellis received four pence for the interlude and game book, and two shillings for writing out the parts. An extant Massacre and Purification play of I 5 I2 purports to be written or copied by one John Parfre. A late 'Conversion of St. Paul' bears the name of Miles Blomefield, and the initials M. B. occur elsewhere. He has, however, been identified with 
the astrologer of Bury, born in 1525, who was evidently a collector, for his copy of de Worde's 'Information for Pilgrims' is now in the library of St. John's College, Cambridge, and John Stow, the historian, mentions having transcribed a poem from 'Master Blomfelds boke.' '

There is one point I should like to mention before I close. Some critics assume that the miracle plays were transmitted orally, and that they grew out of the liturgical drama by a process akin to that which has been postulated for the development of the popular ballad. They are, I think, mistaken. The liturgical plays were written offices of the Church, having their appointed places in the service books. Transition plays are found in the written collections of the 'scholares vagantes.' If English manuscripts are wanting before the close of the fifteenth century, that is no argument for supposing that they did not exist. Written parts for single actors are extant belonging both to the late liturgical drama and to the Miracles of Our Lady. In the sixteenth century we have found William Ellis writing such parts. Collective manuscripts and prompters' copies of the plays of the miracle cycles are alike forthcoming. That plays may have been borrowed, or stolen, orally I do not deny. That many performers were illiterate and had to learn their parts by ear is not impossible. But that, at any period, the texts were normally transmitted otherwise than as written documents is contrary to all evidence and to all probability.

' See at the British Museum, MS. Addit. 29729, fol. 2. 


\section{PROBLEMS OF THE ENGLISH}

I have attempted nothing like a systematic account of the English miracle drama from the bibliographical point of view. My only object has been to put before you a few cases that illustrate the bearing of bibliographical investigation and the examination of records upon the literary history of the religious drama. To several of the points mentioned I shall return in my later lectures.

\section{II.-THE COMING OF ANTICHRIST: RELATION OF THE MANUSCRIPTS OF THE CHESTER CYCLE.}

THE subject I propose to discuss in this lecture is the textual relation in which the manuscripts of the Chester plays stand to one another. This problem is in itself purely bibliographical, but we shall nevertheless find that our investigations will include a number of points of more general interest in the history of the religious drama.

There is a legend as to the origin of the Chester plays which has come down to us in a variety of more or less discrepant versions. Mr. Chambers, comparing these versions with one another and analyzing them in the light of historical records, comes to the conclusion that the original tradition must have represented the plays as written by Ranulf Higden, monk of St. Werburgh's Abbey, Chester, and author of the 'Polychronicon,' in I 328 , during the mayoralty of Richard Herneys, and the papal pardon for the spectators as obtained, 
probably from Clement VI, by Henry Francis, who was senior monk of the abbey in the third quarter of the fourteenth century. ${ }^{\mathrm{T}}$

The traditional date is what on general grounds, historical and literary, we might expect, but the plays themselves have come down to us in a late and much modified form. In support of the authorship it has been argued that one of the plays makes use of unusual authorities which are followed and named in connexion with the same incidents in the 'Polychronicon.' 2 On the other hand, the use of these authorities by the dramatist has been disputed, and a fundamentally composite authorship of the cycle has also, though with less reason, been postulated. 3 There the matter rests. ${ }^{4}$

Our concern lies with the manuscripts in which these plays have come down to us, and with the textual relations subsisting among those manuscripts. The problems they present are many, and the most obvious is raised by the curious fact that of this cycle, probably dating from the first half of the fourteenth century, all the manuscripts that survive were written between I 59 I and I607. It is the only cycle of which more than a single

I 'The Mediaeval Stage,' ii. 348 .

2 S. B. Hemingway, 'English Nativity Plays' (Yale Studies in English, xxxviri), New York, I909, p. xxi.

3 Hans Utesch, 'Die Quellen der Chester-Plays,' InauguralDissertation, Kiel, r 909, p. 9 I.

+ An ingenious and very attractive line of metrical argument, which would go far to prove substantial unity of authorship, was suggested by Alex. Hohlfeld in his essay on 'Die Altenglischen Kollektivmisterien' ('Anglia,' I889, xi. 251). Unfortunately the facts are not as he states them, and his inference is therefore invalid. 


\section{PROBLEMS OF THE ENGLISH}

manuscript is known, while of it we have five, the oldest of which did not come into existence till several years after the plays themselves had been performed for the last time. Nor are they transcripts of a single original, but, as we shall see, the existence of at least four intermediate copies can certainly be inferred. This points to an antiquarian interest in the subject, for the last performance of the cycle took place I 575, and there does not appear to have been much dramatic enterprise after that date. Alleged preparations for a performance in 1600 rest on no cogent evidence.

I will now enumerate the known manuscripts in chronological order. It is perhaps a further

I All are paper and in folio. Bodley's is the only one that has not been rebound. Since no adequate description of these manuscripts appears to exist, I give here a more detailed account of them than was possible in my lecture.

159I. D. In the library of the Duke of Devonshire at Chatsworth (?). Measures I I $\frac{1}{2} \times 7 \frac{1}{2}$ inches. Imperfect at the beginning, the first pageant supplied in a modern transcript from MS. K, probably by J. P. Collier. The first leaf that survives is the original folio 6, on which the second pageant begins. Written throughout in a very good and clear, though somewhat current, English hand, without ornament. Speakers' names centred. Speeches divided and stage directions marked off from the text by long rules; quatrains or half stanzas separated by short rules from the left. 'There were originally 150 folios. The manuscript is perfect at the end, and below the 'Finis' is the note: 'By me Edward Gregorie scholler at Bunbury the yeare of our lord god 1591.? It is not certain whether this is in the same hand as the text. Lower on the same page is the name 'Richard Gregorie.' This manuscript was missing when Deimling prepared his edition.

1592. W. In the British Museum, MS. Addit. 10305. Measures I I X 7 inches. Mutilated at both ends, but the old foliation shows that no leaves are actually missing at the beginning. There are 160 folios, and 96 lines of text, which would occupy two leaves, are wanting at the end. This is the most ornamental 
indication of their antiquarian origin that in each case the scribe has dated and signed his work.

The earliest manuscript of the cycle is one dated 159 I in the possession of the Duke of Devonshire. It is written in a very clear hand without ornament. Five leaves are missing at the start, the text beginning with the second pagent. I call this manuscript D.

Next comes a manuscript at the British Museum, Additional 10305 , dated 1592 . Written in a careful hand, with more ornament than any of the other manuscripts. Mutilated at both ends; no

as well as the smallest of the manuscripts. $\propto$ Speakers' names are centred: these and the stage directions and Latin quotations in the text are in red. Speeches are divided, and stage directions marked off by treble rules with elaborate finials. A head-line giving the name of the craft is enclosed in rules, and more elaborate ornaments decorate the head-titles. Rules surround each page. The stanzas are in no way divided, but the shorter lines, normally the fourth and eighth, are sometimes filled out with stars. Written throughout in a good English hand, clear, but more laboured than that of D. At the end of each play is a signature: "by me Georgi Bellin I 592.' This manuscript was the one printed by Wright: hence the designation $\mathrm{W}$.

$\checkmark$ I600. K. In the British Museum, MS. Harley 2013. Measures I $1 \frac{1}{2} \times 7 \frac{1}{2}$ inches. Perfect, containing 205 folios. The rubrication is similar to that of $W$, and the ornament is also somewhat * similar though much less elaborate. Moreover, rules divide the quatrains or half stanzas. There is a head-line, and stars are sometimes used. At the end of several of the plays occurs a signature : 'per me Georgi Bellin 1600.' Written throughout in a good English hand more flowing than that of $W$. At first sight there appears little resemblance between the two, and one might be inclined to suggest that Bellin was the scribe of the original manuscript from which both are copied. There are, however, some peculiar resemblances of detail between them, and when we take into account the similarity of ornament in the two cases, we shall perhaps conclude that the balance of probability is in favour of both 


\section{PROBLEMS OF THE ENGLISH}

leaves actually lost at the beginning, but two at the end. Known as W.

The third is another British Museum manuscript, Harley 2013 , which bears the date 1600 . In spite of considerable difference of appearance it is probably by the same scribe as the preceding; the ornament is similar though less elaborate. It is the oldest perfect manuscript. I give it the symbol $\mathrm{K}$.

Next comes an Oxford manuscript, Bodley 175. Its date is 1604 . It is perfect; it is the plainest of the manuscripts, and is written in a very current hand. Its symbol is B.

manuscripts being actually the work of the same scribe, and account for the differences in the writing by the evidently intentional - freedom of style in the later example and by the lapse of eight years. Who George Bellin was we have no record, but he must pretty certainly have been a professional scribe. He can hardly be identified with the George Bellin who was 'put down' from brewing or selling ale at an inquisition at Chester in 8 Elizabeth (i.e. 1566 , see MS. Harley 2105 , fols. $29^{b}, 30^{b}$ : his name is said also to occur in MS. Harley 1927 , but I have been unable to find it there), but he may have been of the same family, and also of that of Thomas Bellin, who, when Mayor of Chester in 1578 , caused the Shepherds' play to be performed at the high cross in the Roodee. Deimling labelled the present manuscript ' $h$ ' to distinguish it from the more important $\mathrm{H}$ (Harley 2124), but an examination of his edition shows that the symbols ' $h$ ' and ' $H$ ' are too liable to confusion, and therefore I propose for the earlier manuscript the arbitrary symbol ' $\mathrm{K}$.'

I604. B. In the Bodleian Library, MS. Bodley I 75. Measures I $1 \frac{1}{2} \times 7 \frac{1}{2}$ inches. There are 176 folios in the original vellum wrapper, and the manuscript is perfect. 'The speakers' names are centred as in all the above manuscripts; there is, however, no rubrication and no ornamentation of any kind. The English hand in which the scribe wrote is very current, and though a good hand it often leaves the precise reading uncertain by reason of its haste. The manuscript is signed at the end : ' 1604 , per me gulielmum Bedford.' 
The youngest manuscript is again in the British Museum, Harley 2124 . It is dated 1607 and is perfect. It has some ornament and is the work of two scribes. It is designated $\mathrm{H}$.

I had better at once mention two other manuscripts. One of these is a mere fragment out of a binding, preserved in the Manchester Free Library, and containing the opening of the play of the Resurrection. It is on vellum and has been ascribed to the end of the fifteenth century. This is a mistake. The elaborate writing is deliberately archaistic, and cannot be much earlier than the

* 1607. H. In the British Museum, MS. Harley 21 24. Measures I I $\frac{1}{2} \times 7 \frac{1}{2}$ inches. Perfect in 142 folios, with the original wrapper, * formed of a Latin liturgical manuscript, preserved. TThe speakers' names are no longer centred, but placed in the left margin. They and the stage directions, Latin quotations, etc., are in red. Quat* rains or half stanzas are divided by rules. (The manuscript is in two hands which have not hitherto been correctly distinguished. One is a purely Italian hand, which appears in folios I-44 only. The other then begins, and writes folios $45-56$ and $59-62$ in an Italian hand so far as the text is concerned, but with the speakers' names in a curious spiky writing which must be called English, though the forms of many of the letters are in fact Italian. In folios $57-8$, and from folio 63 onwards, this is used for the text as well. Both Italian scripts are very clear, the English though legible is occasionally misleading. The manuscript is signed at the end, in the second hand: ' 1607 Augusti quarto, per Iacobum Miller.' The name' Williame Broome' occurs on the front cover.

* Fragment c. 1575-1600. M. A fragment, consisting of the upper part of a single leaf, in the Manchester Free Library. It came out of a binding and is much stained; measures about $6 \frac{1}{2} \mathrm{x}$ $7 \frac{1}{2}$ inches. The full leaf must have measured about $9 \frac{1}{2} \times 7^{-\frac{1}{2}}$ inches. It is of stout vellum, and contains $11 . I-I 3$ and $2 I-4 I$ of the play of the Resurrection, elaborately written in red and black. There is a heading, but neither the number of the pageant (xviii) or the name of the guild performing it (the Skinners) is given. The French verses with which this play opens are in Italian script, the 


\section{$3^{8}$ PROBLEMS OF THE ENGLISH}

manuscripts mentioned above. Too little of the text is prescrved for its readings to have much evidential value. It is possible, or perhaps probable, that when complete it contained a single pageant only. In that case its date is presumably before 1575 .

The last manuscript to be described is one of peculiar interest and importance, though it contains nothing but the pageant of the Coming of Antichrist. It belongs to the famous Hengwrt-Peniarth collection now in the National Library of Wales at Aberystwith. It is written on vellum and has unfortunately lost its original wrapper. This most likely bore the name of the guild that performed

English in a careful imitation of black-letter type. The relationship of the text of this manuscript is by no means clear, but its $\#$ closest affinity seems to be with B.

'Antichrist' only, $c$. 1500. P. A Peniarth manuscript now at Aberystwith. On vellum, measuring $1 \mathrm{I} \frac{1}{2} \times 7 \frac{1}{4}$ inches, two gatherings, the first of four leaves, the second of six, 20 pages in all. It is enclosed in a vellum wrapper consisting of a double leaf of a finely written missal probably of the thirteenth century, much injured by damp. But this is not original, for the quires have been folded down the middle, whereas the cover has not. The latter bears a paper label marked: 'Dialogue 229.' It is now protected by a rough cardboard case which bears certain notes: 'Hengwrr MS. 229,' '229 Per my Fathers Catalogue.' 'End of the $15^{\text {th }}$ century. G. F. Warner, Deputy Keeper of MSS. Brit. Mus. Io Odt. 1895. F. J. F[urnivall].' The second of these presumably refers to W. W. E. Wynne's catalogue of the Peniarth MSS. in the 'Archaeologia Cambrensis,' I86I-7 I. 'There appears the entry (1870, p. 75): "This MS. is a dialogue in English verse, of the fifteenth century. I believe it to be a portion or fragment of one of the "Mysteries" of the middle ages. . . The modern press-mark is Peniarth 399. Manly in his edition remarks that Furnivall assigned the manuscript to ' 1475 or a little later,' Warner to 'the end of the fitteenth century.' 
the play-the Dyers, if we may argue from the later records and manuscripts. At the head of the text is the title, 'De adventu Antichristi,' and the number 'Pagina $\mathrm{xx}^{\mathrm{ma}}$.' The date of the writing may be assumed to be the end of the fifteenth century, it might be as late as 1500 . The leaves have been folded down the middle with a view to carrying the book in the pocket, and the rubbed and faded condition of the text suggests that it has been much handled. I refer to this manuscript as $P$.

The difficulty of deciphering the writing of this manuscript, though great, would not have been insuperable had no attempt been made to restore it. But at some comparatively recent date the text has been largely re-written by an officious hand, which has gone over the lines of the old letters, so far as they were distinguishable, with modern ink. The result has been disastrous. The greater part of the manuscript has been either retouched or wholly written over, and although in most places it is still possible to trace the original writing, and thus to get behind the work of the modern restorer, in some it has wholly disappeared, and we have nothing but the superimposed writing to guide us. It is only fair to say that the restorer was a careful workman, and that as a rule his readings may be trusted. There were, however, occasions on which he fell into error. While working he had by his side either Wright's edition or else the manuscript (W) on which it was based, and when the original became more than usually obscure he was inclined to force the traces that remained into the semblance 


\section{PROBLEMS OF THE ENGLISH}

of Wright's reading. In the course of a careful collation I have been able to detect several such substitutions, and I am not altogether confident of having eliminated all spurious cases of agreement between manuscripts $\mathrm{P}$ and $\mathrm{W}$. All suspicious concurrences have, however, been carefully examined, and if errors yet remain I do not think they are likely to be of a kind to vitiate our results. It may be said, in palliation perhaps of the action of the modern retoucher, that he was not the first to tamper with the manuscript. Already in the sixteenth century it had shown signs of fading, and some scribe not only repeated some doubtiul words in the margin or between the lines, but here and there actually wrote over the original text exactly as his successor did later. And in one passage the modern restorer has written on the top of the earlier restorations, so that it is possible to trace no less than three superimposed layers of writing.

The Chester cycle was first edited by Thomas Wright in $1843-7 .^{\mathrm{I}}$ He knew of the existence of

I Extracts had appeared earlier. The complete list of editions, excluding a few popular reprints of individual plays, is, I believe, as follows (see Chambers, 'Mediaeval Stage,' ii. 407):

1818. Chester Mysteries. De deluvio Noe, De occisione innocentium, together with the Banns, edited by J. H. Markland for the Roxburghe Club. From K, with collations of $\mathrm{H}$ and $\mathrm{B}$.

I 836 . Five Miracle Plays, edited by J. P. Collier. Including 'Antichrist,' from D.

1838. A Collection of English Miracle-Plays or Mysteries, edited by W. Marriott. Including 'Noah' and 'Antichrist,' the first from $\mathrm{H}$, the second from $\mathrm{K}$.

1843-7. The Chester Plays, edited by Thomas Wright for the Shakespeare Society. Two volumes. From W, with the banns from $\mathrm{K}$.

I890. English Miracle Plays, Moralities and Interludes, edited 
all five collective manuscripts, and chose $\mathrm{W}$ as the basis of his text no doubt because it was the oldest readily accessible. This he supplemented from $\mathrm{K}$, the next oldest, and in his notes he also quoted a few passages from $\mathrm{H}$, the third manuscript at the British Museum. I do not think that he consulted either the Devonshire or the Bodleian text. $\mathrm{He}$ did not attempt any critical comparison, and chance led him to select for his edition what is perhaps the worst of the extant manuscripts.

The task of criticism was reserved for the industry of Hermann Deimling, the first portion of whose edition appeared in $1893 .^{1} \mathrm{He}$ took $\mathrm{H}$ as his basis, adding a collation of all other available manuscripts. Unfortunately D had been temporarily mislaid. A collation thereof has since been procured and will be included in the second part of the work, the appearance of which has been

by A. W. Pollard. Includes ' $\mathrm{Noah}$ ' and part of 'Abraham and Isaac,' from Wright's edition, compared with $\mathrm{D}$ and $\mathrm{H}$.

I 893 (for 1892). The Chester Plays, edited by Hermann Deimling for the Early English Text Society (Extra Series). Part I., containing the Banns and Text as far as play XIII, 1. 282. From MS. $\mathrm{H}$ with collation of $\mathrm{W} \mathrm{K} \mathrm{B}$; Banns from $\mathrm{K}$ with collation of $\mathrm{B}$.

1897. Specimens of the Pre-Shaksperean Drama, edited by J. M. Manly, vol. i. Including 'Prophets' from Deimling's edition, and 'Antichrist' from MS. P.

I 909. English Nativity Plays, edited by S. B. Hemingway. Including 'Nativity' and 'Shepherds' from $\mathrm{D}$, with collation of $\mathrm{W}$ $\mathrm{K} \mathrm{B} \mathrm{H}$.

The fragment of the 'Resurrection' at Manchester (MS. M) was printed in the 'Manchester Guardian' for 19 May 1883.

1 Through the great kindness of the late Dr. Furnivall, director of the Early English Text Society, I have been able to use the unissued sheets or proofs of the portion of this edition which still awaits publication. 


\section{PROBLEMS OF THE ENGLISH}

delayed owing to the death of the editor. Deimling showed conclusively that $\mathrm{H}$, the youngest manuscript, represents a different recension from the others, and he regarded this recension as superior.

The Peniarth 'Antichrist' was first printed in 1897 by Professor Manly. He was assisted in his difficult task by Furnivall. A few collations from Wright's text were added, and the suggestion hazarded that the new manuscript was most nearly allied to $\mathrm{H}$, but the question of relation was not pursued. It is a remarkable fact ti.at in cases where the modern scribe has wrongly restored the readings of the manuscript, Manly's text sometimes follows the restorer's, sometimes the original reading. ${ }^{\mathrm{I}}$

Deimling's view as to the superiority of $\mathrm{H}$ has been challenged by Dr. S. B. Hemingway of Yale, who took $\mathrm{D}$ as his text for the two Chester pageants which he included in his collection of 'English Nativity Plays.' He regards this manuscript as the best representative of the better tradition, arguing that those passages in which $\mathrm{H}$ has obviously superior readings are in many cases due to editorial emendations by the scribe. ${ }^{2}$

The one thing that has clearly emerged from

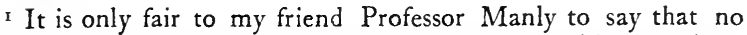
suspicion whatever attaches to him in connexion with the misuse which the manuscript has undergone.

2 His preference for $\mathrm{D}$ appears, however, to be based upon a quite arbitrary judgement as to 'superior readings.' Moreover, though he consulted $\mathrm{D}$, and I presume transcribed his plays from it, I gather that his collations of the other manuscripts are taken from Deimling's edition. 
the discussions so far is that the collective manuscripts fall into two main groups, one of which is represented by the youngest manuscript $\mathrm{H}$ alone. It is also clear that within the larger group a specially close relation unites $\mathrm{W}$ and $\mathrm{K}$, the two manuscripts purporting to be by the same scribe. The position of $\mathrm{P}$ has not been seriously discussed, and indeed the importance of this, by far the earliest text we possess, for the textual criticism of the cycle does not seem to have been recognized. When Deimling wrote its existence was not generally known, but it was actually accessible to Hemingway in a printed edition, and that he should have ventured to form an opinion upon the relative merits of the cyclic manuscripts without taking its evidence into consideration is inexcusable.

In the five collective manuscripts we clearly have texts of the whole cycle as officially recognized. There is nothing in any of them to suggest that they were compiled, like the York 'register,' by transcribing a number of separate play-books in the hands of the various guilds. Where divergencies of tradition appear they seem to affect the whole cycle, not merely individual plays.? Now we have already, in my previous lecture, seen reason to believe that the 'original' of the Chester cycle was an official copy in the possession of the corporation. That 'original' was presumably from time to time renewed, alterations being incorporated in a fresh copy. From some such our present manuscripts must be descended. But their differences prove that they were not all transcribed from the same 'original,' but that they represent 


\section{PROBLEMS OF THE ENGLISH}

at least two presumably official recensions. Which of these is to be considered the more authoritative is a nice point which depends, not only upon the textual evidence of the manuscripts, but also to some extent at least upon the kind of authority we look for.

After what I said last time, you will have little difficulty in recognizing in the Peniarth manuscript one of the prompt copies in the hands of the various acting guilds. The collective manuscripts and the records assign the Antichrist pageant to the Dyers, and though both are later than $\mathrm{P}$, there is no reason to suppose that any change of guild had taken place. You will also remember that we came to the conclusion that the present manuscript was not, like the York Scriveners' play-book, itself an 'original,' but was a copy, either direct or indirect, from an official manuscript of the whole cycle. The absence of any evidence of compilation in the collective manuscripts, together with the fact that $\mathrm{P}$ bears the heading, 'Incipit pagina $\mathrm{xx}^{\mathrm{ma}}$,' seems to me to place this beyond doubt. But if this is so, it follows that $\mathrm{P}$ cannot be the parent of any portion of any of the later manuscripts, but must be ultimately descended from some collective manuscript which is likewise an ancestor of the younger group.

It will be well to consider for a moment what light the general history of the cycle, as traced in the records, may throw on the problem of the manuscript tradition. Our information as to the pageants and the guilds performing them comes, apart from the texts themselves, chiefly from certain 
'Banns,' or versified arguments of the pageants, intended for recitation by way of advertisement of the annual performance. Some of the manuscripts of the plays contain copies of a late set of banns, a more complete version of which is preserved in Rogers' 'Breviary of Chester.' 'These banns belong presumably to the third quarter of the sixteenth century. But an earlier and quite distinct version of the banns is also extant. This, which was copied for Randle Holme out of the "White Book of the Pentice,' is called by Chambers the pre-reformation banns, and is certainly earlier than $1547 .^{2}$ Accompanying each set of banns is a list of the pageants and the guilds performing them. Now the series of pageants described in the two sets differ in two points. The earlier contains a play, 'of our lady thassumpcion,' which is absent from the later, while this records as a single play the Scourging and Crucifying of Christ, which forms two distinct pageants in the earlier. ${ }^{3}$ It has been assumed, not unreasonably, by Chambers and

I The Banns in MS. $\mathrm{K}$ are printed by Wright and Deimling, the latter adds collations from $B$. Eighteen additional lines from Rogers' 'Breviary' (MS. Harley 1944) were printed by Furnivall in the introduction to his edition of the 'Digby Plays,' New Shakspere Soc., I 882 (E.E.T.S, 1896), p. xx.

2 Holme's copy is in MS. Harley 2150 , whence it was printed by $\mathrm{R}$. Morris in his 'Chester in the Plantagenet and Tudor Reigns,' p. 307.

3 At the risk of obscuring the argument I feel bound to add that the 'Assumption' appears in neither list, and that the 'Scourging' and 'Crucifying' are divided in both lists. This, however, only proves that lists and banns are drawn from different sources. Indeed, there is reason to believe that Holme's and Rogers' lists are both copied from the 'White Book.' 


\section{PROBLEMS OF THE ENGLISH}

others, that the disappearance of the 'Assumption' was a result of the Reformation. It is highly probable that the play did cease to be performed, as at York, out of Protestantism. It does not, however, follow that that is the reason why it is not found in the manuscripts. I will leave the question there for the moment.

The discrepancy in connexion with the pageant of the Passion reappears in the manuscripts; $\mathrm{H}$, the youngest of them, agreeing with the later banns in making the play a single whole, while the rest, like the earlier banns, divide it into two. This certainly looks as though $\mathrm{H}$ preserved the younger and the group the older tradition. Curiously enough the internal evidence points in precisely the opposite direction. Deimling, it will be remembered, preferred $\mathrm{H}$. He was led to this conclusion chiefly by a consideration of the numerous passages which appear in the manuscripts of the older group, but are absent from $\mathrm{H}$. It is possible that in some instances the divergence may be due to omissions in $\mathrm{H}$, but in a number of others the additional passages disturb the stanzaic arrangement of the text, and it is evident that $\mathrm{H}$ preserves the more original version. Now in $\mathrm{H}$ the Passion pageant is immensely long, extending to no less than 892 lines. The next longest play is the 'Nativity' with 736 lines; the shortest the 'Ascension' with 192. Assuming $\mathrm{H}$ to be the more original text, it is not difficult to conjecture how this came about, for the play bears traces of revision. It contains namely a variety of passages in a different and shorter measure than the rest. 
These occasionally appear interwoven with the more normal portions of the play, but certain large sections remain which can easily be detached from their context. They are lines 65 to 120 , containing the buffeting, lines 313 to 360 the scourging and crowning, and lines 457 to 600 the crucifixion and casting of lots. There is, indeed, nothing surprising in a different metre being used for these passages, but their subjects might well be represented in dumb show, and the omission of the lines mentioned would reduce the play to the very manageable length of 644 lines. On the other hand, if we assume the group of manuscripts to represent the earlier tradition, it is very difficult indeed to imagine how two originally separate plays should ever have been combined into such an unwieldly whole. The rubrics of the manuscripts, I think, clinch the matter. Immediately following the Trial and Condemnation all the manuscripts have eight lines of the shorter measure, after which $\mathrm{H}$ inserts the direction, "Tunc ibunt versus montem Calvariae,' and proceeds without break. At this point the group insert a short scene of sixteen lines only, containing Peter's denial, at the end of which D has: 'Finis paginae decime sextae. This storye is finished in the leaves followinge.' There are variants in the other manuscripts. The group then proceeds: 'Incipit pagina de crucifixione Christi,' \&c., but there is no fresh number, and when we come to the end D repeats: 'Finis paginae decimae sextae.' The other manuscripts of the group omit this, but in all the play that follows is numbered seventeen, 


\section{PROBLEMS OF THE ENGLISH}

just as it is in $\mathrm{H}$. We have here, I think, proof as absolute as the circumstances admit that the process has been one of severance and not of coalescence, and that it is consequently the youngest manuscript, $\mathrm{H}$, which preserves the earlier tradition.

The occasion of the division was the appearance of two fresh guilds in the group already responsible for the performance of the play. In $\mathrm{H}$ the actors are the Bowyers, Fletchers, and Ironmongers. To these $B$ adds the names of the allied guilds of Coopers and Stringers, but repeats the name of the Ironmongers at the head of the Crucifixion play. The remaining manuscripts, $\mathrm{D} \mathrm{W} \mathrm{K}$, also give this pageant to the Ironmongers, whose name, however, they correctly omit at the head of the preceding Trial play.

How then are we to explain the contradiction between the internal and external evidence? The fact of the Passion appearing as a single play in the younger banns need not, I think, disturb us. However late they may be, there is nothing improbable in supposing that their author had before him as he wrote a manuscript of the earlier type, such as $\mathrm{H}$, in which the play was not divided. Or else he may have been misled by the erroneous numbering which persists in all the divided texts. The real difficulty in the way of regarding the undivided text of $\mathrm{H}$ as original, is that the pre-reformation banns represent the play as already divided at a date when the Assumption play, which has disappeared from all extant manuscripts, was still performed as part of the cycle. 
Those who heard my first lecture will be already familiar with the solution I propose for this contradiction. It is that the Assumption play is absent from the manuscripts of both traditions because, in spite of its appearance in the early banns, it never formed an integral portion of the cycle. We know that it was presented by 'the worshipfull wyves of this towne,' whereas the Chester plays proper were in the hands of the crafts. We know that while the play was acted as part of the cycle in 1477 , it was performed separately in 1488, 1497, and I 5 I $5 .^{\circ}$ We have also seen that the subject was a favourite one for unattached bodies to choose when they joined in the dramatic activities of the guilds. But the conclusive proof that the Assumption play was not a regular member of the pageant cycle is supplied by the banns themselves. It does not appear to have been noticed hitherto that the four lines describing the play form but half a stanza, and that the last of them is widowed of its rime; in other words, they are an insertion made to meet some special occasion, possibly the very performance recorded in $1477 .{ }^{2}$

Having disposed of this objection to the originality of the tradition of $\mathrm{H}$, I may point out that the latter actually finds support in the early banns themselves. For although these clearly state that

'Morris' 'Chester,' pp. 308, 322, 323; cf. Chambers, ii. 409.

2 Even had the 'Assumption' ever formed an integral part of the cycle, the contradiction would not be a very serious obstacle to the originality of H. For the same cause, namely Protestant prejudice, which, it is argued, led to the omission of the play in the later tradition might equally have led to its independent omission in a transcript of the earlier tradition.

C 
the 'Trial' and 'Crucifixion' constitute two distinct pageants, the quatrains describing them were not scparated in the usual manner, but were written continuously as though for a single pageant, and in the margin the names of the performing guilds were originally all written opposite the first quatrain. It seems probable, therefore, that the scribe of the banns copied them from a text in which the description was not yet divided. If these banns are pre-reformation, as Chambers holds, and as certainly seems probable, it follows that the divergence of the tradition in the collective manuscripts (between $\mathrm{H}$ and the group) may well be as early as the fifteenth century. ${ }^{\mathrm{T}}$

The question as to whether the Passion pageant was originally one or two is also of interest in connexion with the Peniarth manuscript of 'Antichrist.' Although all the collective manuscripts number the last play, that of Doomsday, twentyfour, in reality of course the number of pageants in $\mathrm{H}$ is twenty-four and in the group twenty-five. Now the play of Antichrist, which is the last but one of the cycle, is headed in the separate manuscript, $\mathrm{P}$, 'Incipit pagina $\mathrm{xx}^{\mathrm{ma}}$,' from which it follows that the collective manuscript from which it was copied contained only twentyone plays. Hence we are to infer a steady growth in the number at least of separate pageants from twenty-one to twenty-four, and finally to twenty-

I If we could argue with certainty that the banns containing the 'Assumption' actually represent the performance of 1477 , it would follow that the tradition represented by $\mathrm{H}$ was earlier than that year. 
five. A further inference is possible. If the divergence of the textual tradition in the cyclic manuscripts goes back to the fifteenth century, the tradition of $\mathrm{P}$, or rather of its cyclic original, which contained twenty-one plays only, must be considerably older. In that case $\mathrm{P}$ itself, which belongs to the very end of the fifteenth century, cannot have been transcribed from a contemporary 'original,' but is probably a copy of an older promptbook belonging to the guild. This would lead to the conclusion that the common ancestor of $\mathrm{P}$ and the cyclic manuscripts may well be as early as I 400 . In no other cycle will the textual tradition take us back anything like as far as this. ${ }^{\mathrm{T}}$

There are two other instances of a divergence in the tradition which might throw light on the general history of the transmission of the text. It must be borne in mind that the group B D W K, and the sub-group $\mathrm{W} \mathrm{K}$, are well established by general textual considerations. Now the two earliest manuscripts, D and $\mathrm{W}$, give a text of the Resurrection play extending to 432 lines, and finish it off in their usual manner. Clearly their prototype ended at that point; but the play is incomplete, and in the interval between 1592 and 1600 George Bellin, the scribe of $\mathrm{W}$ and $\mathrm{K}$, discovered that there was another tradition, for his later manuscript

I I ought possibly to state that owing to the very faded condition of the original writing in MS. P, it is impossible to be absolutely, certain that the number in the heading is ' $x x^{\text {ma }}$ ' and not ' $x x^{\text {iiia }}$,' though the latter would be an exceedingly unusual form. If P's original contained twenty-four pageants, it brings it very close indeed to $\mathrm{H}$; on the other hand, the further inference as to the antiquity of the whole tradition would collapse. 


\section{PROBLEMS OF THE ENGLISH}

carries on the text for another 95 lines.] The scribe of $\mathrm{B}$, writing in $\mathrm{I} 604$, likewise knew of the fuller text, but apparently no manuscript containing it was immediately available. He ended even earlier than D and W, namely at line 425 , but left the rest of that page and the whole of the next blank. He never supplied the deficiency. Manuscript $\mathrm{H}$ has the full text, and there is nothing to suggest that it was not in the source which the scribe followed elsewhere. We have here then a clear instance of conflation, the only one, I believe, that these plays afford. The additional lines found in $\mathrm{K}$ and $\mathrm{H}$ appear to be quite necessary, and $\mathrm{I}$ suppose that their absence in the other manuscripts is due to the loss of a leaf in the archetype of the elder group. It follows that some at least of the scribes of the elder manuscripts knew of the original of $\mathrm{H}$, and deliberately discarded it in favour of some other, which though imperfect in this particular passage was known to embody more recent reformations.

Another case of anomalous grouping is afforded by the 'Banns.' As already explained, a copy of the later banns is included by Rogers in his 'Breviary of Chester,' but transcripts appear in certain of the cyclic manuscripts likewise. Neither W nor $\mathrm{H}$ ever had them. $\mathrm{D}$ is imperfect, beginning with the second pageant, but the five leaves missing would exactly contain the banns (in the version of $\mathrm{K}$ ) and the first play. $\mathrm{K}$ has the banns complete, so far as introduction and the description of the pageants is concerned, but omits the 'Conclusion' of twenty-four lines preserved by Rogers. B also 
has the banns, but omits seventy lines at the beginning, and adds at the end only the first six of Rogers' conclusion. Now it is clear that these banns, dating from the third quarter of the sixteenth century most likely, cannot have been in the archetype from which our cyclic manuscripts are derived. They might, so far as ascertainable dates are concerned, have occurred in the original of the group B D W K, but the sporadic manner in which they appear and the divergencies of the texts make it pretty certain that they were independently added in each case, and that they consequently throw no light upon the relations of the manuscripts in which they occur.

It is now time to consider the textual relationship of our extant copies in greater detail. Deimling, who was the first to investigate the question, had no difficulty in showing on the one hand that $\mathrm{H}$ stood apart from the rest, and on the other that a peculiarly close bond united $\mathrm{W}$ and $\mathrm{K}$. He was, of course, unable to place the missing D, but a few readings from that manuscript contributed by A. W. Pollard proved that it presented the peculiarities neither of $\mathrm{H}$ nor of $\mathrm{W} K$. The obvious inference was that $\mathrm{W}$ and $\mathrm{K}$ have a common and exclusive ancestor, say $F$, that $F$ and $B$ (and possibly D) have an ancestor $\beta$, and that only in the ancestor of $\beta$ and $H$ do we get back to the archetype of the extant manuscripts of the cycle. No scheme of the sort can, however, be regarded as satisfactory unless it will account not merely for a few selected readings or certain broad features of the texts, but for the whole body of minor variants 


\section{PROBLEMS OF THE ENGLISH}

as well. Deimling made no attempt to prove his scheme in this manner. I do not know whether any of my audience have ever attempted to do so on the basis of Deimling's collations, but I do know that if they tried they failed. The thing cannot be done, for Deimling's collations are both incomplete and, even so far as they go, often inaccurate. It does not seem to be always realised that when you are recording the readings in which a number of manuscripts differ from one selected text, to be incomplete is not merely to give information that is defective, but information that is actually false.

It has, therefore, been necessary to make a fresh collation with a view to determining the relationship of the manuscripts, and for this purpose I have naturally selected the play of Antichrist, for which we have a sixth independent text whereby to check the readings of the rest. For this play I have made a careful collation of all the manuscripts, and though I cannot, of course, say that no variant has escaped me-to do so would be to stamp myself a charlatan-I think it is unlikely that I have overlooked any reading occurring in more than one manuscript, and I do claim with some confidence what is really the important thing, namely, that wherever I have recorded any variant I have recorded all the manuscripts in which it occurs. If that confidence is justified, then, and only then, does my collation afford a sound basis for argument. Two classes of variants I have excluded from purview: those in stage directions, and those which merely affect linguistic forms such as 'ye' and 'you,' 'has' and 'hath,' \&c. Inspection 
shows that each scribe generally pleased his own fancy in these matters, and consequently that to take them into account is only to obscure the evidence. I may also state at once that I regard it as proved that none of the cyclic manuscripts are compilations, and consequently that $\mathrm{P}$ is not an ancestor of any of the other texts.

A few broad facts soon emerge. All the collective manuscripts being dated, the direction of possible copying is known. Further, each contains at least one omission peculiar to itself, which proves that it cannot be the parent of any of the other texts, the possibility of insertion being negatived by the presence of the passage in $P$. Thus the general nature of the relation between the texts becomes apparent.

To begin with, I will take a few of the more striking variants, and see to what detailed relation between the manuscripts they appear to point. The only omissions common to two texts are a number which occur both in $\mathrm{W}$ and $\mathrm{K}$. These might point to omissions in their common original, which we will call $F$, but I am more inclined to ascribe them to mutilations in that manuscript. It is noticeable that in the neighbourhood of the common omissions there sometimes occur further omissions peculiar to $\mathrm{K}$, a fact most readily explained by supposing a progressive deterioration of the original between I 592 and 1600 . The evidence of transposition confirms the existence of $F$, but is of value chiefly in establishing a common ancestor for the cyclic manuscripts apart from $P$. There are, namely, four lines which appear in $\mathrm{P}$ 


\section{PROBLEMS OF THE ENGLISH}

in an earlier position than in the other texts. ${ }^{2}$. The rimes prove that P's arrangement is right, while the sense not being affected it is unlikely that this should have been due to emendation. That being so the cyclic group must have a common ancestor in which the error occurred and which is not an ancestor of P. This is further supported by the misplacement of a stage direction near the end of the play which occurs in the younger manuscripts, but not in $\mathrm{P}^{2}$ Again, there is a minor but yet important transposition in which $\mathrm{P}$ and $\mathrm{H}$ agree against the rest. ${ }^{3}$ The passage is unfortunately corrupt in all manuscripts, but it seems pretty clear that the group BDW K have attempted an emendation from which $\mathrm{P}$ and $\mathrm{H}$ are free. This points to a common ancestor for the group apart from $\mathrm{H}$ and $\mathrm{P}$, and this we will call $\beta$. Its existence is supported by a passage in which $\mathrm{P}$ and $\mathrm{H}$ give to 'Quartus Rex' a speech assigned by the other manuscripts to 'Seueralis Rex,' whatever that may mean. ${ }^{4}$ Another speech is given by $\mathrm{P}, \mathrm{H}$, and also by $\mathrm{B}$, to 'Tertius Rex,' which D W K assign to 'Primus Rex.'s This is important as indicating a common ancestor of $\mathrm{DWK}$, say $\delta$, apart from $\mathrm{P} \mathrm{H} \mathrm{B}$, but unfortunately there is no obvious confirmation of this arrangement. A clear case of

I Lines 637-40. My references are to a parallel text of $P$ and $\mathrm{D}$ which I made for my own use. The numbering does not exactly agree with that of Deimling, who was in the habit of counting in non-existent lines. It does agree, however, with Manly's text.
2 Line 702.
4 Line 197.
3 Lines $193-4$.
5 Line 301. 
degeneracy in the cyclic manuscripts as compared with $\mathrm{P}$ is afforded by the line which appears in the latter rightly as: 'Walke ye furthe youre way,' and was altered in the common ancestor of the former to the unmetrical: "Walke yee furth in the twenty deuylles waye.'

A peculiar feature of $\mathrm{H}$ is the insertion of three single lines not found in any other manuscript. ${ }^{2}$ None of these are required by the sense, but each serves to make two corresponding half-stanzas equal in length, and is, therefore, an obvious metrical emendation. In another place ${ }^{3} \mathrm{H}$ expands a single line into two, also it would seem with a view to improving the metre, though perhaps not with that result. It was clearly the actual scribe of the manuscript $\mathrm{H}$ who was given to emending, for in one place we catch him red-handed. There is a line + in $\mathrm{P}$ which is certainly incorrect as it stands, for it has not got the necessary rime. The group B D W K makes an inversion in the order of the lines which is intended to mend matters, but does not. $\mathrm{H}$ began by copying down the line as it occurs in P: 'You kinges also to you I tell,' then he deliberately drew his pen through the words 'also to you,' and added at the end 'withouten bost,' thereby making it rime as it should. One other instance of the editorial function assumed by the scribe of $\mathrm{H}$ may be mentioned. The two devils who carry off Antichrist at the end of the play leave the stage with some parting jibes at
1 Line 450.
3 Line 453 .
2 After lines 159,411 , and 418 .
4 Line 193. 


\section{PROBLEMS OF THE ENGLISH}

the audience. As his farewell shot the second delivers himself of the line: 'In hell shall they dwell at theyre last ende.' ${ }^{\prime}$ This common damnation seems to have shocked the scribe, who had maybe a keener sense of justice than of humour. He eased his conscience at the expense of the metre by writing: 'All sinnfull shall dwell in hell at ther last ende.'

So far, then, the evidence points in the first place to a common source for $\mathrm{W}$ and $\mathrm{K}$, namely $F$; next we have found $\mathrm{P}$ and $\mathrm{H}$ agreeing together against the rest, while at the same time $\mathrm{P}$ has apparently original readings where all the other manuscripts are corrupt, whence it follows that we must assume a common source for $\mathrm{B}, \mathrm{D}$, and $F$, namely $\beta$, and also a common source for $\beta$ and $H$, which we will call $\eta$. It also seems likely that $D$ and $F$ have a common source, $\delta$, apart from $B$, though of this further evidence is desirable. Lastly, since we have agreed on general grounds that $\mathrm{P}$ is not an ancestor of any of the other manuscripts $\mathrm{P}$ and $\eta$ must have a common source, which would be the the archetype, $\boldsymbol{A}$, of all the known texts. Since, however, there are evident corruptions common to all six manuscripts, not even $\boldsymbol{A}$ can be the original, which, therefore, we shall have to move back into the mists of antiquity at $\boldsymbol{O}$.

Our results are so far in entire agreement with those of Deimling, from which, indeed, they only differ by the inclusion of $\mathrm{P}$ and $\mathrm{D}$ in the scheme. 
MANUSCRIPTS OF THE CHESTER PLAYS.

$\mathrm{P}=$ Peniarth Manuscript: Play of Antichrist-c. 1500.

$\mathrm{D}=$ Duke of Devonshire's Manuscript: Cycle-1591.

$\mathrm{W}=$ British Museum, MS. Addit. I0305: Cycle-1592.

$\mathrm{K}=$ British Museum, MS. Harley 2013: Cycle-1600.

B $=$ Bodleian Library, MS. Bodley 175 : Cycle-1604.

$\mathrm{H}=$ British Museum, MS. Harley 2 I 24 : Cycle-1607.

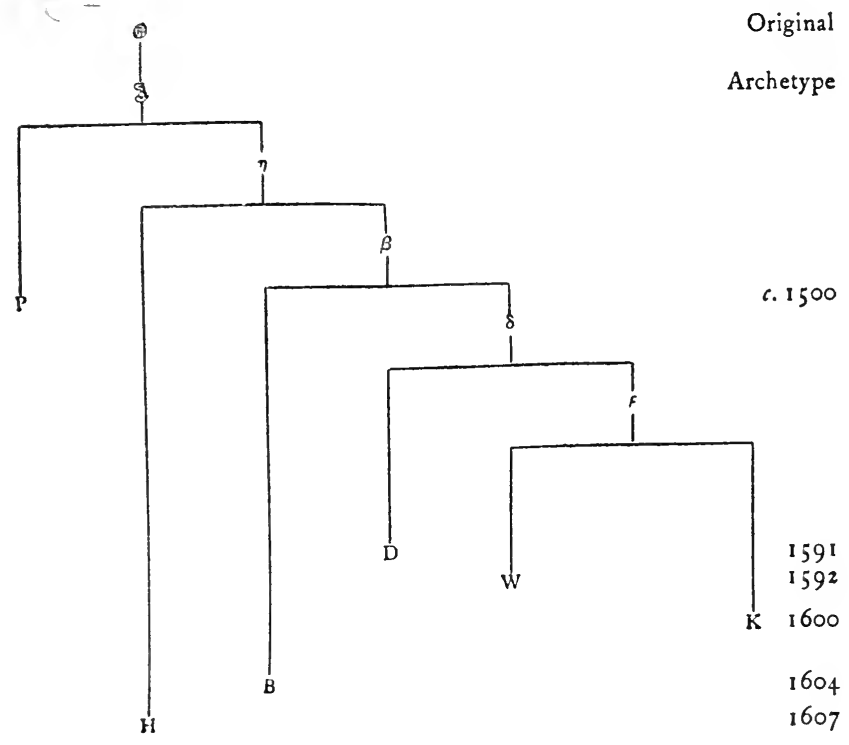




\section{PROBLEMS OF THE ENGLISH}

The table will show at a glance the provisional arrangement at which we have arrived. ${ }^{\mathrm{r}}$

Having now constructed a working hypothesis it remains to see whether it will work. Our scheme fits the facts so far as we have observed them, and I believe it alone will fit them. By the rules of the game it should account for all the variants in the different texts; unfortunately, through the perversity of actual conditions, it does not in the least follow that it will. Let us see.

On the present occasion I shall, of course, be able to treat the question only in the most summary manner. All I can do is to give statistical figures of the readings which support our scheme, and to consider briefly the most important of those readings which appear to contradict it.

There are, to begin with, in every manuscript a number of readings in which it is opposed by a consensus of all others. The numbers of such readings in the different manuscripts are: $\mathrm{P}_{97}, \mathrm{H}_{3} 8, \mathrm{~B} 46$, $\mathrm{D} 27, \mathrm{~W} 53, \mathrm{~K}_{39}$; total 300 . There are also I7 cases in which two or more manuscripts differ from the rest without agreeing among themselves. The total number of variants recorded being 424 , there remain 107 cases in which they fall into groups, and are therefore capable either of confirming or contradicting a scheme of relationship.

I The table must not be taken to imply that, for instance, either $\mathrm{B}$ or $\delta$ is immediately derived from $\beta$, but merely that they are derived from it, and that the intermediate steps, if there were any, are now lost. Similarly in the text, if I speak of errors or emendations introduced by D, I mean, of course, by D or some ancestor of $\mathrm{D}$ subsequent to $\delta$. 
Of these 58 are agreements of $\mathrm{W} \mathrm{K}$ against the rest, that is of variants in $F$, and 20 agreements of $\mathrm{P} \mathrm{H}$, that is variants in $\beta_{.}{ }^{1}$ This leaves about 30 readings which, though not necessarily contradicting our scheme, are worth attention. The most important and numerous group is that to which we must look to determine the positions of $\mathrm{B}$ and $\mathrm{D}$. Four agreements of B D against the rest suggest a common source for these two manuscripts. On examination, however, three of these prove to be easily explained coincidences, and the fourth, though less obvious, and therefore to be allowed some weight, is also capable of explanation. ${ }^{2}$ The evidence in favour of a B D source is, therefore, not strong. On the other hand, there are four readings in which P H D agree against B W K and contradict our scheme, and eight in which P H B agree against D W K and support it. Now, on examination the four anomalous cases all appear capable of ready explanation as coincidences due to obvious emendations or to alterations of obsolete or unexpected readings of the original. ${ }^{3}$ The soundness

I There is one case common to these two classes, namely an instance of $\mathrm{P} \mathrm{H}: \mathrm{B}: \mathrm{D}: \mathrm{W} \mathrm{K}$.

2 The instances of $\mathrm{D} \mathrm{B}$ are:

$278 \mathrm{P}$ (\&xc.) This theffy's comyng to abyd (D B theefe his).

$476 \mathrm{P}$ (\&ic.) Goddis peple that stondis vs bye (D B stande $\mathrm{K}$ standeth). $522 \mathrm{P}$ (\&c.) For thrughe his myght and his maistrye (D B maiestie). $626 \mathrm{P}$ (\&c.) Reigne no longer thowe ne maye (D B lenger nowe thou).

3 The instances of P H D are:

$97 \mathrm{P}$ (\&rc.) Men buryed in graue as ye may see (B W K graues). $167 \mathrm{P}$ (\&c.) Iff I be Crist nowe leuys ye (B ye me IV K you me). I $78 \mathrm{P}$ (\&ic.) And we shall kneling on oure knen (B W K kneele vpon). $534 \mathrm{P}$ (\&c.) Conuertis to me most myghty (B IV K mightelie). 


\section{PROBLEMS OF THE ENGLISH}

of our scheme comes out very strongly when we consider the eight cases of agreement between $\mathrm{P} \mathrm{H}$ B. Of these two at most can with any plausibility be explained in the manner which satisfies the four cases just considered.' Consequently of really cogent variants the group $\mathrm{P} \mathrm{H} \mathrm{B}$ is supported by six or seven, the group P H D by none, and the group B D by one only, and that doubtfully. This, it must be admitted, is fairly satisfactory confirmation. It is a curious fact that there are three cases of agreement of $\mathrm{P} B$ against the rest, but of these two prove on examination to be more apparent than real, while the third is a pretty obvious correction by $\mathrm{B}$ of a corruption in $\eta .^{2}$ A case in which $\mathrm{P} \mathrm{B}$ agree against D W $\mathrm{K}$, while $\mathrm{H}$ differs from and might be a corruption of the reading of either group, may be assumed

The instances of $\mathrm{P} \mathrm{H} \mathrm{B}$ are:

$97 \mathrm{P}$ (\&c.) Men buryed in graue as ye may see (D W K you).

I 2 P (\&c.) Crist that oure name has nomen (D W K our).

I 43 P (\&c.) And ley it lou vndre the greet (D W K burye).

30 I P (\&c.) Tertius rex (D W K Primus).

37 I P (\&c.) Oute on the wysarde with thy wylis (D W roysard $\mathrm{K}$ defective).

4II P (\&c.) That thowe shewyd to these kyngis ( $\mathrm{D} \mathrm{W} \mathrm{K} \mathrm{vnto).}$

$625 \mathrm{P}$ (\&c.) Antecrist nowe ys comyn thy day (D WV K this).

714 P (\&c.) Conspyryd may be no way (D W K by noe).

The instance in line $4 \mathrm{II}$ is not significant, and that in line $7 \mathrm{I} 4$ only doubtfully so.

$=$ The instances of $\mathrm{P} \mathrm{B}$ are:

$415 \mathrm{D}$ (\&c.) So thy ioye nowe yt raygnes (P B nowe).

$448 \mathrm{D}$ ( $\& \mathrm{cc}$.) My cursse I gyue you to amend your meeles (P B mend). $682 \mathrm{D}(8 \mathrm{c}$.) Of soules that should haue bine saued in hell be the lydd (P B thie).

There are reasons for not attaching weight to the first and last of these. 
to be an instance of a disguised agreement of P H B. ${ }^{1}$

Of other anomalous agreements there are several, but of none do more than a couple of instances occur. They are: P H K, P B K, P W K, P K, $\mathrm{H} \mathrm{B}, \mathrm{H} \mathrm{D}, \mathrm{H} \mathrm{W}, \mathrm{H} \mathrm{K}, \mathrm{B}$ K. The most curious perhaps is $\mathrm{PW} \mathrm{K}$, for it turns out to be what I may call a ghost. ${ }^{2}$ Though $\mathrm{W} \mathrm{K}$ is undoubtedly supported by $\mathrm{P}$ according both to Manly's edition and to the apparent reading of the manuscript, the latter on closer examination is seen to be the work of the modern restorer. The original reading, though uncertain, most probably supported the group H B D. There is another similar case in which the restorer has made $\mathrm{P}$ support the group B D W K, though in fact it almost certainly originally supported $\mathrm{H}^{3}$ Another startling agreement is P B K, but this is easily explained as an emendation of a corruption in $\eta$, made independently by $\mathrm{B}$ and K.+ The agreements of $\mathrm{P} \mathrm{K}$ and $\mathrm{P} \mathrm{H} \mathrm{K}$ are due to accidental returns of $\mathrm{K}$ to an original reading. The agreements of $\mathrm{H} \mathrm{D}, \mathrm{H} \mathrm{B}, \mathrm{HW}$, and $\mathrm{B} \mathrm{K}$ are all capable of explanation. Two instances of an agreement of $\mathrm{H} \mathrm{K}$ are certainly puzzling. ${ }^{5}$ In the line: 'These Lowlers the would fayne me greeue' (D), both manuscripts omit the word 'fayne,' and

${ }^{1}$ Line 315 D (\&c.) Nowe wee be readye leeue you this (P B been we $\mathrm{H}$ we).

2 Line $566 \mathrm{D}$ (\&ic.) But I must blesse yt or yt goe (W K I goe P -?-).

3 Line $166 \mathrm{D}(\& \mathrm{c}$.$) God glorified created of degree (H greatest$ P -:-).

4 Line $247 \mathrm{P}$ (\&c.) For we were neuyr so rych in fay (D VW H in good fay'e).

5 Lines $428,488$. 


\section{PROBLEMS OF THE ENGLISH}

in the line: 'That shall full soone make thee to flee' (D), the word 'full.' Both are presumably errors and possibiy mere slips. Such coincidences must now and then be expected, and fortunately these anomalous readings attack our scheme at its strongest point-namely, the grouping of W K.

We have now considered the objections to our hypothesis as to the relations of the manuscripts, and our scheme may be held to have stood the test satisfactorily. As yet, however, I have said nothing as to the relative value of the extant texts. For anything our scheme tells us to the contrary, W may on the whole contain the most original and $\mathrm{H}$ the least original readings within the group of cyclic manuscripts. Happily the independent position of $\mathrm{P}$ affords a certain criterion for the originality of the readings in the other texts. Since the main object of this inquiry is to ascertain the rules that should govern the editing of the Chester plays, we must now apply ourselves to this criticism, remembering that anomalous groupings must first be reduced to the normal ones, of which they are presumably obscured variants.'

After making these corrections we arrive at the following results. $\mathrm{H}$ has 47 readings which are certainly unoriginal, in 38 of which it is opposed by a concensus of all the other manuscripts. There are also six readings in which $\mathrm{H}$ is unsupported,

${ }^{2}$ For instance such a grouping as $\mathrm{P} \mathrm{H} \mathrm{D} \mathrm{:} \mathrm{B} \mathrm{W} \mathrm{K} \mathrm{may} \mathrm{be} \mathrm{an}$ obscured instance of $\mathrm{P} \mathrm{H}: \mathrm{BW} K: \mathrm{D}, \mathrm{D}$ diverging from its own group $\mathrm{BDWK}$ and accidentally returning to the original reading, or else of $\mathrm{PH} D: \mathrm{B}: \mathrm{WK}, \mathrm{B}$ diverging from its own group P H B D and accidentally making the same change as $F$. 
but in which, owing to $\mathrm{P}$ being divergent, it is impossible to say whether or not $\mathrm{H}$ is original. $B$ has 87 certainly unoriginal readings, in 47 of which it is opposed by a concensus, and six possibly unoriginal ones. $\mathrm{D}$ has 64 certain errors, 27 opposed by a concensus, and six possible. $\mathrm{W}$ has I 5 I certain, 53 opposed by a concensus, and five possible errors. $K$ has 145 certain, 39 opposed by a concensus, and five possible errors. Exactly the same method can be applied to the hypothetical manuscripts. Thus $F$ has 92 certain errors and nine possible, $\delta 3 \mathrm{I}$ and six, $\beta 20$ and six.

Summarising we have :-

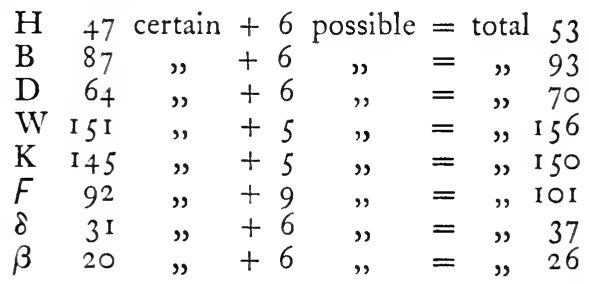

The total number of readings in which $\mathrm{P}$ and $\eta$ disagree is, certain 108 , possible 6 .

It will be noticed that the order of merit is the same whether the possible errors are included or not. In either case $B$, a careless copy of a good original, is on the whole less correct than D, a better copy of a somewhat worse original ; and W, the manuscript selected by Wright for his edition, proves itself, in spite of having fewer omissions than $\mathrm{K}$, to be the most corrupt of the lot.

In the analysis I have just given no account has been taken of the intrinsic merit of the readings.

D 


\section{PROBLEMS OF THE ENGLISH}

If the scheme proposed is correct, or anything like correct, then it is futile to argue that a reading found say in D only, or even in D W K, if opposed by a concensus of $\mathrm{P} \mathrm{HB}$, is original, however plausible it may be. It may be 'correct,' it may be what the author originally wrote, but, apart from conflation, it can only have got into its place by emendation, it cannot have been the reading of the archetype. Where the relation of the manuscripts is uncertain we have, of course, to rely upon the general plausibility of their readings for determining their value, but it is always a precarious test. There are, it is true, in different cases various degrees of improbability in supposing a scribe or corrector to have been responsible for a given reading, and sometimes the improbability is very great, but, logically at least, we are never justified, however strongly we may feel that a certain reading is original, in assuming that it must have been that of the archetype.

I may here state the result of a critical consideration of the differences between $\mathrm{P}$ and $\eta$. In a number of cases $\mathrm{P}$ is certainly corrupt, but in most of these the reading of $\eta$ seems as likely to be an emendation as to be original. There remain, however, two or three in which emendation appears very improbable, and which, therefore, confirm our previous assumption that $\mathrm{P}$ is not the parent of the cyclic group.

There is one warning which should perhaps be borne in mind. Our results strictly apply to the Antichrist play alone. Since we decided that the cyclic manuscripts were not formed by the collec- 
tion of a number of different texts from separate sources, it is not very likely that the relation of the manuscripts should differ in different portions of the text. Still it is conceivable: for instance the two scribes of MS. H might have used different originals. This, in point of fact, they do not seem to have done, for the divergence of $\mathrm{H}$, like the close relation of $\mathrm{W} \mathrm{K}$, evidently persists throughout the cycle. The only doubt is as to the positions of $B$ and $D$. In the course of an analysis of the readings of the second pageant based on Deimling's collations I found D apparently associating itself more closely with $\mathrm{H}$ and $\mathrm{B}$ with $\mathrm{W} \mathrm{K.}{ }^{\mathrm{I}}$ But, as I have said, Deimling's collations are entirely untrustworthy, and such a reversal of relation is in itself extremely improbable. ${ }^{2}$

The procedure which an editor should adopt with regard to the text of the Chester plays will now be evident. Of the two traditions represented by $\mathrm{H}$ and the group B D W K respectively, the former is clearly the earlier or more original,

${ }^{1}$ Hemingway appears to have found this too: see "English Nativity Plays,' p. v. But, as I have said before, I suspect his collations of having been borrowed from Deimling's edition. The apparently anomalous character of the readings of $\mathrm{B}$ as reported by Deimling may be due to the rather difficult hand of that manuscript.

2 It is quite clear that the two scribes of $\mathrm{H}$ follow the same tradition and presumably transcribe from the same manuscript. But, of course, it does not follow that their work is equally accurate. The importance of $\mathrm{H}$ as representing the elder tradition persists throughout; but, supposing the divergencies of $\mathrm{H}$ from $\eta$ to be due directly to the scribes of $\mathrm{H}$ and not to a succession of intermediate copies, the accuracy of the text of $\mathrm{H}$ may vary greatly in different parts. This, of course, might be the case even were only one scribe concerned. 'The 'Antichrist' was written by the second scribe. 


\section{PROBLEMS OF THE ENGLISH}

while the latter presumably represents the form which the plays assumed in the latest official revision. Which of the two an editor elects to follow will depend upon the nature of the text he desires to produce. If, as is probable, he wishes to arrive at the most original text possible, he will, of course, follow the earlier version, but he must keep his eyes open for possible editorial vagaries on the part of the scribe of $\mathrm{H}$. The difference between the versions arises through intentional and intelligible alterations by the younger. The difference between the texts, in passages unaffected by such revision, arises mainly through corruption. It does not follow that the manuscript preserving the earliest recension will also offer the best text. With regard to this, therefore, an editor's practice may be different. As a matter of fact, if he proposes to select for his text a single manuscript and to stick to its readings through thick and thin, then that manuscript must again be $\mathrm{H}$, for this is in itself by far the most correct manuscript we possess. That was Deimling's plan, and his choice of $\mathrm{H}$ has proved fully justified. Hemingway, while quite right in supposing that certain readings of $\mathrm{H}$ are due to editorial interference, was quite wrong in therefore condemning his predecessor's selection, and his own practice of following $\mathrm{D}$ when opposed by a concensus of $\mathrm{H} \mathrm{B} \mathrm{W} \mathrm{K}$ cannot possibly be defended. Nevertheless, it must not be forgotten that $\mathrm{H}$ has been found to contain more than twice as many errors as $\beta$, and that in general the readings of the latter can be restored with certainty. For a critical text, therefore, an editor, while 
adopting the recension of $H$, should take $D$ as his basis, this being the oldest manuscript and that in which the linguistic forms are in general least corrupt. But it will serve as a basis only. $\mathrm{He}$ will need to collate it throughout with $\mathrm{H}$. Where $\mathrm{D}$ and $\mathrm{H}$ differ he will consult $\mathrm{B}$, or should $\mathrm{B}$ fail, then $K$ or $W$. If $B$, or $K W$, supports $H$, he should replace the reading of $D$ by that of $H$. If $\mathrm{B}$, or $\mathrm{K} \mathrm{W}$, supports $\mathrm{D}$, he will not be able to argue that $\mathrm{D}$ is correct, but he will know that there is a divergence between $H$ and $\beta$. In such a case, and in the absence of any independent authority such as $P$, he will have to rely upon internal evidence to determine which is the more likely to be the original reading. He will remember that the scribe of $\mathrm{H}$ has been convicted of editing his text, and that the mathematical probability is about two to one in favour of $\beta$.

\section{III.-CHRIST AND THE DOCTORS:}

INTER-RELATION OF THE CYCLES.

THE comparative study of the English miracle cycles may be said to date from the discovery of the manuscript of the York plays and its publication by Miss Toulmin Smith in 1885 . It then appeared that several of the plays contained in that collection were substantially the same as the corresponding pieces preserved in the Towneley manuscript of what is now commonly regarded as the Wakefield cycle. This naturally aroused curiosity as to the mutual relation of the two collections. Further investigation soon established that the 


\section{PROBLEMS OF THE ENGLISH}

points of similarity were more numerous than Miss Smith had supposed, and also that they differed curiously in their nature. Beside the plays in which the texts are substantially or in large part identical, are others which either, on the one hand, contain close verbal parallels in isolated passages, or else, on the other, present a close similarity in dramatic structure and in the order of events. The literature which has grown up round the subject in the course of the last twenty-five years is considerable, but as yet it can hardly be said either that any authoritative view of the matter has emerged, or that investigation has been pursued to its limit. With regard to the plays in which a considerable portion of common text makes the general relation pretty clear, there yet remain various questions of detail which are open to doubt. What exactly do we mean when we say-as we do say-that the Wakefield cycle borrows from that of York? Was it properly a borrowing at all, or are both descended from a parent cycle to which York adheres rather more closely than its rival? If the Wakefield cycle is a compilation from various sources, was the compiler at liberty to take what he would from York, or did he take what he could? At what period did the borrowing occur? Was the borrowing from York a factor in the original compilation of the Wakefield cycle, or a later process which displaced earlier plays?

In considering those correspondences which do not amount to substantial identity of text various things should be borne in mind. The occurrence 
of verbal parallels should be regarded with suspicion, and various possibilities considered before drawing conclusions even when the connexion is evident. The different miracle cycles contain a great many parallels, and they are not always parallels with one another. The York plays have been shown to be related in this manner to the "Gospel of Nicodemus,' ' while the so-called 'Ludus Coventriae'

I See W. A. Craigie's article in the Furnivall 'English Miscellany,' p. 52. The bearing of this on the history of the cycle has never been fully worked out, but I cannot understand how F. W. Cady comes to state that 'the Passion play in York has been extensively edited by the insertion of episodes from the northern Gospel of Nicodemus,' and moreover, to imply that this is the thesis of Cragie's article ('Modern Philology', x. 589). It is, indeed, perfectly clear that Craigie imagined the plays to have been originally composed under the influence of the Gospel. He cites parallels to the Gospel from plays $\mathrm{xxx}, \mathrm{xxxII}, \mathrm{xxxvI}, \mathrm{xxxvII}$, xxxvir. Of these $\mathrm{xxx}$ and $\mathrm{xxxII}$ are plays of the third period (see below, p. 78), xxxvir of the first, and xxxvirr possibly, xxxvi certainly, of the second. It would therefore appear as though the writers of each of the three periods of composition borrowed from the 'Gospel.' But Craigie cites but a single parallel from play xxxvr, and here I venture to think he has gone astray. The apparent parallelism is due to the fact that the play and the 'Gospel' follow Matt. xxviI. 54 and Mark xv. 39, whereas the Latin 'Evangelium Nicodemi' follows Luke XXII. 47. It is therefore not certain whether the writers of the second period did use the 'Gospel.' In play xxxvir, first period, the parallels are above criticism. They are no less clear in the plays of the third period, $\mathrm{xxx}$ and $\mathrm{xxxII}$, but here the inference that the writer used the 'Gospel' is not legitimate. For he was rewriting plays of an earlier period, and he may have borrowed the passages in question not from the 'Gospel' directly, but from the earlier plays. Indeed, from such a passage as XxxirI. I I $3-20$, which is hardly in the style of the rest of the play, it rather looks as though this was just what did happen. Anyhow it is difficult to be certain that any borrowing from the 'Gospel' took place subsequent to the original composition of the first period plays, though there would be nothing improbable in a number of writers using the same source. I have 


\section{PROBLEMS OF THE ENGLISH}

contains lines from the early fourteenth-century 'débat' of the 'Harrowing of Hell,' namely, the well-known passage beginning:

\section{Harde gates have I gone. ${ }^{x}$}

The most recently discovered are some very interesting and important parallels between certain plays of the Wakefield cycle and the poem known as the ' Northern Passion.' $z$ It is as yet too early to say with confidence what the significance of these may be, but those at present published suggest a bearing upon the development of the cycle which has apparently escaped their discoverer. ${ }^{3}$ For when we have eliminated a number of alleged parallels

little doubt that Cady's remark is due to C. M. Gayley having assumed, in his 'Plays of our Forefathers,' p. 157, that the borrowings from the 'Gospel' were all due to the dramatist of the third period, and having therefore inferred that all the plays in which they occur were either written or revised by him. This view seems to be unfounded (see below, p. 80, note). I suppose Gayley was influenced by a desire to throw back the date of the cycle, for he believes the earliest plays to have been composed before 1330 (p. 133), whereas Craigie appears to hint that a dependence on the 'Gospel' would imply a date not much before 1350. I very much doubt whether any relevant dates can be established sufficiently precisely to justify our saying either that the plays must be earlier than I350 or that they cannot be as early as 1330 .

I 'Ludus Coventriae,' ed. Halliwell, Shakespeare Soc., I 84 I, p. 346; 'Harrowing of Hell and Gospel of Nicodemus,' ed. W. H. Hulme, E.E.T.S., I 907 , pp. 4 and 5.

${ }^{2}$ Miss F. A. Foster, in 'Modern Language Notes,' June I 91 I, xxvi. 169. The text of the "Passion' has since been printed by Miss Foster (E.E.T.S., I 45, I9I3), but her introduction has not yet appeared.

3 F. W. Cady has a footnote on the subject in his article on 'The Passion Group in Towneley,' in 'Modern Philology,' April I9I3, x. 594. 
which are not really parallel at all, what remain fall into two quite distinct groups. There is one passage of several lines which is almost word for word the same in the two works, and there are a number of scattered phrases which have the appearance of being rather more than accidental resemblances. The curious point is that these phrases all occur in portions of plays borrowed by the Wakefield from the York cycle, while the passage of several lines occurs in what is usually regarded as an insertion by a late Wakefield editor. I leave you to draw your own conclusions.

Parallels between different miracle plays are, of course, also common. For instance, in the scene of the Betrayal, Peter's speech to the unlucky Malchus:

\section{Go pleyn thee to Sir Cayphas}

And bid him do thee right,

recurs almost verbally in the Chester and Wakefield plays. ${ }^{\prime} \quad$ Among certain Shrewsbury fragments we actually have part of a liturgical play, not only composed in the same metre as the corresponding play of the York cycle, but having one stanza practically identical with it, a fact which has not, I think, received quite the attention it deserves. ${ }^{2}$ Quite the most instructive, however, of these parallels is one which has been pointed out between the Resurrection plays of the Wakefield and Chester

I 'Chester Plays,' ed. Wright, Shakespeare Soc., I 843-7, ii. 3 I (but the first line is corrupt in MS. W); 'Towneley Plays,' ed. England and Pollard, p. 225 (xx. 682).

"The Shrewsbury fragments have been most recently printed by Osborn IVaterhouse in 'The Non-Cycle Mystery Plays,' E.E.T.S., I 909, p. I (see 11. 39-48); cf. 'York Plays,' ed. L. T. Smith, I 885 , p. 122 (xv. I 20-9). 


\section{PROBLEMS OF THE ENGLISH}

cycles. This is in the striking speech of the risen Christ beginning :

Earthly man that I have wrought,

and unless I am mistaken, the resemblance is more extensive than has hitherto been noticed. ${ }^{\text {I }}$ In the Chester play the speech is in a stanza not only different from that of the rest of the play, but found, I believe, nowhere else in the cycle. And it is not that of the corresponding Wakefield play. This is sufficient proof that neither cycle borrowed the speech from the other. ${ }^{2}$ It is an independent poem, or part of one, which has been taken without change into the Chester play, and rewritten for that of Wakefield, ${ }^{3}$ and it is not impossible that it may yet be recovered in its original form from one

I 'Chester Plays', ii. 89; 'Towneley Plays,' pp. 313, 316. The passage in question extends to 32 lines in Chester, and is substantially the same in all the manuscripts. Chester 11. I-8 correspond to Wakefield, xxvi. 226-3I, and Il. 9-16 to xxvi. 332-7. Pollard, who drew attention to these parallels in his introduction, 'Towneley Plays,' p. xix, does not appear to have noticed that in Xxvi. 328-33 we have a condensed version of Chester, 11. 17-32. He argued that Chester borrowed from Wakefield, but this is impossible, for in that case the passage in Chester would have been either in the same metre as the rest of the play or in that of Wakefield. Pageant XXVI is one of those which Wakefield borows in part from York. I agree with Pollard that a speech of the risen Christ has dropped out of York (it is implied in the stage direction: 'Tunc Iesu resurgente'), but it would be rash to assume that it was the speech in question.

2 Formally, indeed, it would not exclude the possibility of Wakefield having borrowed from Chester. Since it is clear, however, that the passage is not original even in Chester, a common original seems more likely.

3 It is quite possible that in Wakefield xxvi. 226-333 we have a paraphrase of the whole poem of which only four stanzas were borrowed by Chester. 
of the unexplored miscellanies of the middle ages. The stanza is that of the 'Gospel of Nichodemus,' without the 'cauda,' ' but the verses do not appear in that work. In rewriting the lyric the Wakefield author introduced the common tag:

And alle for luf of the,

which is also found modified as:

And all is for his loue,

in the so-called Digby Burial and Resurrection play, a curious composition which includes quite a number of lyrical fragments:

O myn harte, wher hast thou bee?

Com hom agayn and leve with me! ...

Quia amore langueo...

Who can not wepe com lern at me. ${ }^{2}$

The point then at which I have been aiming is that when we find parallels between two miracle plays we must not hastily assume that the fact points to any direct connexion between them.

Where the resemblance between two plays lies in the general construction and the order of events we have to bear in mind the possibility that a common source may have given rise to a similar structure. Where two or more plays are alike closely based upon the scriptural narrative, it is obvious that they will present likenesses which it

${ }^{1} a^{4} b^{3} a^{4} b^{3} a^{4} b^{3} a^{+} b^{3}$, apparently not a very common stanza in Middle-English, but occurring, rather irregularly, in the latter part of Wakefield xxrin. The 'Gospel of Nicodemus' adds a tail cdcd 3 .

2 'The Digby Plays,' ed. Furnivall, New Shakspere Soc., I 882 (E.E.T.S., 1896), p. I 7 I : see 11. $1467,1495-6,1462,693$. 


\section{PROBLEMS OF THE ENGLISH}

is unnecessary to refer to any other cause. Dr. Charles Davidson, after producing an extensive list of parallels from five plays of the Annunciation, rightly concludes that all such resemblances 'are misleading when used to support a theory of direct interdependence among the extant plays.' ${ }^{\prime}$ Nevertheless, two facts remain and have to be taken into consideration-namely, that different cycles do agree in following the biblical story more closely in some places than in others, and that similarities of treatment do occur which are not to be explained by the words of scripture. It is evident that in some cases there was a general tradition as to how a story should be treated. That tradition must have had a basis, and the theory most popular among critics has been that the basis was the liturgical drama. Of late, indeed, the liturgical drama has become something of an obsession with critics. Even Hohlfeld, a sensible man who wrote before the fashion became general, went so far astray as to insist on a liturgical basis for the Assumption play of the 'Ludus Coventriae,' ' which is in fact a very close paraphrase from the 'Legenda Aurea.' An American scholar has recently made an elaborate attempt to determine the common liturgical cycle out of which, according to him, parts at least of those of York, Wakefield, and Coventry all developed. 3 Now, while firmly

1 'Studies in the English Mystery Plays,' 1892, p. 162.

2 'Anglia,' 1889, xi. 274.

3 F. W. Cady in 'Publications of the Modern Language Association of America,' 1909, xxiv. 419; see also 'Journal of English and Germanic Philology,' 1911, x. 573, and 1912, xi. 244, and 'Modern Philology,' 1913, x. $58 \%$. 
holding that the miracle cycle as a literary form did grow out of the liturgical drama, I doubt very much whether it is correct to say of any extant miracle play whatever that it had a liturgical play for its source, or was indeed in any individual manner connected with such. ${ }^{\prime}$ All that we need postulate to explain the observed resemblances between different cycles is, as I have said, a certain general tradition. Such a tradition may have arisen, and doubtless did arise, in various ways. The 'Cursor Mundi,' a poem whose influence on the drama has been often asserted and never proved, ${ }^{2}$ may have had its share; so may others such as the "Northern Passion.' 3 The influence of Bonaventura's 'Meditationes,' whether direct or through the writings of the Hampole school, is already a suspected though a rather indeterminate factor. ${ }^{+}$That of Jacobus de Voragine is far more.

I An exception might be found in the Shrewsbury fragments mentioned above. A liturgical play in the vernacular is, however, in itself such an anomaly, and these particular texts are so late, that a borrowing from and not by the York cycle seems the more probable explanation.

${ }^{2}$ See particularly H. Umgemach, ' Die Quellen der fünf ersten Chester Plays,' 1890, p. 195, and cf. H. Utesch, 'Die Quellen der Chester-Plays,' I 1909, p. 6.

3 See above, p. 72 .

4 The 'Meditationes Bonaventurae de Vita Christi' are printed in the collected edition of his works, Rome, $1588-96$, vi. 349 (and Paris, 1868, xii.). The translation by Nicholas Love, known as 'The Mirror of the blessed Life of Jesu Christ,' was not made till the fifteenth century. But there is an earlier version of the part relating the passion (chapters 73 to 92) which, if not by Richard Rolle of Hampole himself, is certainly the work of an immediate follower. It is printed under the title of 'The Privity of the Passion,' by C. Horstmann, 'Yorkshire Writers,' 1895, 


\section{PROBLEMS OF THE ENGLISH}

The part played by the 'Legenda Aurea' in the formation of the miracle writers' ideas of biblical history has, I am sure, been underrated. The same may be said of Petrus Comestor's 'Historia Scholastica.' And here, lastly, not as a direct source, but as a factor in the formation of the tradition-a factor the importance of which it is very hard for us to gauge, but at any rate an important factor-comes in the liturgical drama itself.

From these general considerations I return to the York and Wakefield cycles, their mutual relation and their respective history. The former collection it is usual to regard as the outcome of three chief periods of literary activity, which have left, as it were, three superimposed layers of composition. The critical study of these plays was founded by Davidson, ${ }^{1}$ and his divisions have been accepted in a general way by later writers. On the whole, his distinction between early and late work is, I think, sound, though it is based on metrical theories with which I entirely disagree. ${ }^{2}$ I would rely on

ii. 198. On the importance of the writings of the Hampole school, including therein the 'Privity' and the 'Charter of the Abbey of the Holy Ghost' (Horstmann, i. 337), see H. Thien, 'Über die englischen Marienklagen,' 1906, p. 48, and Miss Hope Traver, 'The Four Daughters of God,' 1907, p. 126.

I C. Davidson, 'Studies in the English Mystery Plays,' 1892, particularly chap. xxi. The work was a doctorate thesis at Yale University.

${ }^{2}$ Put crudely his view is that the Middle English alliterative line arose through decay of the octosyllabic; or perhaps it would be fairer to say that he failed to recognize alliterative lines when grouped into riming stanzas. Other critics have fallen into the same error, notably $\mathrm{F}$. Holthausen. It was exposed in a very able article by K. Luick in 'Anglia,' 1899, xxii. 384 . 
purely literary considerations which point to an order in the layers identical with the one he proposed. The oldest portions belong to a simple didactic cycle carefully composed in elaborate stanzas and withal rather dull. The "Sacrifice of Isaac,' the 'Exodus,' 'Christ and the Doctors,' the 'Transfiguration,' the 'Harrowing of Hell' are typical plays of this period. I imagine their date to be probably not later than $\mathrm{I} 35^{\circ},{ }^{\mathrm{I}}$ and the resemblance between the different plays is sufficient to suggest a single authorship; they certainly belong to a single small school. The plays of the second period are probably the work of more than one hand, and some of them cannot without difficulty be distinguished from those of the original cycle. Their chief distinction is that they include such attempts at humour as the collection has to offerNoah and his wife, and the offerings of the Shepherds, the latter containing the parallels with the Shrewsbury liturgical fragments - and also the work of a writer who is distinguished as being the only great metrist who devoted his talents to the English religious drama as we know it. His contributions include the 'Fall of Lucifer,' the 'Death of Christ,' and also, I think, 'Doomsday.' The work of the last period, like that of the first, belongs presumably to a single author. With the exception of the 'Last Supper,' an untouched play, of the first period, and the 'Remorse of Judas,' which probably contains portions of more than one

I If Craigie's date for the 'Gospel of Nichodemus' is to be trusted not earlier either, but I am not altogether satisfied of this. See above, p. 7 I, note, at end. 


\section{PROBLEMS OF THE ENGLISH}

second-period play worked over by him, the whole of the Passion series from the 'Conspiracy' to the 'Condemnation' is his original work. He also prefixed a single stanza to the 'Way to Calvary': nowhere else does his hand appear." $\mathrm{He}$ is a very remarkable though uneven writer. A metrist he certainly is not: he writes in powerful but loose and rugged alliterative verse. He also writes at great length and with much rhetoric and rant. But he is a real dramatist, and his portrait of Pilate is masterly. It is he who is responsible for the "trauerspielelemente' which Hohlfeld finds characteristic of the cycle. ${ }^{2}$ His additions can hardly be earlier than I 400 .

The problems connected with the growth of the Wakefield cycle, if not more difficult, are at any rate more varied and complicated than those which centre round the York plays. Again it is customary to suppose three main layers of composition: an original simply didactic cycle, which may or may not have included fragments of yet earlier work; a period of borrowing from, or composition under

I Gayley considers not only that he also remodelled the 'Harrowing of Hell' and the 'Resurrection,' but that the 'Death of Christ," "with its elaborate and unique stanza, is an original production' of his. This I cannot for a moment admit. Even supposing that the 'Death' did quote from the 'Gospel of Nicodemus,' which it probably does not, that would not prove it to be by the author of the Passion series, for there is no evidence that that writer knew the 'Gospel' at first hand, and even if there were it would not follow that all the plays in which it was used must be by him. The 'Death of Christ' is as fine a work metrically as the 'Accusation before Pilate' is dramatically, but in style the two pieces are as different as possible.

2 'Anglia,' xi. 283. 
the influence of, York; and finally, the additions of a single remarkable writer. ${ }^{1}$

There is much that is uncertain about this cycle. Its connexion with Wakefield and with the activities of craft guilds is proved by notes in the manuscript itself, and supported by allusions in at least the latest layer of the work. That the guilds were those of Wakefield is matter of inference. Curiously enough, there is no record of the performance of any cycle at Wakefield, though at least one player from Wakefield is known to have performed in the Corpus Christi plays at York. ${ }^{2}$ A tradition connecting the cycle with the Augustinian house of Widkirk or Woodkirk was at one time recorded and subsequently denied by Douce. ${ }^{3}$ At most it would only imply that the manuscript may at some time have been preserved there; it would not justify any conjecture as to the original authorship, or even as to the collection or transcription of the plays. The manuscript is mutilated, possibly through Puritanical zeal; but it is also

I But opinion is by no means unanimous. Davidson's treatment (cf. chapters Xx and XXII) is less full and less satisfactory than in the case of York. On the other hand, Pollard's introduction to the E.E.T.S. edition is of first-rate importance. It follows in general the lines laid down by Hohlfeld in 'Anglia,' xi. 306. Asmus Bunzen, in his 'Beitrag zur Kritik der Wakefielder Mysterien'(1903, p. I9), attempts an analysis rather too elaborate to be altogether convincing. Cady in the articles already cited argues that the borrowings from York are the latest addition to the cycle. But I do not see how such a play as 'Doomsday' can be explained except as being in substance a York play worked cver by the distinctive Wakefield author.

2 See Hohlfeld, 'Anglia,' xi. 258.

3 See Chambers, 'Mediaeval Stage,' ii. 4 I 5 . 


\section{PROBLEMS OF THE ENGLISH}

manifestly incomplete, since it contains, for instance, no Nativity play. This has been supposed to point to the collection being an eclectic one made for a literary, not a dramatic purpose. ${ }^{1}$ I think the proper inference is that the manuscript, like that of the York plays, is a 'register' made from 'originals' in the hands of the different guilds. If the York scribe could not lay his hand on a pageant when he came to need it, he left a space in his codex, intending to insert it later. In a like case the Wakefield scribe went straight on. Thus the York 'Paradise' was written into its place the better part of a century after its neighbours, while the Wakefield 'Exodus' follows the 'Prophetae,' and 'Lazarus' is added after 'Doomsday'; and the York Vintners' play of the 'Marriage at Cana' remains blank to this day, while the Wakefield manuscript passes direct from the 'Annunciation' to the 'Shepherds.'?

The plays borrowed by the Wakefield from the York cycle belong to the first and second periods of production of the latter, and it seems probable that the borrowing took place before the latest additions were made in either cycle, presumably therefore about the middle of the second half of the fourteenth century. It is just possible that the

I Bunzen, 'Beitrag,' p. 5. Davidson appears to have held much the same view.

2 Particularly perverse seems to me Cady's suggestion that the extensive development of the Shepherds theme by the distinctive Wakefield author led to the omission of the 'Nativity,' 'Publications of the Modern Language Association of America,' xxiv. 441, 'Modern Philology', x. $5^{8} 7$. 
plays borrowed from York may have formed part of the Wakefield cycle from its inception. But those assigned to the first Wakefield period seem pretty clearly earlier than the date at which the borrowing from York can have taken place. If, therefore, they did not form part of an already existing Wakefield cycle, they must have been borrowed from elsewhere, say Beverley. This is possible, but not altogether likely. In any case I think that the York plays must have been edited and in part worked over at the time of their incorporation in the Wakefield cycle, for I fancy it is possible to detect a progressive freedom in the treatment of the text of those plays which are more or less bodily lifted, and furthermore we shall presently see that one of them appears to have reached Wakefield in an imperfect state. Anyhow we seem precluded from postulating an original parent cycle common to Wakefield and York which has been worked over differently at the two places, for that would involve the supposition that at Wakefield plays of this cycle were subsequently dropped in favour of others of a more primitive type borrowed from other places. Presumably, therefore, we are justified in saying that at a given period of its development the Wakefield cycle actually borrowed and incorporated plays from York in the most literal sense of the words.

The extent of this borrowing is uncertain, and will probably never be exactly determined. There are five plays in which large portions of the text are practically the same in the two cycles. The 'Exodus' is almost identical, and in the only 


\section{PROBLEMS OF THE ENGLISH}

important variation it is uncertain which text is the more original. In 'Christ and the Doctors' two important passages have been rewritten in the Wakefield cycle. The 'Harrowing of Hell' has been recast with considerable freedom. These three plays belong to the first York period. Of the 'Resurrection' the opening has been entirely rewritten, and subsequent passages too are treated freely. Of 'Doomsday' portions only have been taken. These two belong to the second York period. It is also practically certain that the 'Conspiracy,' the first part of the twentieth Wakefield pageant, was originally a first-period York play, which has there been displaced by one of the latest additions; while a subsequent stanza in the same Wakefield pageant may be a relic of an original York play of Gethsemene. Pollard hazards the same conjecture with regard to the Emmaus and Judas plays of the Wakefield cycle, ${ }^{\mathrm{T}}$ while Hohlfeld finds either structural or verbal parallels to the York plays in the 'Annunciation,' 'Magi,' 'Flight into Egypt,' 'Massacre of the Innocents,' 'Conspiracy and Betrayal,' 'Scourging,' 'Crucifixion,' and 'Ascension.' 2 In the case, however, of several of these, direct connexion between the plays in their present forms is practically out of the question.

It is then quite clear that the Wakefield cycle borrowed plays from York. Whether the York cycle exercised any influence over that of Wakefield apart from such direct borrowing is a far

I 'Towneley Plays,' p. xxvi.

2 'Anglia,' xi. 307. 
more difficult question, and one which I must leave open. With regard to substantial borrowing there is one further point I wish to notice. It has been repeatedly stated or assumed that such borrowing was oral. I believe it to be far too close and consistent to justify such an hypothesis. We have no evidence whatever that actors in miracle plays learned more than their individual parts and cues, and in any case a text obtained from an actor would almost inevitably betray its origin by preserving some speeches better than others. The remark of a German critic, ${ }^{1}$ that the numerous verbal differences that occur in the text even of the 'Exodus' are inexplicable on the assumption of manuscript transmission, reveals a pathetic innocence of the capacities, or even the normal habits, of medieval scribes.

So much for the York and Wakefield cycles. As far as my knowledge extends, there are, outside those cycles, only two instances in which plays exhibit any substantial correspondence of text. One is in the plays of 'Christ and the Doctors' from the Chester and true Coventry cycles. This involves the York and Wakefield plays as well, and I propose to consider it in detail later on. The other instance is afforded by the plays of the 'Sacrifice of Isaac' from the Chester cycle and the Brome Hall manuscript respectively, and of this a few words must be said in passing. It has been usual, whatever view was taken of the respective merits of the two pieces, to suppose that the Chester play, in spite of its being in the same ' Bunzen, 'Beitrag,' p. I3. 


\section{PROBLEMS OF THE ENGLISH}

metre as the rest of the cycle of which it forms an integral part, was derived either from the Brome play itself, or at least from one of a closely related type. This view has now been questioned. The most recent and much the ablest investigation of the subject that has appeared is one by an American lady, a student of Radcliffe College. ${ }^{\text {I }}$ From this, although the exact relation of the texts is not in all details established, certain points emerge with tolerable clearness. In the first place, the Chester play cannot be derived from that of the Brome manuscript or from any version of a similar type; in the second, the Chester is of a more primitive type than the Brome play; lastly, it is not impossible that the Brome play may be derived from that of Chester, perhaps under the influence of other types, though it may equally be derived from a common original. Like a good deal else in recent criticism, this result tends to establish the fundamental unity and originality of the bulk of the Chester cycle.

I will now return to the play which just now we reserved for more detailed consideration, that of the disputation of 'Christ and the Doctors' in the Temple. It is the only play of which we have texts derived from four different cycles, those namely of York, Wakefield, Coventry, and Chester. ${ }^{2}$ For convenience I shall use the letters

1 See Miss C. A. Harper's article in 'Studies in English and Comparative Literature presented to Agnes Irwin,' Radcliffe College Monographs,' no. 15, i910, p. 51.

2By the Coventry Cycle I mean, of course, the true Coventry guild play's, not the so-called 'Ludus Corentriae.' The texts 
$\mathrm{Y}, \mathrm{W}$, and $\mathrm{C}$ to indicate the extant texts of the first three of these, and $\chi$ to indicate the text of the Chester play as it may be restored by a comparison of the extant manuscripts of that cycle. For purposes of reference I shall also divide the play as follows: Scene I, Mary and Joseph's search for their lost child; scene 2, the Doctors' disputation in the Temple; scene 3 , Jesus and the Doctors (this includes the passage on the Commandments which, we shall see, requires to be considered apart from the rest); scene 4, the finding of Jesus and his departure with his parents. ${ }^{1}$

Some general account of the four plays must be given. It is pretty clear that the York text preserves the play in its most original form. This appears from the regularity of the metrical structure, that text being written almost throughout ${ }^{2}$

will be found in 'York Plays,' ed. L. T. Smith, p. 156, where the parallel portions of the Wakefield play are also printed; 'Towneley Plays,' ed. England and Pollard, p. I86; 'Two Coventry Corpus Christi Plays,' ed. Hardin Craig, E.E.T.S., 1902, p. 58 ; 'Chester Plays,' ed. H. Deimling, p. 2 I2. I have, however, based my comparison upon a parallel edition of the four texts which I have prepared and hope some day to print, and in this I have corrected certain errors of numbering in the 'Towneley' print. Previous comparisons of the four texts have been made by Davidson, 'Studies,' p. 164, and by Craig, as above, p. xxviii, but neither is at all satisfactory. Hohlfeld, 'Anglia,' xi. 260, does not take account of the Coventry play.

${ }^{1}$ In $\mathrm{Y}$ sc. $\mathrm{I}=11 . \mathrm{I}-48$, sc. $2=11.49-72$, sc. $3=11.73-204$ (Commandments $=11.169-192$ ), sc. $t=11.205-88$.

2 A quatrain is omitted after each of the following lines, 224, 232, 240 . Miss Smith failed to notice this, and her numbering of the stanzas is consequently wrong. The Wakefield text makes no attempt to supply the deficiency. 
in twelve-line stanzas riming $\mathrm{a} b \mathrm{a} b \mathrm{a} b \mathrm{ab} \mathrm{cd} \mathrm{cd}$, the octave consisting of lines of four accents, the quatrain of lines of three. It is true that the simple quatrains of the Chester play are regular enough, but a very casual inspection will show that that version contains no more than the fragmentary and sometimes corrupt remains of the others.

The Wakefield play is one of those which reproduce substantially the corresponding ones of the York cycle. It is imperfect at the beginning owing to the mutilation of the manuscript, and two important passages have been wholly rewritten. Otherwise the Wakefield play may be regarded as supplying merely a second manuscript of the same work.

The two remaining plays differ far more widely, and in each the Doctors' play constitutes only a portion of the pageant in which it occurs. At Coventry the episode formed part of the Weavers' play, an extensive composition which likewise included a sort of 'Prophetae' and a 'Purification.' Of this the existing manuscript, still in the possession of the original guild, ' was 'newly translate' -whatever that may mean-by Robert Croo or Crow in 1534 . In so far, therefore, as it was an original composition at all, the play may have been actually written no earlier than that year. If Crow was no more than a transcriber or reviser, the piece

I Craig, to whom belongs the credit of having rediscovered this manuscript, stated (1902) that it was to be placed among the Corporation manuscripts, but this had not yet been done when, through the kindness of the gentleman in whose custody it remains, I examined it in the summer of 1912. 
may have been concocted in I 520 , when Coventry rejoiced in 'new playes at Corpus Christi tyde, which were greatly commended.' ' There is no reason, however, to suppose that the whole cycle was renewed at that date, so that the play may possibly go back, substantially in the form in which we have it, to the fifteenth century. It differs widely from the York version, having been practically rewritten in a different and very irregular metre. Comparatively few lines have escaped more or less profound alteration, but there yet remain considerable sections in which the text is in a general way parallel.

At Chester the Doctors' play formed the second half of a pageant which also represented the Purification of the Virgin. But in this case we have the definite amalgamation of two obviously distinet pieces. The Doctors' play is composed in a different stanza from that used in the body of the cycle, to which the 'Purification' conforms. Moreover, at the end of the pageant there appears an epilogue of eight lines in the usual metre, which clearly belongs, not to the Doctors' play, which it ignores, but to the 'Purification.' The text of this 'Purification' exhibits no parallels with any other version. It is therefore abundantly clear that the episode of the Doctors is a late insertion. How late it would be interesting to know. Now, it is on record that the Smiths of Chester, the guild responsible for the production of the pageant in question, did in 1575 submit alternative plays to

' Chambers, 'Mediacral Stage,' ii. $35^{8}$. 


\section{$9 \circ$ PROBLEMS OF THE ENGLISH}

the choice of the aldermen. ${ }^{\mathrm{I}}$ It seems plausible to suggest that they were the plays of the 'Purification' and the 'Doctors,' especially when we find the older banns recording only a Purification and the later only a Doctors' play. Yet the inference would apparently be incorrect. In 1575 the Smiths borrowed doctors' gowns for their performance, so that they clearly acted the Doctors' play, but their accounts likewise mention 'Seameon' and 'Dame An,' whence it follows that they also acted the 'Purification.' ${ }^{2}$ Indeed, the accounts prove that both plays were performed as early as $155^{1},{ }^{3}$ so that the Doctors' play cannot possibly have been a novel alternative in 1575 . The point is of some importance, since the 'Purification' and the Doctors' play appear together in all the manuscripts of the cycle-that is to say, they belong to the common tradition-and we have seen reason to believe that this common tradition split up probably before the end of the fifteenth century.

The Chester play preserves less than any other of the original composition. Compared with that of Coventry it contains fewer sections of parallel text, and these less extensive; it also alone transposes matter. On the other hand, what it preserves it preserves fairly accurately, at any rate far more accurately than the Coventry play. In

MS. Harley 2054, fol. 17: 'Spent at Tyes to heare 2 plays before the Aldermen to take the best, xviii "'; see R. H. Morris, 'Chester in the Plantagenet and Tudor Reigns' (1894), p. 322, note I; Chambers, ii. 355 .

2 Morris, p. 322, note I.

3 Morris, p. 323 , note 3 , and p. 305 , note I (b). 
general it may be said that the compiler of the Chester text, or we may fairly say the author of the Chester play, while he treats the original far more freely than his rival of Coventry, is at the same time far less given to rewriting what he borrows. This, no doubt, is partly due to the fact that the simple quatrains in which he wrote made direct borrowing from the York stanza easy.

I must explain exactly what I mean by parallel passages, and ask you to bear it in mind in what follows. I call sections of text parallel when not only is the subject treated the same, but it is possible to trace with some certainty a common underlying original. I still call passages parallel although single lines, or even several lines together, may have been so altered as to present no resemblance. And I do not call passages parallel merely because they contain verbal similarities, even though these may point to an undoubted connexion. On a separate leaf I give in parallel columns a typical passage as it appears in each of the four plays, thus illustrating the nature of the variants between the texts.

When we come to place the texts of these plays side by side, and to compare them in detail, certain very curious facts become apparent. In the first place, where $\mathrm{Y}$ and $\mathrm{IV}$ differ neither $\mathrm{C}$ nor $\chi$ is parallel with either. $C$ and $\chi$ are indeed both parallel with $\mathrm{Y}$ where $\mathrm{IV}$ is defective, but there is nothing to suggest that the missing portion of $\mathrm{IV}$ was not in part at least parallel with $Y$. In the second place, just as $\mathrm{C}$ is nowhere parallel to $\mathrm{Y}$, 


\section{PROBLEMS OF THE ENGLISH}

except where $\mathrm{W}$ is also parallel (or may be supposed to have been parallel when complete), so $\chi$ is nowhere parallel to $\mathrm{W}$ except where $\mathrm{C}$ is also parallel. This of course proves, what indeed is evident at a glance, that $C$ cannot have borrowed from $x$, nor $W$ from $C$. But it also justifies our saying that in all probability $W$ did borrow from $Y, C$ from $W$, and $\chi$ from $C$, if for the moment we allow these symbols to stand for types of text instead of individual manuscripts, actual or hypothetical. A table I have prepared will illustrate this part of my argument in a rather striking manner. I have assumed in drawing it that the rules which govern the relation of the texts where all four plays are available also apply where $\mathrm{W}$ is defective.

But there is a third general fact to be noted-namely, that $\mathrm{C}$ is nowhere parallel to $\mathrm{W}$ except where $\mathrm{W}$ is parallel to $\mathrm{Y}$, and $\chi$ is nowhere parallel to $\mathrm{C}$ except where $\mathrm{C}$ is parallel to IV (if W exists). ${ }^{\mathrm{I}}$ In other words, assuming direct borrowing, while $\mathrm{C}$ only borrows from $\mathrm{Y}$ by way of $\mathrm{V}$, and $\chi$ only borrows from $\mathrm{W}$ by way of $\mathrm{C}$, it is also true that $\mathrm{C}$ borrows nothing from $\mathrm{W}$ but what $\mathrm{W}$ borrows from $\mathrm{Y}$, and $\chi$ borrows nothing from $\mathrm{C}$ but what $\mathrm{C}$ borrows from $\mathrm{W}$. This is a most remarkable state of things. How comes it that $\mathrm{C}$ and $x$, in borrowing from $\mathrm{W}$ and $\mathrm{C}$ respectively, avoid borrowing any original matter? It is this paradox

I The table unfortunately does not illustrate this, since it does not show the portions of $\mathrm{W}, \mathrm{C}, \chi$ which are not parallel to $\mathrm{Y}$. But within the portion reproduced it may be observed in the parallel extracts. 


\section{TABLE OF \\ PARALLEL. PASSAGES}

\section{SPECIMEN OF}

A PARALLEL EDITION 







\section{(CHESTER)}

Therfore if thou wold neuer so fayne

I)Ers. The kingdome of heauen is in me light 253 And hath me annoynted as a leach And geven me playne power and might

The kingdome of heauen to tell and teach. 


\section{$\mathrm{Y}=\mathrm{YORK}$}

IEs. Lordingis, loue he with you lentte

And mirthis be vnto this mene.

I MAG. Sone, hense away I wolde thou wente,

For othir haftis in hande haue we.

$2 \mathrm{MAg}$. Sone, whoso the hedir sente

They were nought wise, that warne I the, For we have othir tales to tente

Than now with barnes bordand to be.

3 MAg. Sone, yt the list ought to lere

To lyue hy Moyses laye

Come hedir and thou shalle here

The sawes that we shall saye,

For in som mynde itt may the brynge 85

To here oure reasouns redde by rawes. (cf. $\lambda_{2} 29$ )

Ifs. To lerise of you nedis me no thing

For I knawe both youre dedys and sawes.

I MAG. Nowe herken yone barne with his brandyng, 89

He wenes he kens more than we knawes:

We nay, certis, sone, thou arte ouere yonge

By clergy yitt to knowe oure lawes. 
(YORK)

IEs. I wote als wele as yhe 69 Howe that youre lant. 1 .

2 MAg. Cum sitte, sone schall " For certis so semys it ( 1 MAG.) And if thou wolde ynt 97
If all the liste te + Thou arte nowthir :

To kenne it as a. +100

3 MAG. Itt wer wondir that any 73 Intill oure reasou reche,

And thou sais thou hast Oare lawes truly to $t$

IEs. The holy gost has on $\mathrm{n}$ And has anovnted $m$ And geuen me pleyne $F$

The kyngdom of heu

I Mag. Whens euere this bar 81 That shewes ther 1

IEs. Certis, I was or ye i And schall be attir 


$$
\mathrm{Y}=\mathrm{YORK}
$$

IEs. Lordingis, loue be with you lentte

And mirthis be vnto this mene.

I MAG. Sone, hense away I wolde thou wente,

For othir haftis in hande haue we.

$2 \mathrm{Mag}$. Sone, whoso the hedir sente

They were nought wise, that warne I the,

For we haue othir tales to tente

Than now with barnes bordand to be.

3 Mag. Sone, yf the list ought to lere

To lyue hy Moyses laye

Come hedir and thou shalle here

The sawes that we shall saye,

For in som mynde itt may the brynge 85

To here oure reasouns redde hy rawes. (cf. 入 229)

IEs. To lerne of you nedis me no thing

For I knawe both youre dedys and sawes.

I MAG. Nowe herken yone harne with his brandyng, 89

He wenes he kens more than we knawes:

We nay, certis, sone, thou arte ouere yonge

By clergy yitt to knowe oure lawes.

* Passages not parallel are printed in italics.

liries containing 


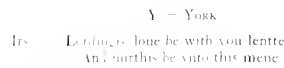

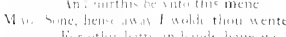

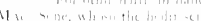

The were neuche whe, that warne 1 the,

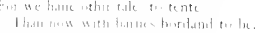

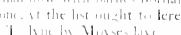

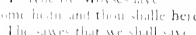

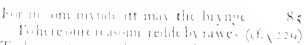

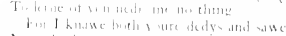

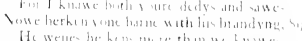

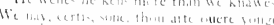

Bu derst bith to knowe tare lawe
W =- WAKFFIHD

Mit.ter, luf he with wh

49

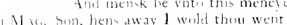

Fot othere haft in hasud hance we

(uil), whimener the hyder ent

Thay were lase atse thus tell I the I

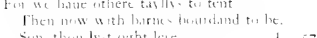

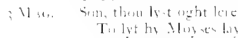

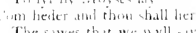

For 11 and mymie if may the brye

1. To here muie waves wet hy rawe

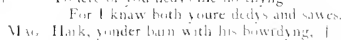

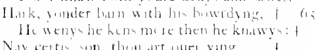

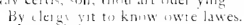

C. COOKnTRs

$1=\mathrm{CHF} \cdot \mathrm{TIR}$

If Londw, moche lewe with you he lent

SS:

Dere sum, awe I wolid

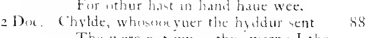
Were nit wyer, thus warne I the. for we have onthur tolis to rent

1) (in Then with chyldur lerordyng to hee. Byz The hy myotele of VI

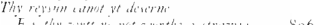

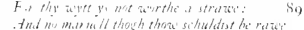

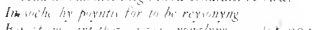

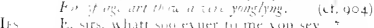

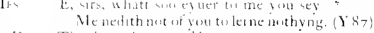

21) The These twerc of lin tung

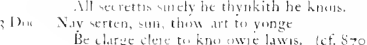

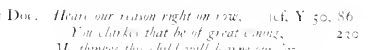

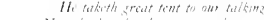
lint my tulk you tukt sorth M.

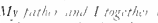

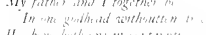

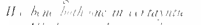

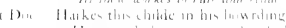

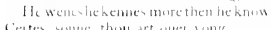
By clerger deane te know cour lawe. 
that forms

problem of the To solve it we and to begin with let us consider rathet closer the relation of the Waketield play to that of Pots not parallel to $Y$. Scene $t$ and part of scene 2 ate lost. The remainder of scene 2 is in quattunn.2. is much fuller than in $Y$, which it in no way resembles. The paralleism begh weth scenc and core again W rewrites the text in quatrains, expanding considerably. Either, thereis te the recacto of dcliberately departed from his copy, or that che was deftective. An how he mas assume

to believe that the Wakeneld bor wings to $k$ ?

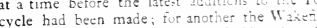
manuseript may possibly be itet: oldee taan the of York. Texiual evidence. io far as it of contan small corruptions not found in $\mathrm{W}$; and occasionally prunes lines which tit cere mets ats. gether conclusse, but the probasulity is in furcu

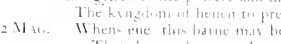

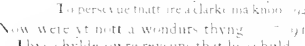

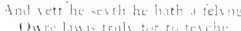

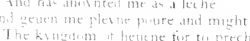

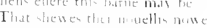

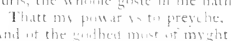

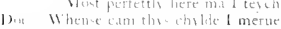

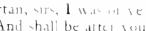


that forms what I may call the problem of the Doctors' play.

To solve it we must turn to the texts themselves, and to begin with let us consider rather closer the relation of the Wakefield play to that of York. So far as $\mathrm{IW}$ is extant it presents only two passages not parallel to Y. Scene $I$ and part of scene 2 are lost. The remainder of scene 2 is in quatrains, and is much fuller than in $\mathrm{Y}$, which it in no way resembles. The parallelism begins with scene 3 and continues to the end, with the exception of the passage dealing with the Commandments, where again $\mathrm{W}$ rewrites the text in quatrains, expanding considerably. Either, therefore, the redactor of W deliberately departed from his copy, or that copy was defective. Anyhow, we may assume that he did not work on our extant manuscript of the York cycle. For one thing, we have previously seen reason to believe that the Wakefield borrowings took place at a time before the latest additions to the York cycle had been made; for another the Wakefield manuscript may possibly be itself older than that of York. Textual evidence, so far as it goes, supports this view. Lines 209 and 2 I I of $Y$ both contain small corruptions not found in $\mathrm{W},{ }^{\mathrm{r}}$ and $\mathrm{W}$ occasionally prunes lines which in $\mathrm{Y}$ are metrically somewhat redundant. The evidence is not altogether conclusive, but the probability is in favour of $\mathrm{W}$ having been copied from a close relative of $\mathrm{Y}$,

1209: Nowe haue [we] sought in ilke a stede ...

22 I: Lo, where he sittis, $y[\mathrm{e}]$ se hym noght ... (W is probably right in reading 'se ye.') Also in $1.89 \mathrm{Y}$ is alone in reading 'brandyng' for 'bourdyng.' 


\section{PROBLEMS OF THE ENGLISH}

possibly the very 'original' in the hands of the Sporiers and Lorimers of York, from which Y also derived, more probably from a defective copy of the same.

$\mathrm{W}$, in those portions where it is parallel to $\mathrm{Y}$, appears to be somewhat the less correct copy of the two. It betrays a tendency to corrupt the metre by introducing a fourth accent into the lines of the quatrain. The most interesting variant is where $\mathrm{Y}$ alludes to the passage in the Psalms, 'Out of the mouths of babes and sucklings,' and W breaks the stanza in order to introduce extrametrically the Latin quotation (Y I I 4, W 90). That the words were intended to be spoken by the actor seems proved by a subsequent alteration.

The portions of $\mathrm{W}$ which are not parallel to $\mathrm{Y}$ appear to have been written in complete independence. As regards the extant portion of scene 2, certain supposed similarities have indeed been pointed out. For instance, it has been suggested ${ }^{\mathrm{I}}$ that the lines in W:

Masters, youre resons ar right good

And wonderfull to neuen, 9-10 are a reminiscence of those in $\mathrm{Y}$ :

That was wele saide, so mot I the,

Swilke notis to neven me thynke wer nede. $6 \mathrm{I}-2$ We could hardly, I think, have stronger evidence of the independence of the two texts. In the divergent passage containing the Commandments there are no parallels except such as are due to the subject matter, unless we regard as such the use

${ }^{\prime}$ Craig, 'Two Coventry Plays,' p. xxx. 
of the form 'slo' for 'sle' (i.e. slay), which is however more likely due to a common dialect. In $\mathrm{Y}$ the Commandments occupy two stanzas, 24 lines. Of these the first four and the last two lines reappear in $\mathrm{W}$, the last seven commandments only being different. The 18 lines peculiar to $\mathrm{Y}$ are replaced by 34 in $W$. Since there is no apparent reason for the change this looks like the filling in of an accidental lacuna.

Let us now consider the relation of the Coventry play to the preceding. When we examine the text closely we find that it has points of agreement both with $\mathrm{Y}$ and $\mathrm{W}$. I will quote three instances of each ; first those in which $\mathrm{C}$ supports $\mathrm{Y}$ :

(i) $\mathrm{Y}$ : And of ther mouthes, he wate full wele ... I I 5

W : Of thare mowthes, sayth Dauid wele... 9 9 I

C: Of chyldurs mothis, ye kno right well ... 933

(ii) Y: Als wyde in world als we haue wente... 133

W: In warld as wyde as we haue went... 109

C: Ase wyde in worlde asse eyuer I went ... 953

( $\mathrm{x}$ : As wyde in world as I haue went... 267)

(iii) Y: They will take rewarde to you all way ... 235

W: Thay will take hede to you alway ... $\quad 227$

C: The haue reygardid you alwey... 1043

next, those cases in which $\mathrm{C}$ supports $\mathrm{W}$ :

(i) Y: Mysese had neuere man more ... 2 I 3

W: Sorow had neuer man mare ... 203

C: In sorro wasse there neyuer man more . . . IO2 I

(ii) Y: Because of elde, this wate ye wele. $\quad 236$

$\mathrm{W}$ : Because of eld, this wote $I$ weyll. 228

C: Because of age, this wott $I$ well. $\quad 1044$

(iii) Y: Wherto shulde ye seke me soo? 257

W: Wherto shuld ye, moder, seke me so? $\quad 249$

C: Modur, why did you seke me soo? 1065 


\section{PROBLEMS OF THE ENGLISH}

These quotations obviously throw a good deal of light on the relation of the texts. I will add two in which it is $x$ that supplies the information, $\mathrm{C}$ substituting some quite different reading, while remaining nevertheless parallel in a general way. In the first $\chi$ supports $Y$ :

$\mathrm{Y}$ : And geuen me pleyne poure and might ... I03

W: And gyffen to me powere and myght... 79

$x$ : And geuen me playne power and might ...255 in the second it supports $\mathrm{W}$ :

$\mathrm{Y}$ : To kenne it as a clerke may knawe.

$\mathrm{W}$ : To know it as a clerk may knaw. $\quad 100$

$\chi$ : To knowe it as a clarke may know. 248

I should mention, before passing on, that there are five cases of apparent conflict between $\mathrm{C}$ and $\chi$; namely, four in which $\chi$ seems to follow $\mathrm{Y}$ and $\mathrm{C}$ to follow $\mathrm{W}$, and one in which the relations are reversed. If these cases are genuine, it is clear that $\mathrm{C}$ and $\chi$ must be independently derived from a far back source, and the fact that $\chi$ retains nothing of that source not also retained by $\mathrm{C}$ lacks explanation. But it is remarkable that in every one of these five cases, while the evidence of $\chi$ is unequivocal, that of $\mathrm{C}$ is more or less obscure, and is capable of a different interpretation.' They may,

${ }^{1}$ I will quote the most instructive of these cases:

Y: For in lande was neure non so light.

IV: In land now lyfis there none so light.

C: For now in hart I am full lyght.

$\chi$ : In land there lyues none so light ...

Here, it will be seen, $\chi$ follows $W$ closely where $W$ differs from $\mathrm{Y}$, whereas $\mathrm{C}$ agrees with $\mathrm{Y}$ in retaining the word ' $\mathrm{For}$ ' at the 
I think, be safely dismissed, and for the moment we may treat $C$ and $\chi$ as a single witness.

Now since $\mathrm{C}$ (or $\mathrm{X}$ ) sometimes follows $\mathrm{Y}$ and sometimes $\mathrm{W}$, it is clear that it cannot be directly derived from either. Two possibilities present themselves: either $\mathrm{C}$ is derived from an earlier form of $\mathrm{W}$, or else $\mathrm{C}$ and $\mathrm{W}$ are independently derived from an earlier form of $Y$. In the latter case $\mathrm{C}$ will point to the original reading where $\mathrm{Y}$ and $\mathrm{W}$ differ, in the former the agreement of $\mathrm{C}$ and $\mathrm{W}$ is only of equal authority with Y. If, therefore, it can be shown that C and $\mathrm{W}$ agree in unoriginal readings, it will follow that $\mathrm{C}$ does not go back to an earlier Y, but only to an earlier W. It is difficult if not impossible to demonstrate this with certainty, but I think the following instances of agreement between $\mathrm{W}$ and $\mathrm{C}$ (and $\mathrm{x}$ ) will be found significant :

(i) $Y_{I}$ : Nowe herken yone barne with his brandyng,

He wenes he kens more than we knawes...89-90

W : Hark, yonder barn with his bowrdyng,

He wenys he kens more then he knawys .. 65-6

C: This besse bweye of his tong

All secrettis surely he thynkith he knois. 902-3

$\chi$ : Harkes this childe in his bourding,

He wenes he kennes more then he knowes.. 24 I-2

In the first line 'brandyng' is an error of Y. In

beginning of the line. In $\mathrm{C}$, however, the line is practically rewritten, so that its evidential value is seriously impaired, and the fact that it begins with the same word as $\mathrm{Y}$ may very well be an accident due to the general construction of the sentence, which in a manner suggests it. This case is typical of the group. For the other instances see Y 134, 147, 197, 198, W I10, 123, 189, 190, C 954, 967, 1005, 1006, × 268, 279, 261, 262. 
the second 'we knawes' is the only reading that makes sense; $W$ and $\chi$ retain the meaningless 'he knawys, while C's alteration is clearly the result of the same error in his copy. I hardly think that Y's reading, 'we,' is likely to be due to an emendation by the scribe who had just corrupted 'bourding' into 'brandyng.'

(ii) Y: Thez are the biddingis ten ...

W: Thise ar the commaundmentis ten ...

$\mathrm{C}$ : How to kepe these commandementis ten. 1000

$x$ : They are my fathers commaundment.

Here the passages are not closely parallel, but the agreement goes to show that 'commandments' and not 'biddings' was in the original of $C$ and $W$. But 'biddings' is required by the metre.

(iii) Y: Mysese had neuere man more ...

The variants have been quoted already (p. 95). The substitution of 'sorrow' for 'misease' in W and $\mathrm{C}$ destroys the alliteration. Other instances might be quoted, but I think I have said enough to establish a strong presumption that $\mathrm{W}$ and $\mathrm{C}$ are not independent witnesses for the text of the earlier Y. There is just one passage which might be thought to reveal a metrical irregularity common to $\mathrm{Y}$ and $\mathrm{C}$, but not to $\mathrm{W}$; but there is no difficulty in supposing that the earlier $\mathrm{W}$ contained, like $\mathrm{Y}$, a redundant vocative which has been pruned away in the extant manuscript. ${ }^{1}$

So much for the passages in which $\mathrm{C}$ is parallel to $W$. Something must now be said about those

I $\mathrm{Y} 245, \mathrm{~W} 237, \mathrm{C} 1053$; but the case is a very doubtful one. 
where this is not the case. To begin with, both $\mathrm{C}$ and $\mathrm{X}$ are partly parallel to $\mathrm{Y}$ in scene $\mathrm{I}$ where $\mathrm{W}$ is defective. The fact that nowhere else are they parallel to $\mathrm{Y}$ except where $\mathrm{W}$ is also parallel makes it almost certain that if the missing leaves of the Towneley manuscript were to be recovered they would be found to contain the first scene of the play in a form parallel to $\mathrm{Y}$. In scene 2, W is not parallel to $\mathrm{Y}$, nor is $\mathrm{C}$ parallel to either. Nevertheless, there are a few (actually five) lines or phrases in $C$ which appear reminiscent of $Y .^{{ }^{I}}$ I do not think that they can be regarded as conclusive evidence that the compiler of $\mathrm{C}$ had a knowledge of the corresponding scene of $\mathrm{Y}$, but I am willing to consider the possibility. The most interesting is the expression 'clargy clere,' which occurs in the second scene both of $\mathrm{Y}(54)$ and of C (870), for the latter introduces it again later on in the play, where we have:

$\mathrm{Y}$ : By clergy yitt to knowe oure lawes.

W: By clergy yit to know oure lawes.

$9^{2}$

C: Be clarge clere to kno oure lawis.

68

$\chi$ : By clergie cleane to know our lawes.

905

244

The other passage in which $\mathrm{W}$ departs from $\mathrm{Y}$ is that containing the Commandments. $\mathrm{C}$ is again parallel to neither, yet it apparently contains reminiscences of both. These are so curious that I will quote them in full:

(i) W : Both wyfe, chyld, seruand and beest. C: Thy selfe, thi serwande, and thy best.

I The cases not mentioned in the text will be found in $\mathrm{Y} 49$, cf. C 857 ; Y 64 , cf. C 858 ; Y 65 , cf. C 876 ; Y 67 , cf. C 878 . 
(ii) $\mathrm{W}$ : Bot in thare nede thou thaym socoure... I 55

C: With all thy myght thow schuldist them succure. 984

(iii) $\mathrm{Y}$ : (sloo) No man nor woman by any way ... I I76

C: Man nor woman that thou schuldist kyll ...986

(iv) Y: Youre neghboures goodes more or lesse ... I 82

C: Thy neyburis goodis more nor les... 990

Again, I do not pretend that these resemblances are conclusive of imitation on the part of $\mathrm{C}$, but I should be sorry to adopt a theory that forced me to regard them as fortuitous. Lastly, at the end of the play $\mathrm{C}$ has a long extension of the doctors' disputation, which is carried on after the departure of Jesus. It is in no way parallel to the $\mathrm{Y}-\mathrm{W}$ text, but scattered through it are at least six apparent reminiscences, some of which are quite conclusive of imitation, but all of which are reminiscences of passages common to $\mathrm{Y}$ and $\mathrm{W} .{ }^{\mathrm{I}}$

It may be well to pause for a moment and inquire what textual relations will best account for the facts we have so far observed. What we have chiefly to account for is that in scene 2 and the Commandments, where $\mathrm{W}$ departs from $\mathrm{Y}, \mathrm{C}$ also ceases to be parallel to $\mathrm{Y}$ without being noticeably parallel to $\mathrm{W}$. Now $\mathrm{Y}$ must have have had a source, say $v$, which was presumably an 'original' in the hands of the guild. From the same source was derived, directly or indirectly, but not through $Y$, the copy which underlies $W$ and $C$, say $F$. This copy we must suppose to have been defective: it lacked scene 2 and a portion at least of the

${ }^{1}$ C 1085 , cf. Y 272; C 1086, cf. Y 271 ; C 1087 , cf. Y 279; C III3-4, cf. Y 275-6; C I I24, cf. Y 268. 
Commandments, though in both cases there was some indication of the matter that was wanting. $F$ was closely followed by the compiler of $\mathrm{IV}$, who, however, supplied the missing portions with original composition in a different stanza. $F$ was also used by the compiler either of $\mathrm{C}$ itself, or of an earlier $C$, say $\kappa$. In respect of scene 2 and the Commandments he was faced with the same difficulty as the compiler of $\mathrm{W}$, and like him he had recourse to his own invention. But he seems not to have relied upon this alone. If we may trust the evidence, he attended the performances of the play both at Wakefield and at York, and gathered therefrom not only their common matter, but likewise a few scattered phrases of each.

And what of the Chester play? I have drawn attention to the general evidence in favour of its derivation from $\mathrm{C}$, or from some closely similar source, and also to the paradox in which such an assumption apparently involves us. The derivation is placed beyond possible doubt by a more detailed examination of the texts, and it will be sufficient if I quote one remarkable instance :

Y: With men of myght can I not mell, Than all my trauayle mon I tyne,

I can noght with them, this wate thou wele,

They are so gay in furres fyne. 229-32

W has substantially the same text (221-4).

C: Ey, Mare, wyff, ye kno ryght well $1037-40$ As I haue tolde you many a tyme With men of myght durst I neyuer mell Loo, dame, how the sytt in there furis fyn! 


\section{I02 PROBLEMS OF THE ENGLISH}

$\chi$ : Mare, wife, thou wottes right well

That I must all my trauayle teene,

With men of might I can not mell

That sittes so gay in furres fyne.

Here $\mathrm{C}$ and $\chi$ agree in a remarkable inversion and in various minor points. $\chi$ is far closer to the original than is $\mathrm{C}$; it retains 'thou wottes' where $\mathrm{C}$ has 'ye kno,' the whole of the second line which $\mathrm{C}$ alters, 'can not' where $\mathrm{C}$ has 'durst neyuer,' practically the whole of the last line. On the other hand $\mathrm{C}$ preserves the order of 'mon I tyne' (corrupted as 'many a tyme') which $\chi$ alters, that of ' can I' (as 'durst I') where $\chi$ has 'I can,' and the personal pronoun in the last line where $\chi$ has a relative. Obviously then $\chi$ is not derived from $C$ itself, but from a somewhat more original source, $\kappa$, the readings of which can be pretty confidently restored thus:

Mary, wife, thou wottes right well

That all my trauayle mon I tyne,

With men of might can I not mell

They sit so gay in furres fyne.

This passage well illustrates the relations in which $\mathrm{C}$ and $\chi$ stand to the $\mathrm{Y}-\mathrm{W}$ text. Although on the whole $\chi$ takes from the original far less than $\mathrm{C}$, and even transposes matter, what it takes it preserves in a far less altered form. The history of the texts has been discussed by Davidson and others, and it has been, I think, generally held that $\chi$ at least came into being through oral borrowing. '

' See Craig, 'Two Coventry Plays,' pp. xxix, xxxiv. He credits Hohlfeld with this view ('Anglia,' xi. 264-5), but this 
Curiously enough this view has been supported by pointing to a passage near the beginning of the play, where a breakdown in the compiler's memory is alleged to have caused the helpless repetition of one line.' Those who have relied on this argument have failed to notice that the repetition destroys the stanzaic regularity of the passage, and must therefore be a subsequent corruption of the manuscripts, of which the original compiler was innocent. By no possibility can it throw any light upon the conditions under which the play was composed. For my own part I find some difficulty in believing that the theory of oral transmission will account satisfactorily for the elaborate patchwork which characterizes the Chester play. Take, for example, the following stanza:

This is nothing to my intent,

Such speach to spend I red we spare:

As wyde in world as I haue went

Yet found I neuer so ferly a fare.

Here the first two lines correspond to one portion of Y:

Nay, nay, than wer we wrang,

Such speking wille we spare...

and the last two are from an earlier passage:

As wyde in world als we haue wente

Yitt fande we neuere swilke ferly fare... I $33^{-4}$

seems to be an error, for the German critic expresses himself very guardedly concerning "verwirrung und verderbniss, wie wir sie nur bei sehr ungeschickter oder irgend wie erschwerter herübernahme aus einer anderen fassung erklären können.'

${ }^{1}$ Chester, 11. 224, 228. 


\section{PROBLEMS OF THE ENGLISH}

It appears to me that the compiler of $\chi$ is selecting and recombining at will matter that lies before him in a written text. If so, that text was a manuscript intermediate between $F$ and $\mathrm{C}$, and we will call this $\kappa$ as above. Consequently an examination of $\chi$ will throw light upon the relation of $\mathrm{C}$ to its immediate source, and we find that $\kappa$ must have approximated far more closely to the Y-W text than does C. This explains why $x$, although nowhere parallel to $\mathrm{W}$ where $\mathrm{C}$ is not, yet retains in a number of passages more or less the wording of the original where this has wholly disappeared from C. But we still have to account for the fact that $\chi$ is nowhere parallel to $C$ where $\mathrm{C}$ is not parallel to $\mathrm{W}$. It is obvious that $\mathrm{C}$ contains, and we may infer that $\kappa$ contained, various passages that were not in $F$, yet of these passages $\chi$ shows no knowledge whatever. Now, the most important of these, and the only ones of which we can say with certainty that they were present in $\kappa$, are scene 2 and the Commandments. Scene 2 is wholly absent from $\chi$; the Commandments are rehearsed in a quite different form. Why? The fact that the compiler of $x$ is constructing a short piece to form an appendix as it were to the 'Purification,' and is therefore compressing his material as much as possible, will account, I think, for his omission of scene 2. The case of the Commandments is more difficult, but may, I think, be explained on the same ground. Y and W, though different, both endeavour to combine what I may call the 'duologue'- - honour thy God, love thy neighbour-with the ordinary decalogue, by 
reducing the latter to eight 'biddings' only. The matter is developed at some length, and the incongruity is not very apparent. In $\mathrm{C}$, however, the passage is considerably compressed so that no one could help noticing the unusual form of the exposition. I conjecture that the compression was due to $\kappa$, and that the compiler of $\chi$ disapproved of what he found there. Anyhow he substituted what is meant to be a version of the ordinary decalogue, though it is true that he has made a sad mess of it. That $\chi$ borrows nothing from the incidental expansions of $\mathrm{C}$ or from the lengthy appendix is, I conjecture, simply due to these being additions of $\mathrm{C}$ not present in $\kappa$. It is true that the appendix contains lines clearly suggested by phrases occurring earlier in W, but I imagine that these lines appeared in $\kappa$ in their original places, and that it was merely the compiler of $\mathrm{C}$ who dropped them there and worked them into his appendix. ${ }^{\mathrm{T}}$

I A curious point, which at first sight raises a rather serious difficulty, occurs in $\chi 229$. This is the first line of scene 3 , and the passage is not parallel to any of the other texts. Nevertheless the line in question,

$$
\text { Heare our reason right on row... }
$$

seems reminiscent of two lines in $\mathrm{Y}$ :

And rede youre resouns right on rawes...

To here oure reasouns redde by rawes ... 86

The first of these occurs in scene 2, which has nothing parallel either in $W$ or $C$, the second in scene 3 where $W$ has:

To here oure sawes red by rawes...

but where $\mathrm{C}$ is again divergent. And yet it is almost certain that the compiler of $\chi$ must have known both lines of $Y$, or else a line 


\section{Io6 PROBLEMS OF THE ENGLISH}

We may, therefore, finish our story of the versions by adding that $F$ served as a source for $\kappa$, that $\kappa$ was largely rewritten and worked over, possibly more than once, till it reached the state known to us as $\mathrm{C}$; lastly, that $\kappa$ was also used as the basis for, or rather supplied certain matter to, $x$. The author of $x$ worked in an eclectic way, taking what he required and rearranging matter according to his liking, without however altering very greatly the language of what he borrowed.

The text $F$ I imagine to have been obtained expressly for use at Wakefield, and to have served immediately for the compilation of $\mathrm{W}$. That $\kappa$ originated at, or was made for the use of, Coventry seems to me very doubtful; at any rate, it appears unnecessary to suppose so. It might not be unreasonable to suggest that $\kappa$ may have been the Beverley play. Indeed, it seems not unlikely that the manuscript reached Chester first and was passed on to Coventry after it had served the purpose of the Chester playwright. That a writer at

that combined their characteristics. Now there is evidence that $\kappa$ was parallel to 1.86 of Y (W's 'sawes' is clearly corrupt), for in the non-parallel lines that $\mathrm{C}$ introduces at this point the word 'reysun' occurs and 'rawe' (in a different sense) is actually a rime-word (C 895, 897). Moreover, we have already seen reason to believe that the compiler of $\kappa$ had some acquaintance orally with scene 2 of $\mathrm{Y}$. We may then conjecture that a reminiscence of 1. 50 led him to alter 1. 86:

To here oure reasouns redde by rawes ...

into:

To here our reasouns right on rawes ...

and thus supply the compiler of $\chi$ with the material for the line as it there appears. 
Chester should draw material from Yorkshire need not surprise us, nor need it that a Coventry writer should seek it at Chester, the headquarters of the diocese, while on the other hand a plausible connexion between Coventry and Yorkshire would be far harder to establish. Whether $\kappa$ was ever actually performed at Coventry we have no means of knowing: it may have been largely rewritten in the direction of $\mathrm{C}$ as soon as it arrived. But it is tempting to believe that $\kappa$ was the actual play introduced at Coventry in 1520 or earlier, and that the peculiarities of $\mathrm{C}$ are due solely to the literary efforts of that diligent but clumsy litérateur, Robert Crow.

There is one incidental matter I should like to mention before I close. It may have occurred to some of you that the York, Wakefield, and Coventry plays we have been considering supply us with an independent criterion for judging of the manuscripts of the Chester text, somewhat similar to the Peniarth manuscript in the case of the Antichrist play. I cannot, of course, enter into the matter at length, but may as well state the general results. The grouping of the manuscripts appears to be the same as elsewhere, though there is not much evidence regarding the position of $\mathrm{B}$ and $\mathrm{D}$. There are several curious correspondences, but nothing to upset the results at which we previously arrived. There are also one or two remarkable instances of an original form having survived in $\mathrm{W}$ and $\mathrm{K}$, while it has been independently modernised in the other three manuscripts. But the most substantial result is certainly the vindication of the 


\section{IO8 PROBLEMS OF THE ENGLISH}

tradition represented by $\mathrm{H}$. Of this I will quote one rather remarkable instance. At 1.257 of the Chester play, $\mathrm{H}$ reads :

Behold how he has lead our lawes...

while D B W K substitute 'learned' for 'lead.' Deimling adopted this reading, and suggested that in H 'lead' is an error for 'read.' Now the York play has:

Behald howe he alleggis oure lawe ... and that of Wakefield:

Behald how he lege oure lawes...

There can be little doubt that $F$ read:

Behold how he a lege oure lawes...

and that $\kappa$ followed this. C altered the line completely. The compiler of $\chi$ took ' $a$ ' to be a verb, ' ha' = has, and either misread or altered 'lege' to 'lede,' whence $\mathrm{H}$ 'lead.' The reading of the other manuscripts is due to an editorial emendation by the scribe of $\beta$.

\section{IV.-LUDUS COVENTRIAE.}

THE cycle of miracle plays preserved in a Cottonian manuscript, and known commonly as the 'Ludus Coventriae,' is one of the chief puzzles of our early dramatic literature. ${ }^{1}$ The name under which

I British Museum, Cottonian MS., Vesp. D. viii. The best account of the problem is that given by $E$. K. Chambers, 'Mediaeval Stage,' ii. 4I9, to which I am much indebted. 
it passes is unfortunate, for one of the few things concerning it of which we can feel tolerably certain is that it has no connexion with Coventry. The person responsible for the error is Cotton's librarian, Richard James, who in the earlier part of the seventeenth century wrote the following description in the beginning of the manuscript: 'Contenta Novi Testamenti scenice expressa et actitata olim per monachos sive fratres mendicantes: vulgo dicitur hic liber Ludus Coventriae, sive ludus Corporis Christi : scribitur metris Anglicanis.' It has not unnaturally been supposed that James based his note upon some tradition which reached him along with the manuscript itself. ' There is, however, no sufficient reason to suppose that this was the case. The manuscript already bore, in an Elizabethan hand, the title, 'The plaie called Corpus Christi,' and the Coventry miracles were by far the most famous Corpus Christi plays in England. It will be noticed how James uses the terms 'Ludus Coventriae' and 'Ludus Corporis Christi' as though they were synonymous. His value as a witness is not enhanced by his describing the collection as confined to the New Testament, a limitation which applies to the Coventry guildplays, but not to the collection in question. Moreover, the Coventry Greyfriars' plays, which it is clear James had in mind, are almost certainly

${ }^{1}$ Presumably from Robert Hegge of Durham, author of 'The Legend of St. Cuthbert,' who has left his name in the manuscript, and who, like James, was a member of Corpus Christi College, Oxford. The cycle is consequently sometimes known by the not very happy name of the Hegge Plays. 


\section{IIO PROBLEMS OF THE ENGLISH}

an invention of seventeenth century antiquaries. Lastly, not only is the manuscript clearly the work of an East-Anglian scribe, but, as Herr Kramer has shown, the dialect of the plays themselves bears no relation to that of Coventry, being of a much more easterly type. ${ }^{1}$ We must, therefore, give up the Coventry legend altogether. The only suggestion of a locality in the plays themselves is the tantalising announcement in the prologue that
A Sunday next, yf that we may, At six of the belle we gynne oure play In $\mathrm{N}$ towne,

which most probably indicates a variable locality. I shall, therefore, speak of the cycle as the $\mathrm{N}$-town plays. $^{2}$

The manuscript was edited for the Shakespeare Society by J. O. Halliwell in $184 \mathrm{I}$. Judged by the standards of the middle of last century the edition is commendably accurate. If it falls short of modern requirements it is less through errors in

' Max Kramer, 'Sprache und Heimat des sogen. Ludus Coventriae,' I 892. His conclusions are on pp. 68-9. He believes in a rather problematical 'urheimat im südlichsten ostmittellande,' possibly Wiltshire, but agrees that in its present form the cycle 'dem nördlichen ostmittellande angehöre.' He also thinks 'dass die aufzeichnung im norden stattgefunden hat,' which seems questionable.

${ }^{2}$ Some interesting arguments have recently been advanced for supposing the cycle to be that of Lincoln. The suggestion is not altogether new, but as yet the evidence falls far short of proof. The idea of connecting the elaborate development of the childhood of the Virgin in these plays with the festival of St. Anne at Lincoln is certainly attractive. See 'Athenæum,' 16 Aug. and 13 Sept., 1913. 
the text-though indeed these are not rare-than in that it hardly reflects at all the extraordinary confusion of the original manuscript, and consequently affords no clue for the unravelling of the bibliographical and literary history of the cycle. The editor yielded to the craze for making things look tidy. In his introduction he wrote (p. xii.): 'The divisions in the MS. being very incorrectly given, I have endeavoured to make as correct an arrangement as possible.' Well, that was exactly what the scribe had endeavoured to do, and I think it would be difficult to say whether he or his successor made the worse muddle; but whereas the one was ingenuous and usually left the difficulties of his arrangement visible to the reader, the other at least partially succeeded in covering them up. A further division, agreeing neither with the scribe's nor with Halliwell's, was proposed by E. K. Chambers, in what is by far the best account of the cycle that has so far appeared; but even this is not wholly satisfactory, since, as Chambers himself observes, it is obvious that considerable portions of the cycle were not intended for division at all.

For the internal history of the plays we have three main sources of information: the make-up of the manuscript, the indications of division afforded by the scribe, and the comparison of the plays as we have them with the descriptions given us in the Prologue. Of course, beyond this there are general guides afforded by internal connexions between individual plays, resemblances and differences of style, and the evidence afforded by the 


\section{2 PROBLEMS OF THE ENGLISH}

different metres used. Broadly, the first two sources may be said to be bibliographical and the rest literary, and it is only by using both kinds to the utmost that we can hope to disentangle the history of this very complex cycle. In what follows I shall say enough to make plain the bearing of the bibliographical evidence, but I wish to state at once that the more minute bibliographical analysis applies chiefly to matters the importance of which is only apparent when we come to criticise the construction of the cycle in far greater detail than is possible in a lecture such as this.

As regards the subsidiary sources of information, I shall repeatedly have occasion to refer to correspondencies or contradictions between different plays, and shall attach a good deal of weight to the evidence they afford. On the other hand, I shall say very little about style, all judgments thereon being notoriously subjective. The question of metre will necessarily occupy our attention a good deal, since the evidence it affords is of the greatest possible help. I may say at once that the most important metrical forms employed in the cycle are three in number. The first is a stanza of thirteen lines riming ababababcdddc. This rime-form is of a well-known northern pattern, being that of the whole body of Scottish stanzaic alliterative verse, and also of the distinctive compositions of the great Wakefield playwright. I refer to these stanzas for short as 'thirteeners.' The second is a stanza of eight lines riming $\mathrm{a} a \mathrm{abaa} a \mathrm{~b}$ or $\mathrm{a} a \mathrm{abcccb}$. In some passages 
the lines are much shorter than elsewhere, and sometimes the eight lines are cut down to six. These variations appear to be intentional. Both longer and shorter forms are very familiar, being for instance the metre of the bulk of the Chester cycle; they are often known as romance eights and sixes. I refer to them indifferently as 'romance stanzas.' The third metrical form is the eight-line stanza riming $a b a b b c b c$. Of this there are two rather well-marked varieties according as the lines are long or short. I call them 'long' and 'short octaves' respectively. Certain other forms, none very elaborate, also appear, and will be described in their proper places. They are less important than the above, and the total range is far less extended than in either of the great northern cycles.

There is one critical principle that I wish to lay down as regards metre. It is this, that, although there is no reason why more than one stanza should not have been used in the original composition of a single play, an author would not change from one to another without some rational cause. It follows that wherever a change of stanza occurs without discoverable reason we are justified in supposing that we have not got the play in its original form. This canon has been commonly assumed by critics, and I do not think, if it is reasonably applied, that anyone is likely to quarrel with the results.

We will now see what sort of evidence may be expected from each of the three chief sources of information which I mentioned before. The manuscript is written on paper-this happens to 


\section{4 PROBLEMS OF THE ENGLISH}

be fortunate-and the size is quarto.' Almost all the leaves have been detached and mounted on guards, but a set of late signatures, in conjunction with the water-marks, enables us to reconstruct the original quires with all but absolute certainty. With the exception of one play the whole original text is in a single hand. ${ }^{2}$ This is a good plain hand of the second half of the fifteenth century, showing marked East-Anglian peculiarities; near the middle of the manuscript occurs the date 1468 , and there is no reason to doubt that this is actually the date of writing. The play of the Assumption, which immediately precedes 'Doomsday,' is in a different hand, the home of which is less clear. Halliwell (p. 418) assigned this hand to the reign of Henry VIII. Had he examined more carefully the manuscript he was editing he would have found the hand of the main scribe both correcting and rubricating the additional play.

When we come to examine the make-up of the manuscript numerous irregularities become apparent. In some cases it would seem that the scribe wrote on a series of detached leaves, and though there was probably some reason for his doing so, this is not always easy to discover. In other cases the dislocation in the natural sequence of the leaves throws welcome light upon the manner in which the cycle was compiled. I shall have occasion to make use of the evidence such

I That is to say, each leaf is one quarter of a sheet. Striktly speaking, even a paper manuscript has no format.

$=$ There are a few incidental additions which are not in the same hand as the text. 
dislocations supply later on, and will here confine myself to the discussion of two remarkable instances. One occurs in the course of the scene representing the Last Supper. This, which is laid at the house of Symon the Leper, is interwoven by means of alternating scaffolds with that of the Conspiracy. Now it happens that in one place the scene originally shifted from the house of Symon to the Council Chamber at the junction of two quires. This is proved by an original catchword. But at this point two leaves were inserted containing an elaborate version of the incident of Jesus warning his disciples that one of them was about to betray him. This incident already appeared in simpler form further on, so that the insertion caused actual duplication. The catchword was altered to connect with the inserted leaves. But that was not all. One further leaf was prefixed to those already inserted. This contained the incident of Mary Magdalen washing the feet of Christ, an incident which, unlike the Last Supper, really did take place at the house of Symon. The catchword was yet again altered.'

The other most conspicuous dislocation is the insertion of the Assumption play. We have

1 The insertions occur at p. 263 of Halliwell's edition, immediately after the stage direction (which is deleted in the manuscript). This direction was originally immediately followed by the speech of Judas, 'Now cowntyrfeted,' on p. 26\%. The earlier insertion includes from the speech of Jesus, 'Myn herte is ryght sory,' on p. 265 to the end of the stage direction on p. 267. This duplicates the passage on pp. 274-5. The subsequent irısertion includes from the speech of Mary on p. 2.63 to the end of the stage direction on p. 265. 


\section{II6 PROBLEMS OF THE ENGLISH}

already seen that this is written in a different hand from the rest of the manuscript. It is also written upon an independent quire of quite different paper, which is inserted in the middle of what is now the last quire of the codex. Previous to the insertion, 'Doomsday' foilowed quite regularly upon 'Pentecost.' The present arrangement, however, dates from the original make-up of the manuscript, for the 'Assumption' takes its place in the consecutive numbering indicated by the original scribe by means of large red numerals placed in the margins.

Before passing on I should like to conclude what there is to be said about the 'Assumption.' It is an independent insertion written in a different hand. I may so far anticipate as to say that there is no mention of it in the Prologue. All this suggests that it may have had an origin different from that of the other plays. After a careful study I have not been able to detect any difference of dialect, and in any case, as we shall see, later on, the extremely complex origin of the cycle must necessarily detract from the value of any evidence that dialectal peculiarities might afford. There is, however, one striking characteristic that must force itself upon the attention of anyone who studies the play in the original manuscript, though it is completely obscured in the printed edition. I allude to the metrical form which is peculiar in the extreme. The play is written in thirteeners and octaves of rather long and clumsy lines, but these stanzas are linked together by means of intercalary lines usually repeating the first rime of the following stanza. The rubricator thoroughly 
understood the metrical structure intended, for he prefixed a large paragraph to the first line of each stanza, and a small one to the first line of each intercalary group. I may be exposing my ignorance, but I do not remember to have met with this device elsewhere. Nothing at all similar occurs in the rest of the cycle. It suggests that the play was written in imitation of the stanzaic forms found elsewhere in the cycle by one whose powers of composition were inadequate to the task of forcing his matter into so exacting a metre.

The instances of dislocation I have detailed will give some idea of the nature if not of the extent of the bibliographical puzzles that anyone who wishes to make a serious study of the $\mathrm{N}$-town cycle will have to face. Over and above the combination of different sources and the repeated revision of the text before it came into the hands of our scribe at all, we have complications introduced by the fact that his actual manuscript appears in parts to have been cut about and re-arranged like the pieces of a puzzle.

I pass now to what I called our second main source of information, and as briefly as I can I will give a general outline of the text as the scribe has written and divided it. He has split up the cycle into a number of separate plays by means of large red arabic numerals placed in the margins of the leaves. Doomsday is numbered 42 , but the number I 7 has accidentally been omitted, so that the number of plays into which the scribe saw fit to divide the cycle is actually 41 . Halliwell makes 42 , Chambers 43 ; the Prologue records 40 . But while in parts 


\section{8 PROBLEMS OF THE ENGLISH}

the action falls naturally into separate scenes, which are written as individual plays or pageants, in others the composition and writing are alike continuous, and all division and numeration purely arbitrary. For instance, the second play is made to begin in the middle of a stanza. In referring to the plays I use throughout the numbering of the scribe.'

The first three plays - 1 , the first day of Creation and the fall of Lucifer; 2, from the second day to the Expulsion; 3, 'Cain and Abel'-are written quite continuously. It would appear to have been the original intention of the scribe to make play 4 , 'Noah,' continuous likewise, for he has placed the heading, 'Introitus Noe,' not at the head of play 4 , but at the end of play 3. Play 5, the 'Sacrifice of Isaac,' is written continuously with the preceding, but is quite independent in composition. Plays 6 and 7, the 'Giving of the Law' and the 'Prophets,' are separate both in action and writing.

Plays 8 to $\mathrm{I} 3$, containing the Birth of Mary, her Presentation in the Temple, her Marriage, the Annunciation, Joseph's trouble, and the Visit to Elizabeth, are written more or less continuously and are woven into a connected group by the appearances of an expositor called Contemplatio. We shall see later on that this group, though well defined, is not, as has sometimes been sup-

I Readers must be so good as to bear in mind that neither the numbering nor the division of the plays as I give them necessarily agrees with Halliwell's edition. As a rule, the relation will be obvious to anyone who follows the printed text, but in cases where difficulties arise I add footnotes giving the exact reference to Halliwell's text. 'The second play begins with the speech of Deus near the foot of p. 21 . 
posed, an original whole, but is of very complex origin.

Next we have Play I 4, "Purgation of Mary and Joseph'; I 5, 'Nativity'; I6, 'Shepherds'; I8, 'Magi'; I9, 'Purification'; 20, 'Massacre of the Innocents'; 2 I, 'Christ and the Doctors '; 22, 'Baptism'; 23, 'Temptation'; 24, 'Woman taken in Adultery'; 25, 'Raising of Lazarus.' These are all distinct plays separately written.

The next group deals with the events leading up to the Passion. It may be called the Entry group. Opening with a sort of prologue spoken by Lucifer, it continues through the Council of the Jews, the Entry into Jerusalem, the Last Supper, the Conspiracy, the Agony in the Garden, and the Betrayal. Both action and writing are perfectly continuous, the insertion of the numbers 26 to 28 being wholly arbitrary. The representation was also meant to be continuous, as appears from the stage directions, and to take place on a number of scaffolds disposed round an open space.

The same is true of the next group. This opens with another prologue, introducing a procession, and contains the Passion and Resurrection. There is an appearance of Contemplatio immediately following the prologue and beginning play 29, and the writing is continuous down to the end of the 'Hortulanus' scene. This is a very complex group, and the insertion of the numbers 29 to 37 is for the most part quite arbitrary.

The last group again consists of separate and independent plays: 38, 'Emmaus'; 39, 'Ascension'; 40, 'Pentecost'; 4I, 'Assumption 


\section{I20 PROBLEMS OF THE ENGLISH}

of the Virgin'; 42, 'Doomsday.' The end is lost.

Now, in the speech by Contemplatio, which forms a sort of second prologue or preface to the Passion group, there occurs a remarkable reference to 'the matere that we lefte the last yere.' This has been the subject of frequent comment, and it is clear that, in the form for which this preface was designed, the cycle, whatever it may have comprised, was intended for performance in yearly sections. It has been less generally remarked that the preface clearly states that the matter that "last yere we shewyd'began with the Entry-in other words, that it comprised no more than the immediately preceding group of plays. If, therefore, Contemplatio's prologue is intended, as it presumably is, to apply to the cycle in its present form, we must suppose that this was meant to be acted in several, according to the above analysis in six, yearly sections.

The third main guide in our investigation is the comparison of the text as we find it with the description of the individual pageants supplied by the 'vexillatores' of the Prologue. This is by far the most powerful instrument of criticism at our disposal, and to it and to the metrical and other analysis of the plays themselves we must now turn. I propose to go more or less systematically through the cycle, and as I go I shall gather together whatever evidence I can find for the unravelling of the problems it presents. You will, of course, understand that in such a lecture as this it is impossible to do more than brush the surface of a fascinating 
subject and select a few of the more striking points for comment. Our survey must needs be cursory, and I must ask your indulgence if in the course of it I touch upon certain points the bearing of which may not be immediately apparent. It must suffice if by the end of my allotted hour I can produce sufficient points of evidence to warrant the very general and provisional inferences I propose to draw.

The Prologue is spoken by three 'vexillatores' or standard bearers, who recite in turn the subjects of the various pageants. It is composed, like a large portion of the cycle itself, in thirteeners. As a rule one stanza describes one pageant, but occasionally the description fills two stanzas, or one stanza describes two pageants. Two stanzas near the beginning are imperfect, consisting of four lines each, space being left in the manuscript for their completion. Towards the end four stanzas are distinguished by the greater length of their lines, and have apparently been rewritten. The first stanza is introductory, the last valedictory. The pageants as described in the Prologue are numbered, but the numbering has been tampered with by the original scribe. The first seven are regular, we then proceed: $x, x, x i$, xii, xiv, $x v$, $\mathrm{xvi}$; then jump back to $\mathrm{xv}$ again and proceed regularly to $\mathrm{xl}$. The irregular numbers are all over erasures, the original numeration from $\mathrm{i}$ to $\mathrm{xl}$ having been perfectly regular. What has happened is that the scribe has endeavoured to bring the numbering of the Prologue into agreement with that of the text. He succeeded in doing this 


\section{PROBLEMS OF THE ENGLISH}

all right as far as play I 6, but when he discovered that he had omitted the number 17 altogether from his numeration of the text, he appears to have given up his attempt in disgust. I refer to the pageants of the Prologue throughout by their original, not by their altered numbers.'

According to the Prologue the first play contains the Creation of Heaven and the Fall of Lucifer; the second, the events from the Second Day to the Expulsion from Paradise. This agrees with the text. But we have already remarked that the text, or rather the rubrication, begins play 2 in the middle of a stanza. Such an arrangement is clearly impossible, and we are forced to the conclusion that in this instance at least the Prologue was not written for the text as it stands. This is unfortunate, for these early plays are in thirteeners like the Prologue, and it would be natural to suppose that they belong together. But there are signs of the text having been altered. The first play is very summary, and the account of the Fall of Lucifer abrupt in the extreme. There are fragmentary stanzas near the beginning of the second play, and, whereas the Prologue expressly states that woman was made from a rib of the man, this is ignored in the text. I conclude that in this case drastic compression and rewriting may have brought the division between two original plays into the middle of a stanza. Such

' Halliwell, of course, prints the altered numbers in his text of the Prologue. I also follow the practice of the manuscript in referring to the plays themselves by arabic numerals, to the descriptions in the Prologue by roman. 
revision would, of course, be later than the composition of the Prologue.

The second play includes a passage, namely, the Curse, in a different metre from the rest. It consists of eleven romance stanzas, and its insertion must have displaced original thirteeners. There is no actual proof that it is later than the Prologue, though it is natural to suppose so, and one piece of internal evidence points in that direction. The Prologue in no way identifies the Serpent with the Devil: in the text the thirteener portion simply has 'Serpens,' while that in romance stanzas makes the identification clear and speaks of 'Diabolus.'

'Cain and Abel' is a regular play in thirteeners agreeing with the Prologue.

The fourth play deals with Noah. The description in the Prologue does not give us much detail whereby to identify the actual piece. In the text the play opens in thirteeners, but with the appearance of the Angel to Noah the metre changes to octaves of long lines, which continue to the end of the pageant. In the latter portion occurs a very remarkable passage. The author namely avails himself of the interval of a hundred years that elapse while Noah is absent building the ark, to introduce the apocryphal story of the death of Cain at the hands of blind Lamech, an incident not elsewhere treated in the English drama. Of this there is no hint in the Prologue, a fact which points to the play there described being the original thirteener play, the opening of which is alone extant in the text, though it 


\section{PROBLEMS OF THE ENGLISH}

cannot be held to afford actual proof that this is so. It should be observed that the stage directions in the octave portion-'Hic recedat Lameth et statim intrat Noe cum navi cantantes,' 'Et sic recedant cum navi'-seem to imply a fixed open stage on to which large properties could be brought, not a movable pageant.

The fifth play is the 'Sacrifice of Isaac.' It is a quite regular play in octaves, the lines of which are, however, very much shorter than in the preceding piece. Like all the plays in short octaves, this of Isaac is perfectly independent, and it is marked off from its neighbours by the heading 'Introitus Abrahe' and an 'Explicit' at the end. The description in the Prologue is couched in far too general terms to enable us to say whether it was written for the extant play or not.

The sixth play contains the Giving of the Law to Moses. It is again an independent play in short octaves. The Prologue is in general agreement with the text, though it is true that it does not explicitly mention the Burning Bush as the scene of the Lawgiving! Considering, however, what an unusual subject for a play the incident is in English drama, it is difficult to resist the conclusion that, in spite of the difference of metre, the description in the Prologue was actually written for the pageant we possess.

The last of the Old Testament plays is a 'Prophetae,' another independent pageant in short octaves. Prophet plays, of course, abound, and there would be no reason to suppose that the one described in the Prologue was in fact the one now 
found in the text, were it not for the stress which both Prologue and text lay upon the 'Radix Jesse.'

We now pass to the second group of plays, what we may call the Incarnation section, and agreement with the Prologue ceases abruptly. The separate pageants are linked together by speeches of Contemplatio. In a sort of preface this character promises a representation of events down to the Visit to Elizabeth 'and therwith a conclusyon.' This promise is fulfilled. But it is the first three plays, namely the 'Conception,' 'Presentation,' and 'Marriage of the Virgin,' that are the most intimately connected, there being appearances of Contemplatio in the intervals between these plays, numbers 8, 9, and 10 . The 'Annunciation,' play I I, also begins with a speech by Contemplatio, but this is either a mere blunder on the part of the scribe or else a very clumsy piece of botching on that of the reviser. For an examination of the passage in the manuscript proves beyond all doubt that, of Contemplatio's four stanzas, the first two should be spoken by the Angels and the second two by the Archangels.' There is no further

1 The passage is certainly assigned to Contemplatio by the scribe, but at the top of the page, above the first stanza (there is, of course, no heading), there stands in the manuscript ' $1{ }^{9}$ ', i.e. Primus. Before the first line of the third stanza is the figure ' 2 .' Stanzas 5 and 6 are spoken by Virtutes, stanza 7 by Pater (i.e. God), after which the discussion is carried on by Veritas, Misericordia, Justicia, and Pax. Now, elsewhere Contemplatio is an expositor who takes no part in the action of the play. But in the four stanzas assigned to him here the deity is directly addressed, and the intercession on man's behalf begun, which is carried on in the speech of the Virtues. It is clear then that the speaker or speakers of these lines (for the manuscript clearly suggests that we 


\section{I26 PROBLEMS OF THE ENGLISH}

appearance of Contemplatio till the end of the " $\mathrm{V}$ isit to Elizabeth,' play I 3, when he makes his promised 'conclusyon.'

Speaking very generally, and disregarding insertions and revision, we may say that the 'Conception' and 'Presentation,' plays 8 and 9, together with the 'Visit to Elizabeth,' I3, are in long octaves, the 'Marriage' and 'Joseph's Trouble,' plays $\mathrm{I} O$ and $\mathrm{I} 2$, in thirteeners, and the 'Annunciation,' I I, in short octaves. The speeches by Contemplatio are mainly in long lines and follow irregularly various metres. The make-up of the manuscript affords fairly conclusive evidence that they were written in after the rest in spaces left for the purpose. They are, therefore, presumably the work of a reviser or compiler who was handing the copy to our scribe piecemeal.

Now, in the Prologue we find no trace of the Conception, Presentation, and Elizabeth plays at all. These are the long octave pieces, and it will be remembered that the Prologue was likewise silent on the subject of the Lamech episode in the

have to do with two speeches, not one) must be characters of the play on a par with the Virtues. Who they are appears from the lines in speech of the latter:

$$
\begin{aligned}
& \text { Aungelys, archaungelys, we thre, } \\
& \text { That ben in the fyrst ierarchie, } \\
& \text { For man to thin hy mageste, } \\
& \text { Mercy, mercy, mercy we crye. }
\end{aligned}
$$

Angels, archangels, and virtues do in fact form, in ascending order, the first or lowest hierarchy of heavenly beings. Bonaventura, upon whose 'Meditationes' the subsequent 'parliament of heaven' is ultimately based, mentions the intercession of the "beatissimi spiritus' in heaven, and there could be no point in the playwright selecting the Virtues alone. 
same metre. The portions in long octaves are, therefore, additions to the cycle subsequent to the composition of the Prologue. This is our first important result in analysis. Plays viii and ix of the Prologue contain the Marriage of the Virgin, $x$ the Annunciation, xi Joseph's Trouble.

Let us take the plays of the text in order. The 'Conception' is quite regular in long octaves. The 'Presentation,' in the same metre, includes a passage written in quatrains and shorter lines, but the change is accounted for by the subject, the recitation of the Fifteen Degrees. With regard to the 'Marriage' it will be noticed that two Prologue plays correspond to a single play in the text. There is reason to suppose that the latter has been considerably cut down as well as revised and interpolated, and there is satisfactory evidence both that it contains the remains of the plays described in the Prologue, and also that it has a different origin from its immediate predecessors. They, of course, leave Mary an inmate of the temple, whereas the present play, like the Prologue, makes her parents bring her to the temple, in response to the priest's summons, in her twelfth year. Again, the Prologue explicitly states that at her departure the priest provides her with three maiden companions, whom the text duly introduces by name, Susanne, Rebecca, and Sephor. The play has been interpolated. Two passages in octaves have been inserted after the present manuscript was written, a third towards the end of the play belongs to an earlier date. In this the lines are fairly short, though it can hardly be assigned 


\section{28 PROBLEMS OF THE ENGLISH}

to the short octave group. As we have seen in the previous play, the long octave writer could compose quite short lines when he pleased, and I have no hesitation in regarding this passage, which deals with the Psalter, as an insertion by the hand that wrote the Fifteen Degrees above. There is no mention of it in the very full description in the Prologue.

The Annunciation play, in short octaves, is one of the most remarkable in the cycle. It begins with what Contemplatio (in the link between plays 9 and 10 ) calls the 'parlement of hefne,' the well-known contention of the four daughters of God, and then proceeds to a Salutation simple in design, but elaborate and distinctly ecclesiastical in composition. Now the stanza in the Prologue describes a quite simple Annunciation play of the usual type, and cannot by any possibility have been written for the play we have in the text. Observe in particular that the Prologue expressly states that Mary's three maidens hear the Angel's voice, but see no one, while the text makes no mention of them whatever. This connects the piece described in the Prologue with the foregoing Marriage play, and there is no temerity in the conjecture that the original piece, displaced by the present composition in octaves, was like the 'Marriage,' written in thirteeners.

The next play both in Prologue and text is the 'Joseph.' Clearly it was originally a thirteener play, though but few fragments in this metre now survive. For it is connected with the Marriage and Annunciation plays of the Prologue by the 
reappearance of Susanne and Sephor in thirteener passages. The play as we have it is, however, chiefly written in a ten-line stanza riming a ababbcbc, which we have not met before. That the mixture of metres is not original is proved by contradiction in the text. As it stands, namely, the appearance of the Angel to Joseph is in response to a prayer by Mary, written in the ten-line stanza, that God would enlighten her husband, since she herself would rather suffer shame than reveal the origin of her condition. So at least I read the passage.' But this she had already repeatedly done in the earlier thirteener portion. This fact points rather to borrowing from a different source than to revision proper. There is no direct evidence that the combination took place later than the composition of the prologue, though it is, of course, natural to suppose so. The 'Visit to Elizabeth,' which completes this group, is, as we have already seen, unrepresented in the Prologue.

The next group includes the Nativity and Missionary Life of Christ. The plays comprised in it are independent of one another. The first two have the peculiarity that the stanzas describing them in the Prologue are imperfect. In either case four lines only are written; these just mention the subject of the play, and a blank is left in the manuscript for the-completion of the stanza. That this

: 'For I have levyr abyde respyt,

To kepe thi sone in privite, Grauntyd by the Holy Spyryt,

'Than that it xulde be opynd by me.'

Halliwell, p. 121. But 'respyt' should surely be 'despyt.'

$\mathrm{H}$ 


\section{30 PROBLEMS OF THE ENGLISH}

is not due to accidental damage to the copy the scribe was following is shown, not only by each quatrain being complete in itself, but also by the fact that, as we shall see in a moment, the introduction of the second of these plays accounts for a discrepancy between the Prologue and the text in the one that follows.

The play numbered $x$ ii in the Prologue and I4 in the text is a remarkable composition headed 'Pagentum de purgatione Marie et Joseph.' The subject, unknown elsewhere in English drama, is treated in short octaves with a good deal of rude force. A prologue, not originally contemplated by the scribe, has been prefixed. ${ }^{1}$ It is in romance stanzas, topical and comic.

The next play, Prologue xiii, text I5, is again

I As originally written, the play began with the stage direction, Halliwell, p. I 32 . The scribe provided the following stanza with a three-line initial, and put the play number, I4, in the margin opposite to it. But when he did this he had not yet finished writing play 13. He had got, I think, as far as the line: 'He xal remedy it whan it plesyth his mercy;' (p. I 28), which was the end of his copy for that play, and he left nearly two and a half pages blank for the 'conclusy on' by Contemplatio which he knew he had to expect. When he was then handed the prologue to play if he made use of the last of these blank pages for the insertion. Next he received, not only Contemplatio's 'conclusyon,' but three and a half additional octares to the text of play 13. All this had to be crowded into something less than a page and a half, and a very tight fit it was. I may point out that the three lines printed by Halliwell on p. r28:

' Come and (should be I) pray yow specialy;

Iwys ye are welcome, Mary;

For this comfortabelest comynge, good God, gramercy!'

have no business where they are. The manuscript add them in the margin as an alternative ending in place of the 28 lines that tollow. 
in short octaves with an insertion in confused metre, and deals with the Nativity. It includes the journey to Bethlehem, the seeking of the midwives, the birth, and the miracle of Salome's hand. The Prologue mentions nothing but the fetching of the midwives. As regards both this and the preceding piece, there can be no question that the plays in the text and the quatrains in the Prologue are alike insertions.

The proof of this statement is to be found in the following Shepherd's play, Prologue xiv, text 16. For the Prologue expressly says that "In the fourteenth pageant Cryst shal be born,' while no such thing happens in the text. Indeed, it is obvious that as soon as a Midwives' play was introduced into the cycle it had to include the Nativity. In the play itself we find that the first stanza, 'Gloria in Excelsis,' and one subsequent one are thirteeners, while all the rest, except for one short passage misplaced, are romance stanzas. The thirteeners must be fragments of the original play, the opening of which has been bodily cut out as duplicating what went before, while the remainder? has been almost wholly rewritten. It should be observed that the half burlesque names of the shepherds in this play serve to connect it with the comic prologue to the 'Purgation' in the same stanza.

Looking back for a moment, we shall now perceive that the original cycle described in the Prologue began, so far as the New Testament plays are concerned, with the series: 'Marriage of the Virgin' (two plays), 'Annunciation,' 'Joseph,' 


\section{PROBLEMS OF THE ENGLISH}

'Nativity and Shepherds, and that all these were written in thirteeners. Subsequently a different Annunciation play was substituted, and Purgation and Midwives' plays were added from a different source in short octaves. The original Nativity and Shepherds play was revised presumably at the same time. The Prologue was amended so as to include the two new plays, but no systematic attempt was made to bring it into accordance with the text. The Joseph play was also revised, but at an uncertain date.

The make-up of the manuscript shows that the Magi play, Prologue xv, text I8 (should be 17), is a very composite affair, but the details are singularly obscure. There are fragments of a presumably original thirteener play, but most of the piece is in romance stanzas, and five quatrains of long lines have been prefixed by a reviser.

The Prologue now immediately proceeds to the 'Massacre of the Innocents.' The text interpolates a play on the Purification. It is a quite regular play, and is entirely composed in the ten-line stanza already noticed in the 'Joseph.' Its nonappearance in the Prologue proves that the revision of the 'Joseph' must have been subsequent to the introduction of the 'Purgation' and the 'Midwives.'

The 'Massacre of the Innocents' occupies two plays in the Prologue (xvi, xvii), but only one in the text (20). Distinctive points in the description of the former are that the Knights bring in dead children to show to Herod, and that Death appears and kills him and his knights, the Devil taking 
their souls. Both points appear in the text, the former, however, in a romance, the latter in a thirteener passage. In general, indeed, the earlier portion of the play is in the one, the latter in the other stanza. What seems to have happened is that an original play in thirteeners was expanded into two plays by the addition of romance matter, that the present stanzas of the Prologue were written for this expanded play, and that it was subsequently cut down again to its present dimensions. It should be noticed that the initial stage direction, belonging to the romance portion: 'Tunc respiciens senescallus vadyt ad Herodem, connects with the end of the Magi play, a fact of interest alike as proving the insertion of the 'Purification' to be later than the work of the romance reviser, and also as illustrating the tendency of that writer to contemplate continuous representation.

'Christ and the Doctors,' Prologue xviii, text $2 \mathrm{I}$, the 'Woman in Adultery,' xxi and 24, and the 'Raising of Lazarus,' xxii and 25, are regular short octare plays, and agree with the Prologue, though it cannot be confidently asserted that the stanzas in the latter must have been written for the extant plays. In particular the remarkable and lively drama of the Adulteress seems rather inadequately described. The 'Baptism' and 'Temptation of Christ,' Prologue xix, xx, text 22 (not numbered'), 23, also agree with the Prologue, and

I The scribe cancelled two lear es at the beginning of this play, and in their place inserted one leaf with the verso not quite full. On this inserted leaf he forgot to repeat the play number. 


\section{I34 PROBLEMS OF THE ENGLISH}

are in thirteeners. This concludes the third section of the cycle.

It would be useless on this occasion to make any detailed analysis of the Entry and Passion sections, since the problems they present are far too complicated to yield to any but the most minute investigation. A few very general remarks must therefore suffice. The most striking feature of these sections is the appearance of a source which has not so far been in evidence, even if it has been present at all. Considerable portions of this part of the cycle are, namely, written in a mixture of quatrains, some of long, some of short lines, and of couplets. To what extent the former may be due to the breakdown under revision of earlier octaves we need not inquire, since this can hardly account for all cases in which they appear. But that considerable revision and rewriting has taken place is evident. The correspondence with the Prologue, except in one important respect to be mentioned later, breaks down utterly. The two sections are, each within itself, continuous both as regards action and composition, the former taking place in an open space about which are disposed certain located scaffolds. Besides the inew source we can trace fragments in thirteeners, short and long octaves, and romance stanzas. There has also heen revision apparently by the writer of the Contemplatio passages.

Some isolated points deserve notice. After the long satirical speech by Demon in long octaves, which forms the introduction to the Entry section, there is a passage in somewhat shorter octaves by 
John the Baptist. This strange insertion prophesies of the coming of Christ, and can only be regarded as a fragment of a Baptism play. ${ }^{1}$ Now we have already seen that the "Baptism' extant in the cycle is the original thirteener play. The inference is that what we have here is a fragment of the rejected 'Baptism' of the short octave source, worked in as a sort of preface to the events of the Passion. The lines are, it is true, a little long, but this may be due to their having been revised. With the curious insertion of the scene of the Magdalen washing Christ's feet, which occurs in the middle of the Last Supper, we have already been concerned. It is substantially in thirteeners, which proves that the cycle must have originally contained a play on the real Supper at the House of Simon of which the Prologue has lost all trace.

The Passion section is introduced by a procession of the Apostles interpreted in quatrains by two Doctors. This is written as an independent Prologue, not forming part of any numbered play, and has several blank pages hefore and after it. But the play immediately following opens with another prologue by Contemplatio which supplies us with the famous clue as to the yearly sections. Through the Trial the correspondence between the text and

Halliwell, p. $2+3$. It is quite true that the Baptist sometimes appears in prophet plays, and that there was a time in the development of the liturgical drama when the 'Prophetae' served as a prologue to the Passion. It might, therefore, be possible to regard the position of the present fragment as original if we could bring ourselves to believe that such a late and composite work as the $\mathrm{N}$-town cycle preserved such very primitive and exceptional features. For my own part I am quite unable to believe this. 


\section{I36 PROBLEMS OF THE ENGLISH}

the Prologue vanishes altogether. But from immediately after the Condemnation four Prologue plays, numbers $\mathrm{xxx}$ to $\mathrm{xxxiii}$, agree in essentials with four plays, numbers 32 to 35 , as marked in the text, ${ }^{2}$ and though the correspondence is not perfect it is clear that still less is it fortuitous. Now these four stanzas of the Prologue have longer lines than the rest, and there can be no reasonable doubt that they were written after the text had assumed approximately its present form. They are, therefore, much later than their neighbours. A good deal of the latter part of the Passion, particularly the Harrowing of Hell and the Resurrection, is written in romance stanzas, and the frequent changes of scene and the connecting directions suggest that it was actually written for a polyscenic stage. The section ends with what is really an independent short octave play on the Appearance to Mary Magdalen, which agrees with the description in the Prologue (numbers 37 and $\mathbf{x} \times \mathbf{x v})$.

The last division of the cycle opens with an Emmaus play, number 38 . This is duly described in the Prologue as pageant xxxvi, but whereas the latter contains the Peregrini episode only, the text includes the return of the disciples and the Incredulity of Thomas as well. Moreover, the two portions of the play are distinguished by being, the first in short, the second in long octaves. Now, the Incredulity is the subject of play xxxvii of the Prologue, a distinct pageant, the description of which, however, is included in one stanza with 'Halliwell, p. 316, speech of 'Primus mulier'(!), to p. 353 foot. 
pageant $x \times x$ viii, the 'Ascension.' Since the Ascension play of the text, number 39 , is in thirteeners, we may infer that the Prologue 'Incredulity' was probably in the same metre. It follows that the original play has been cut out and the loss made gond by an addition to the preceding Emmaus pageant.

The Ascension play, number 39, or what is left of it, is, I have said, in thirteeners. But it has been severely cut down. Some four stanzas are all that remain. Then comes a small blank in the manuscript followed by three stanzas, lacking speaker's name, which describe the election of Matthias. Halliwell printed these as though they were part of the foregoing speech of the Angel. They doubtless belong to Peter. There is no suggestion of them in the description of pageant xxxviii of the Prologue. Presumably, therefore, they are the remains of an originally independent play on this subject which has been cut out of the Prologue list.

The play of Pentecost, number 40, has been even more cruelly cut down, three stanzas alone remaining, the first of which was strangely misprinted by the editor. ${ }^{1}$ One word of warning I ought to add. Although what remains of these two plays is in thirteener stanzas, these are not of the usual type. The usual formula begins abahabab: here we have ababbchc. It is, therefore, possible that these pieces may not be original.

The 'Assumption,' play + $\mathrm{r}$, which follows next,

The curious jumble that appears at the head of this play in the printed text really constitutes the first four lines of the first stanza, the name, being those of the spcaker. 


\section{38 PROBLEMS OF THE ENGLISH}

has been already sufficiently described; ${ }^{1}$ it is unrepresented in the Prologue. The last of all, 'Doomsday, number 42 , is again a regular thirteener play, and agrees with pageant xl of the Prologue so far as it goes. But it is imperfect owing to the loss of a quire at the end of the manuscript.

Now, what conclusions are we to draw from the facts noticed? A few I have ventured to suggest as we went along, but it remains to formulate some sort of general theory as to the growth of the cycle.

To begin with, the Prologue has been revised at two different periods and by two different hands. Four stanzas near the end have been rewritten after the Passion section had assumed more or less its present very late form, and the rewriting was done by one who was unable to imitate the terse short lines of his model. But the two imperfect stanzas inserted earlier prove that there had been a previous revision by a writer whose work is not metrically distinguishable from that of the original author.

Pcrhaps the latest revisional work on the text was done by the author of Contemplatio's speeches. He seems to have been writing while the present manuscript was in course of compilation, and is probably responsible for a good deal of revision throughout. I suspect that he wrote the four late stanzas of the Prologue, and possibly also the Assumption play. What makes it difficult to recognize his work is that he did not affect any one stanza particularly. His lines are long and flabby. Closely associated with his work are the portions in long octaves. That they are revisional I See p. I 16 above. 
work, expressly written for the positions they now occupy, and not borrowed from an independent source, is, I think, clear from the Incredulity episode appended to the Emmaus play. Observe also that the plays on the Conception and Presentation of the Virgin, which are in this metre, appear to be expressly written to lead up to that on the Marriage. It is just possible that these portions were written by the author of the Contemplatio passages, though for my own part I think it unlikely. They are later than the first revision of the Prologue.

Another portion which there seems good ground for believing to be revisional is that written in romance stanzas. 'The introduction to the "Purgation,' which must obviously have been written for its present place, is in this metre, and work in it appears to overlie original thirteener composition in the Paradise, Shepherds, Magi, and Innocents plays. That the Prologue takes account of it seems proved by the last of these. Both thirteener and short octave plays have been modified by the addition of matter in romance stanzas. Now the task of the first reviser of the Prologue was, we saw, precisely the combination of thirteener and short octave sources; and the Prologue takes account of romance passages. The conclusion seems inevitable that the combiner of the two sources, the first reviser of the Prologue, and the romance author are one and the same.

Of the quatrain and couplet portions I do not propose to speak. They seem to point most likely to an independent source, hut the whole problem 


\section{PROBLEMS OF THE ENGLISH}

of the Entry and Passion sections is too complicated and obscure to be treated on this occasion.

The insertions in the Joseph play in a ten-line stanza, and the whole of the 'Purification' in that metre, are almost certainly borrowings from an independent source subsequent to the first revision of the Prologue. They are remarkable for their more lyrical tone.

There remain the thirteener and short octave portions only. In the 'Annunciation' we found a clear case of a play in short octaves being substituted for an earlier one presumably in thirteeners, and a similar process was traceable in the Nativity group. It is clear, therefore, that the short octave plays are intruders. Did they come from an independent source, or were they written expressly for insertion in the present cycle? If we are right in regarding the curious speech of the Baptist in the Entry section as a fragment of a short octave Baptism play, the former is the correct alternative. And, in any case, the absence of any work of a revisional nature in this stanza points strongly to that conclusion. Moreover, the plays in short octaves are the most sharply defined and independent of the whole cycle, and are, therefore, in striking contrast to the work of the man responsible for their introduction, whose original composition favours continuous representation.

This brings us to the conclusion, which I regard as being as certain as anything in so complicated a case can be, that the cycle consisted in the first instance of a homogeneous series of plays in the thirteener stanza. 
Let me bring this lecture, and with it my course as Sandars Reader, to a close by resuming as briefly as I can what seems to me to have been the history of this remarkable cycle. An original series of plays, the extent of which cannot now be certainly ascertained, but must have been considerable, composed throughout in a distinctive stanza of thirteen lines, with a Prologue in the same metre, was modified and expanded by the substitution and insertion of other plays drawn from another cycle written, so far as we know throughout, in short-lined octaves. The amalgamation was effected by a reviser who himself worked over the whole and made additions in the romance stanza. It was apparently this same reviser who was responsible for working up two sections of the cycle, the Entry and the Passion, into continuous wholes, and in these he would seem to have drawn upon another source, which is, to say the least, not in evidence elsewhere. He also revised the Prologue somewhat perfunctorily, inserting stanzas in the original metre (but sometimes imperfect) to correspond with the new plays he had introduced, but, in cases where he had substituted a new play for an old, usually leaving the original stanza, even if it did not accurately describe the new piece, and refraining from touching the description of the two sections he had recast.

After he had finished his work one whole play and portions of a second were introduced from yet another source, distinguished by its unusual ten-line stanza as well as by stylistic peculiarities of its own.

A different reviser wrote and inserted in the 


\section{PROBLEMS OF THE ENGLISH}

cycle what practically amounts to three whole plays of the Incarnation group, besides considerable passages elsewhere, all in long-lined octaves.

Lastly, yet another reviser, it would seem, wrote the distinctive Contemplatio prefaces and links, and worked over various portions of the cycle to no small extent. He imitated various metres, rewrote four stanzas of the Prologue in the Passion section to agree with the text in its final form, and possibly added the Assumption play as an original contribution.

I have spoken of these revisions as successive. That is the natural way to regard them, but it may not be actually true. The work of the last reviser was clearly going on while the extant manuscript was being written. But when the scribe wrote the Purgation play he certainly had not before him the first reviser's introduction to it. Of course, the last reviser may have omitted to hand it to him. But it is also possible that there were several revisers at work upon the cycle about the same time, circa 1465 to 1470 , and that they had different opportunities or inclinations for bringing the Prologue into agreement with their own work. They must, however, have worked over one another's contributions to some extent.

Each of the three original sources consisted of separate and independent plays of the type adapted for processional acting. It was the revisers alone who contemplated continuous performance on a polyscenic stage. When the Prologue was first revised the cycle had already ceased to be processional, though it continued to be described as 
though it were a series of independent pageants. Whether the allusion at the end: 'At six of the belle we gynne oure play In $\mathrm{N}$ towne,' belongs to the original composition or to the first revision, I see no means of determining, but it clearly still contemplates the performance of the whole cycle at some annual festival, and msut mean six o'clock in the morning. Whether the cycle in anything like its present shape was ever acted seems doubtful. That it was designed for production in a series of annual sections is clear, but how far this represented a serious intention it is impossible to say. One thing, I think, is certain: the extant manuscript was written, not for purposes of acting, but of private reading. Why else has the scribe ornamented the margins of his leaves with elaborate genealogical tables based upon the 'Legenda Aurea,' and notes as to the dimensions of the ark? And it was only in the extant manuscript that the cycle assumed its final form. 
THE DE LA MORE PRESS LTD. ;2 GEORGE

STREET HANOVER SQLARE LONDON W. 



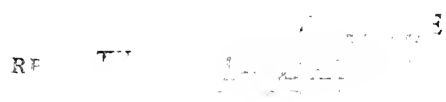

JAN 271975 " 


\section{GENERAL LIBRARY - U.C. BERKELEY

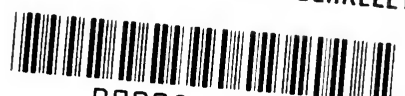 \\ B000854153}


